\title{
BENEFIT-COST ANALYSIS FOR THE MODERNIZATION AND ASSOCIATED RESTRUCTURING OF THE NATIONAL WEATHER SERVICE
}

Robert E. Chapman

U.S. DEPARTMENT OF COMMERCE

Technology Administration

National Institute of Standards and Technology

Office of Quality Programs

Gaithersburg, MD 20899

Sponsored by:

U.S. DEPARTMENT OF COMMERCE

National Oceanic and Atmospheric Administration National Weather Service

1325 East-West Highway

Silver Spring, MD 20910

$-Q C$

100

.456 



\section{BENEFIT-COST ANALYSIS FOR THE MODERNIZATION AND ASSOCIATED RESTRUCTURING OF THE NATIONAL WEATHER SERVICE}

\section{Robert E. Chapman}

U.S. DEPARTMENT OF COMMERCE Technology Administration National Institute of Standards and Technology

Office of Quality Programs

Gaithersburg, MD 20899

Sponsored by: U.S. DEPARTMENT OF COMMERCE National Oceanic and Atmospheric Administration National Weather Service 1325 East-West Highway

Silver Spring, MD 20910

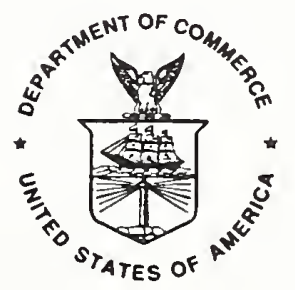

U.S. DEPARTMENT OF COMMERCE Barbara Hackman Franklin, Secretary

TECHNOLOGY ADMINISTRATION

Robert M. White, Under Secretary for Technology

NATIONAL INSTITUTE OF STANDARDS

AND TECHNOLOGY

John W. Lyons, Director 



\section{EXECUTIVE SUMMARY}

The mission of the National Weather Service (NWS) is to provide the nation with the most complete, accurate, and timely meteorological and hydrological services possible within existing scientific, technological, and economic constraints. These services include data collection, data analysis, forecasting, and information dissemination. One of the most important elements of this overall mission is the NW' ' $^{\prime}$ sponsibility for public warning and forecast services. The goal of these services is to provide timely and accurate meteorological, hydrological, and oceanographic warnings, forecasts, and planning information. The NWS also has the responsibility to improve these services by developing new techniques and procedures, and by applying new technology. One approach towards meeting these responsibilities is the proposed modernization and restructuring of the NWS. Alternatively, efforts could be made to continue and augment the current NWS configuration until the early part of the next century (i.e., 2005).

The purpose of this study is to analyze rigorously the benefits and costs associated with two alternative NWS configurations. The first configuration represents a continuation of the status quo; it is referred to as the current system. The second configuration represents a full deployment of the proposed modernization and restructuring of the NWS; it is referred to as the Proposed system.

The two systems differ greatly in their capabilities. The Current system is rapidly becoming obsolete and will require significant commitments if it is to continue service into the next century. Even with major commitments, in terms of staff and financial resources, the current system's forecast quality, as viewed by the public, is likely to deteriorate. This undesirable outcome has serious implications for the perceived value of the system to the public.

The Proposed system represents deployment of a suite of technologies focused on improving the accuracy, timeliness, and capabilities of the NWS. These technologies are being tested in the field to simulate the environment under which the proposed system would operate. The emphasis being placed on risk reduction should ensure that only "appropriate" technologies are deployed.

The economic evaluation was carried out in two stages. In the first stage, a baseline analysis was performed. In the baseline analysis, all data entering into the benefit and cost calculations were fixed at their most-likely values. In the second stage, four variables were varied in combination according to an experimental design. The objective of this "structured 
sensitivity analysis" was to evaluate how uncertainty in the values of the four "input" variables translated into changes in the values of four key economic indicators. These indicators are: (1) the benefit-cost ratio; (2) the present value of benefits; (3) the present value of net benefits; and (4) the present value of costs. The present value of net benefits is equal to the present value of benefits minus the present value of costs.

The baseline analysis produced results which strongly favor the Proposed System. Two key economic measures, the benefit-cost ratio and present value of benefits, were dramatically higher for the proposed system. For example, the benefit-cost ratio was 7.915 for the Proposed system, the corresponding value for the current System was 4.873 . Another key measure, present value of net benefits, was $\$ 44.0$ billion for the Proposed system and $\$ 22.4$ billion for the current system. The difference between the two, $\$ 21.6$ billion, accrues to the public in terms of weather-related losses averted, gains in efficiency to selected weather-sensitive operations, and higher value imputed to weather information. These results indicate that the proposed system is clearly the approach which has the greatest net benefits.

The structured sensitivity analysis produced results which were similar to the baseline analysis. Once again, the Proposed system was strongly favored - three of the four key economic indicators were markedly better for the Proposed system than for the current system. The fourth indicator, present value of system costs exhibited an interesting outcome. Although the mean value of costs for the Proposed system exceeded the mean value of costs for the current system, the range of costs for the Proposed system was a subset of the range of costs for the current system. In particular, the cost variability for the current system is seven times higher than for the Proposed system. A statistical test was performed to determine if the costs of the Proposed system exceeded those of the current system. The results of this test indicated that the costs of the Proposed system exceeded those of the current system.

Taking all of the information presented above and elsewhere in the study into consideration, leads one to conclude that the Proposed system, full deployment of the proposed modernization and restructuring of the NWS, is the most economical solution to the NWS' needs and responsibilities. When intangibles, such as reductions in weather-related fatalities and the potential for new products/services, are taken into consideration, the Proposed system emerges as an approach for positioning the Nws to meet the needs of the American public throughout the $1990 \mathrm{~s}$ and into the beginning of the 21 st century. 
EXECUTIVE SUMMARY . . . . . . . . . . . . . . . . . iii

IIST OF FIGURES . . . . . . . . . . . . . . . . . viii

LIST OF TABLES . . . . . . . . . . . . . . . . . . ix

LIST OF ACRONYMS . . . . . . . . . . . . . . . . . xi

ACKNOWLEDGEMENTS . . . . . . . . . . . . . . . . xii

1. INTRODUCTION . . . . . . . . . . . . . . . 1

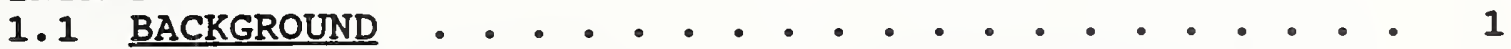

1.2 PURPOSE ..................... 2

1.3 KEY CONSIDERATIONS . . . . . . . . . . . . 3

2. METHODOLOGICAL ISSUES . . . . . . . . . . . . 7

2.1 SCOPE . . . . . . . . . . . . . . . . 8

2.2 ASSUMPTIONS AND CONSTRAINTS . . . . . . . . . . 8

2.2 .1 Basic Assumptions . . . . . . . 8

2.2.2 Review of Mandatory Sources of Supply . 10

2.2.3 Conversion Issues and Costs . . . . . 11

2.3 METHODOLOGY . . . . . . . . . . . . . 13

3. ALTERNATIVES ANALYZED . . . . . . . . . . . . 15

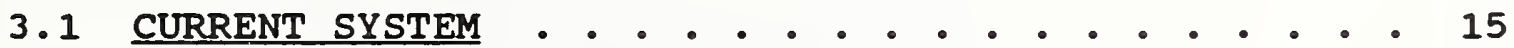

3.1.1 National Meteorological Center . . . 15

3.1.2 Field offices . . . . . . . . . . 16

$\begin{array}{ll}\text { 3.1.3 Automation of Field Operations and } \\ & \text { Services (AFOS) System . . . . } 17\end{array}$

3.1.4 Advanced Satellite Observing Systems • 18

3.1.4.1 Geostationary Satellites . . . . 18

3.1.4.2 Polar Orbiting Satellites . . . . 19

3.2 PROPOSED SYSTEM • • . . . . . . . . . . . . . . 19

3.2.1 National Meteorological Center . . . . 20

3.2.2 Field offices . . . . . . . . . . 20

3.2.3 New Technologies . . . . . . . . . 21

3.2.3.1 Automated Surface Observing system

3.2.3.2 Next Generation Weather Radar

3.2.3.3 National Center Advanced Computer

3.2.3.4 Advanced Weather Interactive

Processing System (AWIPS)/NOAAPort . 23

3.2.4 Advanced Satellite Observing Systems . . 23 
4. $\cos T S$

4.1 CURRENT SYSTEM

4.1.1 Special Considerations

4.1 .2

Estimated costs

4.2

PROP

SYSTEM

$4 \cdot 2 \cdot 1 \cdot 1$

Special considerations

$4 \cdot 2 \cdot 1 \cdot 2$

Transition Strategy

4.2.1.3 Modernization and Associated

Restructuring Demonstration (MARD)

Activities . . . . . . . . . 34

4.2.1.4 Certification Process . . . . . 36

4.2.2 Estimated Costs.......... . . 36

5. BENEFITS • . . . . . . . . . . . . . . . . . . . 440

5.1 CURRENT SYSTEM •. . . . . . . . . . . . . . . . 42

5.1 .1 Non-Recurring Benefits . . . . . . . . 42

5.1 .2 Recurring Benefits . . . . . . . . . 42

5.1.2.1 Benefits of Weather Information to

5.1 .2 .2 Potential savings Due to Improved

$5.1 .2 .3 \quad$ Potential Efficiency Gains Due to

$5.1 .2 .4 \quad$ Improved Forecasts $\cdot$ Sumary of Recurring Benefits for $^{\circ}$

the Current System ....... . . 45

5.1.3 Non-Quantifiable Benefits . . . . . . . 49

5.2 PROPOSED SYSTEM . . . . . . . . . . . . . . . . 49

5.2 .1 Non-Recurring Benefits . . . . . . . . 49

5.2 .2 Recurring Benefits . . . . . . . . . . 49

5.2.2.1 Benefits of Weather Information to

the Public............. 49

5.2.2.2 Potential Savings Due to Improved

$5.2 .2 .3 \quad \frac{\text { Forecasts }}{\text { Potential Efficiency Gains } \dot{\text { Due }} \text { to }}$

51

58

5.2 .2 .4 Summary of Recurring Benefits for the Proposed System ....... . 64

$5 \cdot 2 \cdot 3$ Non-Quantifiable Benefits

5.2.3.1 Reductions in Weather-Related

Fatalities .......... . . 67

5.2.3.2 Basic and Applied Research . . . . 68

6. COMPARATIVE BENEFIT-COST SUMMARY . . . . . . . . . . . . 73

6.1 CURRENT SYSTEM

6.2 PROPOSED SYSTEM 
7. SENSITIVITY ANALYSIS . . . . . . . . . . . . 86 7.1 METHODOLOGY: AN INTRODUCTION TO STRUCTURED SENSITIVITY ANALYSIS $. \cdot . \cdot \cdot \cdot \cdot \cdot \cdot \cdot \cdot \cdot \cdot \cdot \cdot 86$ 7.2 KEY VARIABLES USED IN THE SENSITIVITY ANALYSIS • 87 7.3 RESULTS OF THE SENSITIVITY ANALYSIS . . . . . . . . 94 7.4 EVALUATION OF RESULTS . . . . . . . . . . . . 9 96

8. FINDINGS AND CONCLUSIONS . . . . . . . . . 103 


\section{LIST OF FIGURES}

Figure 7.1 Distributional Analysis of the Benefit-cost Ratio............... . . 97

Figure 7.2 Distributional Analysis of Benefits . . . . . . 98

Figure 7.3 Distributional Analysis of Net Benefits . . . . . 99

Figure 7.4 Distributional Analysis of Costs . . . . . . . 100 
Table 4.1 Comparisons of National Investments for Meteorological Services and Gross National Product .................. . . 25

Table 4.2 Fiscal Yeax 1990 NwS operating Plan . . . . . . . 26

Table 4.3 Estimated NWS Operating Costs: Fiscal Year

Table 4.4 1990 through Fiscal Year 2005 .. . . . . . . 28

Table 4.5 Estimated Costs for the Advanced Satellite observing systems ................ . 29

Table 4.6 Summary of Costs for the current system . . . . 30 Summary of Non-Recurring costs for the

Table 4.7 Proposed System ......... . . . . . . 38

Table 5.1 Summary of Costs for the Proposed System . . . 39 Estimated Population of Persons Aged 18 and

Table 5.2

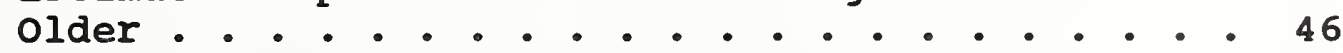

Table 5.3 Estimated Value of the Benefits of Weather Information to the Public: Current system . . . 47

Table 5.4 Summary of Recurring Benefits for the Current System ...................... . . 48 48

Table 5.5 Summary of Annual Dollar Losses Due to Adverse Estimated Value of the Benefits of Weather Information to the Public: Proposed System. . . 50 Weather In the United States: Estimated and

Table 5.6 Preventable . . . . . . . . . . . . 53 Percents of Protectable Losses Due to operational Improvements and Scientific Advances by Forecast Period . . . . . . . . . . . 54

Table 5.7 Weighting Factors for Each Activity Group and Forecast Period . . . . . . . . . . . . 56

Table 5.8 Summary of Potential Annual Savings Due to Operational Improvements, Scientific Advances and Total Gains Due to Improvements in Weather Forecasting. . . . . . . . . . . 57

Table 5.9 Estimated Annual Savings Due to Improvements in Weather Forecasting Attributable to the Modernization and Restructuring of the NWS . . 59

Table 5.10 Estimated Annual Efficiency Gains Due to Improvements in Weather Forecasting Attributable to the Modernization and Restructuring of the NWS .. . . . . . . . 65

Table 5.11 Summary of Recurring Benefits for the Proposed

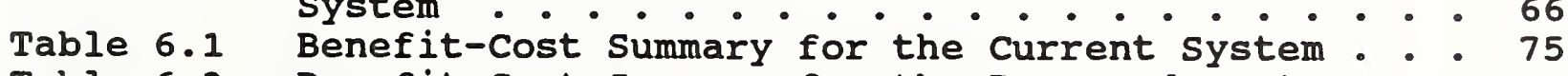
Table 6.2 Benefit-Cost Summary for the Proposed System . 81 
Table 7.1 Baseline and Extreme Values Used in the Structured Sensitivity Analysis . . . . . . . 89

Table 7.2 Values of Key Variables Used in the Structured Sensitivity Analysis . . . . . . . . . . . 90

Table 7.3 Experimental Design Used in the Structured

Table 7.4 Sumary statistics on the Benefit-Cost Ratio $\dot{0}^{\circ} \cdot 101$

Table 7.5 Summary statistics on the Present Value of

Table $7.6 \quad$ Summary statistics on the Present Value of Net Benefits in \$M . . . . . . . . . . . . 102

Table 7.7 Summary Statistics on the Present Value of System Costs in \$M ............. 102 


\section{IIST OF ACRONYMS}

AFOS

AMSU

ASOS

AVHRR

AWDS

AWIPS

AWIS

AWS

BCR

CDF

COMCOS

COSINC

$\mathrm{DAR}^{3} \mathrm{E}$

DECPAY

ERL

FIPS

FIRMR

FSS

GOES

MARD

MARDI

NEDS

NESDIS

NEXRAD

NHC

NMC

NOAA

NOC

NPV

NSSFC

NWS

OMB

POES

PROTEUS

PVB

PVC

RFC

WFO

WILPAY

WSFO

WSO

Automation of Field operations and Services

Advanced Microwave Sounding Unit

Automated Surface Observing system

Advanced Very High Resolution Radiometer

Automated Weather Distribution system

Advanced Weather Interactive Processing System

Automated Weather Information System

Air Weather Service

Benefit-Cost Ratio

Cumulative Distribution Function

commissioning cost

cost Increase

Denver AWIPS Risk Reduction and Requirements

Evaluation

Decreased willingness to Pay

Environmental Research Laboratory

Federal Information Processing standard

Federal Information Resources Management Regulation Flight Service stations

Geostationary operational Environmental Satellite

Modernization and Associated Restructuring

Demonstration

Modernization and Associated Restructuring

Demonstration and Implementation

Naval Environmental Display station

National Environmental Satellite, Data and Information Service

Next Generation Weather Radar

National Hurricane Center

National Meteorological Center

National Oceanic and Atmospheric Administration

Navy Oceanography Command

Net Present Value - - Present Value of Net Benefits

National Severe Storms Forecast Center

National Weather Service

Office of Management and Budget

Polar Orbiting Environmental Satellite

Prototype Real-time Operational Test Evaluation and User Simulation

Present Value of Benefits

Present Value of Costs

River Forecast Center

Weather Forecast office

Willingness to Pay

Weather Service Forecast Office

Weather Service Office 


\section{ACKNOWLEDGEMENTS}

The author wishes to thank all of those persons who contributed to the preparation of this report. Special appreciation is extended to Dr. Merrill M. Hessel and Ms. Judith F. Gilsinn of the National Institute of standards and Technology (NIST) for their assistance throughout the project. Appreciation is also extended to Dr. Wayne A. Cassatt and Mr. Walter Leight of NIST for their many helpful suggestions and to Mr. Nick Scheller of the National Weather service for his prompt responses to the author's many requests for reports, data, and other information resources. Mrs. Karen Rademaker and Ms. Jo Ann Maccherola lent their considerable skills in document preparation to the presentation of the material contained in this report. 


\section{INTRODUCTION}

\subsection{BACKGROUND}

The mission of the National weather Service (NWS) is to provide the nation with the most complete, accurate, and timely meteorological and hydrological services possible within existing scientific, technological, and economic constraints. These services include data collection, data analysis, forecasting, and information dissemination. One of the most important elements of this overall mission is the NWS' responsibility for public warning and forecast services. The goal of these services is to provide timely and accurate meteorological, hydrological, and oceanographic warnings, forecasts, and planning information. The NWS also has the responsibility to improve these services by developing new techniques and procedures, and by applying new technology.

With the advent of the Automation of Field Operations and Services (AFOS) system in the 1970s, the first step was taken in the NWS to bring automated support systems into the field forecast offices. AFOS was not, however, designed to incorporate the voluminous and fine-scale observational data that are becoming available from advanced remote sensors and from radars. Also, while AFOS does provide the field offices with some computational capabilities, the capabilities are much too limited to incorporate state-of-the-art techniques for interactive processing, display, and automated analyses. Finally, within several years the operational limitations and the maintenance cost of AFOS will have become unacceptable; AFos will have reached the end of its useful and economic life."

Warnings and forecasts are provided to the public through a nationwide network of field offices. AFOs, the current backbone of field forecasting operations, lacks the capability to integrate the large-scale guidance materials, supplied by the National centers, with the fine-scale observational data for the local forecaster's "area of responsibility." This limitation of the AFOS system is becoming ever more severe as: (1) the quantity and quality of the fine-scale data continues to increase; and

${ }^{1}$ M.M. Hessel, R.E. Chapman and E. Bromberg, NBS Review of the Procurement for the Advanced Weather Interactive Processing System (AWIPS) for the 1990s, Gaithersburg, MD: National Bureau of Standards, 1988. 
(2) improved methods for processing, displaying, and analyzing these data continue to emerge. ${ }^{2}$

The three National Centers, the National Meteorological Center (NMC), the National Severe Storms Forecast Center (NSSFC), and the National Hurricane Center (NHC), process and analyze a wide variety of data, and distribute guidance products to field forecasters throughout the country. The National centers receive data in many forms. The observations and derived information are displayed and analyzed using different formats, map projections, and techniques (including manually-prepared graphics). The observations, analyses and forecasts cannot be assimilated, juxtaposed, and integrated with the centers' existing operational systems. Hence the forecasters are forced to use a variety of heuristic methods in attempting to compare and analyze the diverse data. These methods are often ineffective, narrow in application, and usually very inefficient.

The thirteen River Forecast centers (RFCs), each serving a major drainage area, taken collectively serve as the "National center" for the NWS Hydrologic Services Program. Current RFC operational systems similarly restrict the ability of RFC forecasters to assimilate, display, analyze, and apply forecast procedures to the diverse data describing hydrologic conditions.

\subsection{PURPOSE}

The NWS is involved in a major program to provide more comprehensive, accurate, and timely observational data to forecasters, and also to provide new tools and techniques so the forecasters can analyze data from these sources rapidiy and extract the most meaningful information.

The goal of the modernization and associated restructuring of the NWS is to assure that the major advances which have been made in our ability to observe and understand the atmosphere are applied to the practical problems of providing weather and hydrologic services to the nation.

The modernization and restructuring of the NWS will require significant changes in the current weather service infrastructure

${ }^{2}$ The AFOS system is routinely overloaded during several peak use hours each day. The AFOS system requires manual operation at a number of critical points where current technology would use automation. This is expensive, because it is labor intensive, and open to interruption of communications. 
and operations. As new products become available to forecasters, they will be able to review and manipulate data and information as never before. Combining new products with training and education should result in new insights, increased usability and improvements in forecast accuracy.

A major objective of this overall effort is to produce a more cost effective Nws through which Nms employees can achieve higher levels of productivity. The development of new technologies is guided by the principal of balancing technical and service improvements with overall costs. An earlier review by the National Institute of standards and Technology (NIST) revealed a strong commitment to modernize the NWS through the deployment of proven observational information and communication technologies and to establish an associated cost-effective structure. ${ }^{3}$

One way through which this balancing of enhanced capabilities against costs can be examined critically is through the application of benefit-cost analysis techniques. The purpose of this study is to apply these techniques to analyze rigorously the benefits and costs associated with two alternative NWS

configurations. The first configuration represents a continuation of the status quo; this configuration is referred to as the current system. The second represents a full deployment of the proposed modernization and restructuring of the NWS; this configuration is referred to as the Proposed system.

\subsection{KEY CONSIDERATIONS}

The types of weather that cause the most destruction and disruption pose special problems to the forecaster because they generally affect small geographic areas and develop and change very quickly.

The present operational capabilities for acquiring observational data, performing analyses, and producing computer-generated forecasts provide guidance to the field forecasters. Broad regions where fair or stormy weather will predominate are well predicted 24-48 hours in advance. However, these large-scale synoptic analyses and forecasts do not and cannot predict the

${ }^{3}$ M.M. Hessel, R.E. Chapman, T.S. Cress, P.W. Driscoll and E.V. Edelstein, Industry/Government Panel Review of the Advanced Weather Interactive Processing System (AWIPS) for the 1990s at the Definition Phase, Gaithersburg, MD: National Institute of standards and Technology, 1989. 
fast-breaking changes in local (mesoscale) weather (for example, the occurrence of downbursts, tornadoes, severe thunderstorms, hail, flash-floods, rainfall, high winds, locally heavy snows, etc.).

The use of reliable mesoscale models is not a present reality. There are several reasons why such models cannot be used operationally:

- The number of calculations that are required for mesoscale modeling taxes even the fastest computers.

- The data collection and analysis, and the model initialization procedures may be a greater problem and require more computing time than the running of the model itself.

- Mesoscale events, though embedded in large-scale systems, are often controlled by local energy sources and sinks; this requires extensive parameterization of processes associated with condensation, evaporation, and surface heating and cooling.

- Fine-scale models are capable of simulating realistic, mesoscale structures; however, small position errors in predicted features could lead to very large errors in the forecast at individual points.

Nevertheless, there is a practical approach to mesoscale forecasting:

- Continue improving the dynamic models to provide the field forecasters with more complete and accurate guidance materials so they can better focus daily weather surveillance activities.

- Provide local forecasters with the tools and techniques which will enable them to integrate the guidance products with the high temporal and spatial resolution data that are becoming available from advanced observing systems.

This approach will enable the local forecaster to refine the predictions of where and when specific storms will occur. Also, once a storm has begun, the forecaster will be able to monitor the storm's movement continuously, and improve forecasts of its intensification or decay. A similar approach is also needed for those far more common events which do not attain "severe" status but which collectively have enormous economic impact. For these phenomena (fog, low clouds, convective precipitation, temperature inversions, etc.), the problem is to predict the onset and duration based on conditions that often vary with local atmospheric circulations and topographic features. 
Hence, successful prediction of significant weather on local and regional scales requires access to data on the state of the atmosphere at any given instant. Generating such data sets requires: (1) observing the local and regional weather and the underlying mesoscale processes with adequate spatial and temporal resolution; and (2) communicating, processing, and assimilating these data in an informative, timely fashion in order to serve both forecasters and end users in their respective tasks. Forecasting the fine scale and rapid development of significant weather systems taxes the capabilities of the national weather services, both in the USA and abroad, which are geared historically to forecasting the larger, more slowly evolving, regional/national scale events. At present, however, operational and research observing capabilities are advancing rapidly in response to new national needs and to ongoing efforts by the weather service agencies to harness breakthroughs in sensor, telecommunications, and computer technology.

The need is to use meteorological and hydrological understanding and computer processing to cull from the vast amounts of data those (relatively few) features that are truly telling, and to extract the information that defines the present state of the atmosphere and hydrologic situation and influences on the future evolution of events. Information, not data, is the basis for user decisions and actions.

Several issues are associated with this task. First, there are those issues which are purely mechanical or technological in nature. They include, for example, communicating the data from the sensors to centralized collection points; calibration, checking for errors, and filtering out noise; converting sensor data to physical variables (e.g., converting radiometer radiances to temperatures, radar reflectivities to rainfall rates, Doppler frequency shifts to wind speeds, etc.); averaging over space and time, and performing a host of interpolations (and other forms of data "massage"). All these tasks must be accomplished very quickly (i.e., in times that are short when compared to the life cycles of the weather phenomena of interest).

A second set of issues is associated with appropriate applications of scientific principles of hydrology and meteorology to further analyze the available data, derive additional parameters, and forecast the evolving situation. Physical, statistical, and conceptual models of hydrological and meteorological processes are amenable to automation to provide timely information to aid forecaster decision making.

A third set of issues concerns displaying the data in a meaningful format with high impact for the trained viewer. This includes both hardware and software development for automated superpositioning or overlaying of satellite and ground-based radar data (taking into account the necessary reorientation of 
the satellite data into the radar perspective or vice versa); the merging of these displays with surface network data and with geopolitical maps; contouring of network data; display and superposition of derived parameters and simulations; "threedimensional" data displays; use of color to highlight various features or contours of interest; and animation to reveal temporal changes more effectively. The assimilation systems must be flexible, offering the forecaster an opportunity to tailor the displays according to the needs of the moment.

Other issues involve manipulations of the data and automated analyses; preparing the data for initializing weather prediction models; and finally, aiding the forecaster in the preparation of warning and forecast products for dissemination. 
Benefit-cost analysis is a technique for assessing the economic utility of public programs. The technique can be used to indicate whether a specific expenditure should be undertaken. It can also be used to determine the appropriate size of the expenditure as well as the optimum configuration of the "system," timing for installing components, and other aspects of program design.

Benefit-cost analysis is simple in concept, reflecting a most elementary decision rule:

No rational person could be expected to undertake actions where anticipated costs exceeded anticipated benefits.

However, from a practical standpoint, the application of benefitcost analysis to public decision problems may become quite complicated.

It is appropriate to make the distinction between benefit-cost analysis and cost effectiveness. The term "cost effectiveness" emerged from the analysis of military programs where objectives were prespecified and the purpose of the analysis was to explore the relative merits of alternative means of accomplishing the specified objective. In cost-effectiveness studies, emphasis is placed on exploring the relative costs of the "alternatives" that are available. Stated another way, costs are to be minimized for a given output, set of requirements, or some other set of "constraints."

The benefit-cost analysis described in this document can be divided into four stages:

(1) identification; (2)

classification; (3) quantification; and (4) presentation. The identification stage involves identifying and listing all the various effects of two alternative configurations of the Nws. In principle, this set of effects produces a checklist of all the items that should be taken into consideration. The second stage entails classifying these various effects into benefit categories and cost categories. The third stage produces estimated values for each of the benefit categories and cost categories. The final stage of the benefit-cost analysis is presentation of the relevant information in a straightforward manner (i.e., in a form that clearly spells out the important assumptions underlying the analysis and the implications of those assumptions for the study's conclusions).

At the heart of any benefit-cost analysis is an economic concept referred to as the time value of money. This concept relates to the variations with time of the purchasing power of money (i.e., as the result of inflation and deflation), along with consideration of the real earning potential of alternative 
investments over time. The discount rate reflects the decision maker's time value of money. The discount rate is used to convert, via a process known as discounting, benefits and costs which occur at different times to a base time. Throughout this study, the term "present value" will be used to denote the value of a benefit or cost found by discounting future cash flows to the base time. Consistent with the guidelines set down in OMB circular $A-94$, a real discount rate of $10 \%$ per year is used for all costs and benefits.

\subsection{SCOPE}

In this study, benefit-cost analysis is applied to two alternative configurations of the NWS: (1) continued use of the current NWS configuration, the current system (i.e., the status quo); and (2) full deployment of the proposed modernization and restructuring of the NWS, the Proposed system.

The two alternatives have different costs. Maintenance of the status quo does not require additional funds beyond the current appropriation, assuming adjustments to base to cover fairly steeply rising operations and maintenance costs. The proposed modernization and restructuring of the NWS requires substantial outlays initially, with significant savings in operations and maintenance costs once deployment has been completed.

For severe weather and flood warnings and short range forecasts, cloud imagery and atmospheric sounding data from the geostationary meteorological satellites will continue to be a major data source for either alternative. For example, the new Geostationary Operational Environmental satellite (GOES) I-M system will have separate instrumentation that allows simultaneous image and sounding data to be observed and transmitted to ground stations. For longer-range forecasting, soundings from the polar orbiting satellites are a primary data input for the National Meteorological Center numerical forecast models.

\subsection{ASSUMPTIONS AND CONSTRAINTS}

\subsubsection{Basic Assumptions}

Public Law 100-685 was signed by the President in 1988. In part, it specifies conditions on the planning, reporting and accomplishment of the modernization and restructuring of the NwS. Public Law 100-685 requires an identification of the basic service improvement objectives of the modernization, the pivotal new technological components, and the associated operational changes required to fulfill the objectives of weather and flood warning improvements. 
The modernization and restructuring goal will require significant changes in the current weather service infrastructure and operations. Accordingly, the following principles will guide the planning and implementation.

Throughout the process of change, the NWS is committed to its mission of providing weather and flood warnings, public forecasts and advisories for all of the United states, its territories, adjacent waters and ocean areas, primarily for the protection of life and property. NWS data and products are furnished to private meteorologists for the provision of all specialized services. The following principles are essential to meet the NWS' operational mission and will be continued throughout the modernization and restructuring transition period.

The principle that the modernization and restructuring process will not result in the degradation of services to the general public. Also, service and structural changes and improvements will be implemented only when certified in accordance with Public Law $100-685$ to be beneficial to users.

The principle that NWS employees will be involved because their participation is crucial to a successful transition and improved operations. Significant levels of training and education will be provided so that employees will gain the necessary expertise to utilize the new technologies, understand the new sciences underpinning the modernization and restructuring of the Nws, and provide the improved services to the nation.

The principle that the United States will meets its international meteorological and hydrologic obligations during and after the modernization and restructuring of the NWS. The exchange of global atmospheric data is essential to the successful interpretation and forecast of weather phenomena in the United states. The NWS is a partner supporting national security interests on a global basis.

The principle that NWS employees will continue to provide the quality weather services required by the nation in the most economical manner.

To implement the proposed modernization and restructuring effort, the NWS has proposed a configuration consisting of 110 Weather Forecast offices (WFOs) for the coterminous United states ( 115 WFos including Alaska, Hawaii and Puerto Rico). The alternative to full implementation of the proposed modernization and restructuring of the NWS is to continue with the existing configuration of 249 field offices. Both alternatives include 13 River Forecast Centers (RFCs). No other alternatives are considered in this study because a partial deployment (i.e., reduced system deployment or a reduction in the number of WFOs) might not meet the requirements of Public Law 100-685 and 
reference to currently available information could not justify an analysis of configurations representing more than full deployment.

In developing estimates for the annual costs of each alternative (i.e., the current system and the Proposed system), the study placed a premium on information provided by the NWS. This information included official NWS publications as well as planning and budget documents. This approach was taken to ensure that all cost estimates reported in the study represented a consensus among NWS planners and managers. Issues related to the variability of individual cost estimates, either by year or by type, are addressed in the sensitivity analysis.

\subsubsection{Review of Mandatory Sources of supply}

FIRMR, Part 201-30.009, requires an evaluation of alternative sources of supply. One potential alternative to the proposed modernization and restructuring of the NWS is to draw on the meteorological services provided by other federal agencies. The two federal agencies which operate major meteorological programs are the Department of Defense (DOD) and the Department of Transportation (DOT). Brief descriptions of these programs are provided to identify those services and technological factors which could be used by the NWS.

The Navy Oceanography Command (NOC) of DoD is in the process of installing, the Federal Aviation Administration (FAA) of DoT is in the process of procuring, and the Air Weather service (AWS) of DoD is in the process of developing major automated weather information systems to serve the needs of their individual field office organizations. All three systems are similar to the NWS/AFOS system in that they are distributed data processing systems and perform common processing functions such as computation, display, storage, and communications.

The NOC provides meteorological, oceanographic, and other services to the operational fleet. A significant development for them has been the initial operational capability of the Naval Environmental Display Station (NEDS). This system handles the transmission, receipt, storage, manipulation, and multicolor visual display of graphic, alphanumeric, and satellite data. NEDS units are already installed and operating at the Fleet Numerical Oceanography Center, in three Naval Oceanography Centers, in two Naval Oceanography Command Centers, and at the National Military Command Center.

The FAA is responsible for an array of support services necessary for the safe and efficient use of the National Airspace system. One of these services is the acquisition and dissemination of aviation weather information. The backbone of this system is a network of over 300 Flight service stations (FSS) which are the 
focal points for the acquisition and dissemination of aviation weather data.

The AWS serves the environmental support requirements of the Air Force and the Army. AWS presently is developing an Automated Weather Distribution System (AWDS), the goal of which will be to utilize new technology in environmental sensing, communications, display, and automation to modernize their fixed base and tactical weather support; to eliminate or reduce manpower intensive tasks in their forecasting, observing and maintaining activities; and to replace outdated sensors, long-line communications, and local communications equipment.

The NWS AFOS system and the automated weather information systems of the other agencies discussed in this section are all similar in the many functions each performs, though quite different in form and complexity, mainly because of the varying agency missions and requirements each serves.

Although the modernization and restructuring of the NWS is complementary to efforts by other federal agencies to develop capabilities to satisfy mission-responsive requirements, there is no other system under development that has the capability to address the NW' ' broad data handling and communication requirements. As stated in The Federal Plan for the coordination of Automated Weather Information systems (AWIS) Programs issued by the Office of the Federal Coordinator for Meteorological Services and Supporting Research, it is considered that "many of the basic AWIS functional requirements are common to all agencies. .... However, at the next level of detail, the similarities fade. .... [FAA and DoD] requirements are driven by narrow operational interests, whereas NWS is required to support the entire spectrum of users nationwide including FAA and DOD." A review of DOD and FAA systems in various stages of development confirm this conclusion. ${ }^{4}$

\subsubsection{Conversion Issues and costs}

NWS operates 249 field offices. Of these, 52 Weather Service Forecast offices (WSFOs) have staffs of about 22 each and have forecast responsibility for entire states and warning responsibility for parts of states. A second tier of weather Service offices (WSOs), generally with staffs of 8 to 12 , have forecast and warning responsibility for parts of states. As proposed, the NWS would consolidate the 249 offices into one tier with 115 standard WFOs. The 13 existing River Forecast centers (RFCs) would continue in the modernized NWS.

\footnotetext{
${ }^{4}$ M.M. Hessel, et al, 1989, op cit.
} 
The NWS proposes a formal Modernization and Associated Restructuring Demonstration (MARD). The primary objectives of the MARD are: (1) to demonstrate more accurate and timely warnings and forecasts; and (2) to evaluate the services provided and the responses of users within the context of the most costeffective organizational structure. As currently planned, the MARD will take place within a five-state area in the central United States -- an area extremely prone to severe weather. The MARD will also provide an opportunity to examine the possibility of additional organizational efficiencies that may be gained while applying and operating new technology.

In going from 249 field offices to 115 WFOs, the NWS will incur substantial site preparation costs. In all, 98 new facilities will be required. Although one might expect that most of the old field offices selected for inclusion in the modernization and restructuring of the NWS could be converted fairly easily, siteby-site examinations conducted by the NWS concluded that in most cases new construction would be more economical. There are several reasons for NW''s reliance on new construction.

More than 50 of the existing offices are in leased space and are substantially undersized. Many have less than half the floor space required to accommodate a new WFO. General Services Administration regulations define expansions greater than 10 percent as major modifications. Such expansions require readvertising and a new competition to provide required space. Relocations of many offices may result.

At 11 locations, planned airport modifications include demolition of existing buildings, requiring the NWS and other occupants to relocate.

More than 40 existing offices are inadequate for future use, even if expanded, due to layout/configuration constraints that prevent effective operational equipment arrangements and/or due to age and poor condition of the existing building.

Ten offices are in locations where current lease terms and costs of services are very high and where, consequently, the cost of new construction could be amortized very rapidly.

Many currently leased locations do not meet current Federal requirements for health and safety. Provision of handicapped access, as required by the Architectural Barriers Act (1968) and the Uniform Federal Accessibility Standards, at 19 existing offices on upper floors on multi-story buildings would require installation or replacement of an elevator or installation of other costly means to provide safe and easy access to the WFO.

If the Doppler radar is located 30-40 miles away from major urban centers, as is desirable, and the office remains in the downtown 
area, then radar information must be routed to the office using a wide-band communications system.

\subsection{METHODOLOGY}

Benefit-cost analysis, as used in this study, follows the general guidelines established in Federal Information Processing standard Publication 64, FIP8 PUB-64. As indicated earlier, the analysis consists of four stages.

In the first stage, detailed lists were developed to identify all major items to be included in the analysis. The development of these lists was facilitated through reference to NWS publications, previous work by NIST, and a NASA report on improved weather forecasting.

In the second stage, each item was assigned to either a cost category or a benefit category. To the maximum extent feasible, each of the cost categories was made consistent with those listed in FIPS POB-64.

In the third stage of the analysis, estimates for each of the cost categories and benefit categories were developed for each year. This process resulted in a series of detailed tables, presented in Chapters 4,5 and 6 . The estimation of costs and benefits for each of the two alternatives produced a series of cash flows. That is, for each cost or benefit category, an annual value was estimated. These costs and benefits were then discounted to a present value. In particular for each alternative, $i$, and cost category, $k$, the present value of costs, $\mathrm{PVC}_{\text {it }}$ is given by

$$
P V C_{i k}=\sum_{j=0}^{15} C_{i k j} /(1+D)^{j}
$$

where $c_{i k j}=$ the costs incurred in year $j$;

$$
\begin{aligned}
D & =\text { the discount rate, taken to be } 108 ; \\
i & =1,2 ; \text { and } \\
k & =1, \ldots, k_{c} .
\end{aligned}
$$


Similarly, for each alternative, $i$, and benefit category, $k$, the present value of benefits, $\mathrm{PVB}_{\mathrm{ik}}$, is given by

$$
P V B_{i k}=\sum_{j=0}^{15} b_{i k j} /(1+D)^{j}
$$

where $b_{i k j}=$ the benefits expected in year $j ;$ and

$$
\mathrm{k}=1, \ldots, \mathrm{k}_{\mathrm{b}} \text {. }
$$

The present value of total costs, $\mathrm{PVC}_{\mathrm{i}}$, and benefits, $\mathrm{PVB}_{\mathrm{i}}$, for the $i^{\text {th }}$ alternative is then given by

$$
\begin{aligned}
& P V C_{i}=\sum_{k=1}^{k_{c}} \sum_{j=0}^{15} c_{i k j} /(1+D)^{j} \\
& P V B_{i}=\sum_{k=1}^{k_{b}} \sum_{j=0}^{15} b_{i k j} /(1+D)^{j}
\end{aligned}
$$

The net present value, $N P V_{i}$, and the benefit-cost ratio, $B C R_{i}$, for each alternative is then given by

$$
\begin{aligned}
& \mathrm{NPV}_{\mathrm{i}}=\mathrm{PVB}_{\mathrm{i}}-\mathrm{PVC}_{\mathrm{i}} \\
& \mathrm{BCR}_{\mathrm{i}}=\mathrm{PVB}_{\mathrm{i}} / \mathrm{PVC}_{\mathrm{i}}
\end{aligned}
$$

As with most studies of this type, there is less detailed information on the values of benefits than on costs. consequently, a sensitivity analysis was carried out, as described in Chapter 7.

In the final stage, the results of the benefit-cost analysis are presented. The presentation includes a comparison between the two alternatives of expected costs and benefits. The primary evaluation criterion used in the analysis below is the net present value of the alternative. This results in the maximum difference between system benefits and system costs to meet the total requirements. 


\subsection{CURRENT SYSTEM}

The core of the Nws warning and forecast program includes the National Centers and the NWS field organization, which is administered by geographic regions. Six regional headquarters (Eastern, Central, Western, Southern, Pacific, and Alaska) and the National Meteorological Center (NMC) report to NWS

Headquarters. The regional offices manage the field offices, and the NMC administratively manages the National severe storms Forecast Center (NSSFC) and the National Hurricane Center (NHC).

\subsubsection{National Meteorological Center}

The NMC provides operational weather analyses and forecast guidance for all NWS field offices, other government agencies, and private meteorological services. It also provides several other services:

- special global aviation weather forecast guidance;

- wind forecasts for domestic and international aviation;

- the development, evaluation and implementation of operational analysis and forecast models; and

- provision of a communications switching center for both domestic and international data.

The responsibilities of the NMC span the entire globe, with special emphasis on the Northern Hemisphere and the tropical regions of the Southern Hemisphere. The NMC also has extensive forecast and analysis development and verification responsibilities. The NMC, like the NSSFC and the NHC, relies heavily on real-time surface, satellite, radar and upper air data and employs a wide range of systems for analysis, prognosis and development support.

Among the capabilities of the NMC systems are the following:

- model development, test evaluation and assessment in support of global scale numerical analysis and prognosis activities;

- quality control of data observations;

global scale model output refinement, revision, etc. as required;

unique product preparation: quantitative precipitation forecasts, aviation wind forecasts, and other general guidance and outlooks; 
- manually-generated graphic product encoding; and

- domestic and internationally distributed graphic product formatting.

All tornado and severe thunderstorm watches issued within the United states originate from the NSSFC. The NSSFC is also responsible for the following:

- advising area forecasters and the aviation community of any adverse en route weather conditions on a nationwide basis;

- verifying all convective watches and warnings;

- maintaining a national climatological data base for tornado records;

- issuing media releases concerning present severe weather conditions; and

- developing and implementing new analysis and forecast techniques directly related to its operational mission.

In its support role, the NSSFC provides on-line backup to the Automation of Field operations and Service (AFOs) System Monitoring and Coordination Center and shares processing facilities with the collocated Satellite Field service station.

The NSSFC makes extensive use of real-time surface, satellite, upper air, and radar data, both in the analysis of national weather conditions and in the development of advanced techniques. It also relies on routine weather data as provided by existing NWS and FAA distribution networks.

The NHC provides tropical storm and hurricane analyses and forecasts for the Atlantic Ocean, Caribbean Sea, Gulf of Mexico and all adjacent coastal areas, and disseminates relevant information to other NWS facilities, the public, and the media. Like the NSSFC, the NHC also has a responsibility for the development of forecasting procedures and techniques with direct application to its operational mission. It relies extensively on real-time surface, satellite, radar and upper air data, and on "routine" data and products from existing national and regional communications networks. Except for its more regionalized area of responsibility and its specific focus on tropical storms and hurricanes, the NHC is very similar to the NSSFC.

\subsubsection{Field Offices}

The current field structure has, in general, one professionally staffed Weather service Forecast office (WSFO) per state from which all forecasts for the state originate. These forecasts are 
adapted locally at several weather service offices (wsos) within each state. The River Forecast Centers (RFCs), whose areas of responsibility are delineated by river basin boundaries, provide river and flood forecast guidance to the WSFOs and WSOS. The WSFOs and WSOs interpret this guidance and disseminate appropriate warnings and forecasts. The RFCs also provide a wide variety of products and services directly to water resources cooperators. Demand for this type of support has increased significantly in the last decade and is expected to increase greatly in the future.

3.1.3 Automation of Field Operations and Services (AFOS) System

The current backbone for field forecasting operations is the AFOS system. AFOS represented the introduction to NWS field operations of modern computer and communications technology to distribute observed data, analyses, and forecast guidance products throughout the organization. With AFOs came transition from reliance on low-speed teletypewriters, facsimile circuits and the associated hard copy output, to digital communications, computer-supported distributed data bases and soft copy (CRT) displays.

AFos has motivated field forecasters to acquire new skills in the use of computers to manipulate and display the data and analyses in their local data base. Field offices use the on-site computer with locally-developed software to accomplish some of the specialized, as well as routine, analysis and decision tasks they face. Such applications as plotting and displaying radiosonde data, creation of weather depiction charts, deriving estimates of precipitable water, and forecasting the occurrence of summer stratus of the northwest coast of the United states are in routine local use.

AFOS constituted the operational environment for NWS field offices during the 1980s. However, the AFOS system was designed in the early 1970 s and the specified technologies for its implementation were selected by the mid-1970s. By the early 1990s, the AFOS system was more than 15 years old. Many other systems making major improvements in the NWS short-term mesoscale forecasting skills were simply never intended to become part of the AFOS system. For example, AFOS was never designed to deal directly with satellite or high resolution radar data.

Furthermore, significant improvements are already available in state-of-the-art scientific work stations and interactive processing techniques. Forecasting models and techniques once conceivable for use only in larger data processing centers are now becoming well within reason for use on scientific work stations. Many components of the AFOS field office hardware are no longer produced, so that parts replacement and maintenance is already becoming increasingly difficult. Finally, because of 
vendor and hardware limitations, the computer operating system software, which normally is maintained by the manufacturer, has been modified by the NWS to meet its requirements. This situation significantly reduces the flexibilty in modifying AFos software to support modern techniques for interactive data processing. As a result, the AFOS system has reached obsolescence.

\subsubsection{Advanced Satellite Observing Systems}

Major enhancement programs in meteorological satellite observing systems will provide valuable support to the NWS' warning and forecast operations in the 1990s. The National Environmental Satellite, Data and Information Service (NESDIS) office of NOAA operates two satellite observing systems. The geostationary satellite system consists of satellites that are placed in orbit over equatorial areas of the earth and travel at the earth's rotational speed so that the same portion of the earth's surface is always within the satellite's observational view. The Polar Orbiting Environmental Satellite system, on the other hand, uses orbits with a general north-south direction so that different portions of the earth are within observing view of the satellite with each successive satellite orbital pass.

\subsubsection{Geostationary Satellites}

The Geostationary operational Environmental Satellite (GOES) System provides data coverage for the coterminus United states, over a major portion of the central and Eastern Pacific ocean, and the Central and western Atlantic Ocean. The GoEs satellites currently provide cloud images every half hour for almost the entire hemisphere and enable the tracking of tropical storms and outbreaks of severe weather, such as thunderstorms, in the United States.

The GOES next generation (GOESNEXT) advanced satellite systems are designed to provide several operational improvements. These include greater flexibility to select areas of meteorological interest, a more rapid and frequent delivery of data to NWS offices and other users, and more precise geographical location of data. These enhancements allow the data to be more readily used in conjunction with other data displays to support the warning and forecast process.

In the GOESNEXT era, some regional scale products will be generated at the National centers. The products generated will be transmitted to NWS offices and may include satellite data in combination with surface and upper air observations and radar data, and analysis and prediction model output from the National Meteorological Center. 


\subsubsection{Polar Orbiting Satellites}

While the NWS will emphasize improvements in mesoscale forecast operations in the 1990s, it will maintain its historic focus on the area of regional/national scale forecasting. The NOAA Polar Orbiting Environmental Satellite (POES) System has become a reliable supplier of high-quality data for numerical data prediction models. The POES satellites carry instruments that supply temperature and moisture soundings and include microwave radiometer channels to facilitate sounding retrievals in cloudy areas. The principal sensing capabilities used by the NWS and carried out on the POES satellites include the TIROS operation Vertical Sounder (TOVS) and the Advanced Very High Resolution Radiometer (AVHRR).

The next generation of polar orbiting satellites, designated as NOAA $K-M$, is expected to provide enhanced capabilities to the present POES System. A major system instrument improvement scheduled for these satellites is the Advanced Microwave Sounding Unit (AMSU) which will give an increased capability to produce more accurate vertical temperature and moisture soundings in cloudy areas. The AMSU will provide global soundings in cloudy regions at nearly the same level of accuracy as those presently produced in clear air. The AMSU will, in addition, provide increased higher resolution soundings vital to improvements in estimating sea surface temperatures, an important indication of the energy available to the atmosphere.

\subsection{PROPOSED SYSTEM}

The proposed modernization and restructuring of the NWS would: (1) change the number and location of field offices to take maximum advantage of new technologies; (2) gradually transform the workforce to become more professional in its makeup; and (3) reallocate operational responsibilities between field offices and the National Centers. These changes will be effected in accordance with the certification provisions of Public Law 100685 .

The effective use of the advanced technologies planned for the NWS is closely linked to the scientific abilities of NWS personnel and the national field office structure. The current field office structure has evolved intermittently throughout the agency's history. Today, the structure supports a labor intensive observation and dissemination network. If the new technological network were constrained by the current field office structure, required staffing levels and overall costs would increase unnecessarily.

The need to restructure is twofold. First, the combination of new operational concepts, new data sets, and an evolving scientific understanding of the dynamic processes associated with 
the most dangerous weather phenomena requires an increase in the number of meteorologists. During periods of impending severe weather and flooding, operational personnel are under extreme pressure to make timely and accurate decisions. The increased proportion of meteorologists in the NwS workforce will improve warnings and forecasts by taking full advantage of the capabilities of the new technologies. Second, productivity and efficiency gains will occur as a result of increased integration of the new technological observation, information processing and communication systems with the staff. An increased effective range of the radar systems and the ability to assemble all data at a reduced number of offices increases productivity and efficiency. The reduced number of offices places a special emphasis on the effective delivery of weather services to communities.

There are key tradeoffs in the restructuring process among human capabilities, costs, and programmatic, scientific, and technological opportunities. Factors to be considered include: (a) the quality of warning and forecast services; (b) the ability to establish a more uniform observational network across the country: (c) the automation of observational duties; (d) orographic characteristics (effects of mountains); and (e) the ability of the NWS workforce to employ and understand new technologies and science.

The modernization and restructuring of the NWS will meet the increasing demands for more timely and accurate warning and forecast services under tight financial and personnel constraints. NWS is modernizing its field office organization by integrating new technologies with NwS operations and by making adjustments in the mix of professional and paraprofessional personnel at forecast offices. The current and emerging technologies (e.g., observation, communication, interactive processing, and modeling) are providing the foundation for improvement of the observation and forecast of mesoscale phenomena throughout the 1990s.

\subsubsection{National Meteorological Center}

The National Centers will continue to provide a wide variety of forecast and guidance services to other NWS elements and the public. New emphasis will be placed on improved mesoscale forecasting techniques and long-range forecast services.

\subsubsection{Field offices}

The heart of the new structure is the Weather Forecast office (WFO). Such offices will concentrate professional expertise and technology on warnings and forecast products for a small area (local and multi-county). Emphasis will be placed on the hazardous weather and flash flood warning program, public weather 
program, near shore and/or coastal marine forecasts, and aviation terminal forecast program. Forecasts and outlooks beyond 24 hours will be locally prepared products adapted from the guidance provided by the NMC. At the WFO, advances in hydrometeorologic science and supporting technology will be concentrated and focused to provide state-of-the-art products and services. The WFO will be the repository of three ingredients essential to effective weather and hydrologic services: (1) locally assembled, high volume, mesoscale data necessary to resolve weather systems on the local scale; (2) information processing, storage, and display capability to organize and rapidly present mesoscale data and derived information for forecaster assimilation; and (3) a professional workforce possessing the expertise and experience to make accurate forecast decisions based on available information. The staffing level for a wFo is estimated to be 25 personnel, providing an average of two forecasters per shift.

The role of the River Forecast centers (RFCs) will change significantly with the proposed modernization and restructuring of the NWS. RFCs will become highly visible sources of hydrologic forecast expertise, both to the public and water resources cooperators. The centers will provide river and flood forecast guidance to the WFOs for interpretation into warnings. Warnings will continue to be issued by field offices other than RFCs. RFCs will provide both short and extended range hydrologic forecasts directly to water resources cooperators to support the two-way information exchange process necessary to provide the most timely and accurate hydrologic forecasts for all users. The future RFC staffing will be augmented significantly. Each RFC will be collocated with a WFO.

\subsubsection{New Technologies}

A suite of new technologies are being deployed to improve warning and forecast services and to replace obsolete and/or unreliable equipment. Among the new systems being deployed are: (1) the Automated Surface Observing System (ASOS); (2) Next Generation Weather Radar (NEXRAD); (3) National Center Advanced Computer Systems; and (4) the Advanced Weather Interactive Processing system (AWIPS)/NOAAPORT.

\subsubsection{Automated Surface Observing System (ASOS)}

Automating surface observations will relieve staff from the manual collection of surface observations. Over 1000 Asos sites across the nation will provide data on pressure, temperature, wind direction and speed, runway visibility, cloud ceiling heights, and precipitation on a nearly continuous basis. The 1000 ASOS sites include approximately 750 airport installations under the jurisdiction of the Federal Aviation Administration and approximately 250 NWS sites. The Department of Defense is also 
considering the acquisition of additional units. The observational data provided by the ASOS sites supports aviation operations and provides meteorological data needed by severe weather, flash flood, and river forecasting programs. The national capability to observe and transmit critical changing weather conditions almost as they occur represents an important enhancement for improving warning and forecast services.

\subsubsection{Next Generation Weather Radar (NEXRAD)}

Utilizing Doppler radar technology, the NEXRAD system will observe the presence and calculate the speed and direction of motion of severe weather elements such as tornadoes and violent thunderstorms. NEXRAD will also provide quantitative area precipitation estimates that are essential to the water resources forecasting effort at the RFCs and the WFo flash flood program. The severe weather and motion detection capabilities offered by NEXRAD will contribute toward an increase in the accuracy and timeliness of NWS warning services. For example, due to the limitation in the current radar detection systems, tornado warnings are usually issued only when visual sightings have been reported. The advent of NEXRAD will not only allow for an earlier detection of the precursors to tornadic activity, but will also provide data on the direction and speed of tornado cells once they form. The national network of 175 NEXRAD systems provides a significant improvement in uniform coverage over the present day radar network. The NWS plans to operate 113 NEXRAD systems; the remainder of the NEXRAD systems will be located at Federal Aviation Administration and Department of Defense locations, but the NWS will have access to data from a number of these systems.5

\subsubsection{National Center Advanced Computer Systems}

Future warnings and forecasts prepared by NWS offices will rely heavily on the basic analyses and guidance products provided by the NMC, especially for periods of 36 hours and beyond. These analyses and guidance products result from numerical models of the atmosphere run on high-speed computers. The future requirement for guidance products for mesoscale warnings and forecasts is greatly increased over the present. Fundamental

${ }^{5}$ The NWS will operate 110 WFOs in the coterminus United states, each of which will have a NEXRAD system. In addition, the NWS will operate 3 NEXRAD systems in the coterminus United states which are not collocated with a WFO. The 5 NwS-operated WFOs in Alaska, Hawaii and Puerto Rico will rely on FAA-acquired NEXRAD systems. 
model improvements are necessary to satisfy these requirements and provide guidance products of sufficient quality and frequency to support the warning and forecast operation at each office.

Class VI computers do not possess sufficient capacity to support the improvements needed at the National Centers. These increased demands require the acquisition of dedicated class VII computer capabilities with a processing capability an order of magnitude greater than class VI computers.

\subsubsection{Advanced Weather Interactive Processing system (AWIPS)/NOAAPOrt}

AWIPS will be the nerve center of WFO operations. AWIPS will be the data integrator, receiving the high-resolution data from the observation systems, the centrally-collected data and the centrally-prepared analysis and guidance products from the NMC. The integration of all of these data from multiple sources represents the information base from which all warning and forecast products will be prepared. AWIPS will provide fastresponse interactive analysis and display of the data to help support the meteorologists who make rapid decisions, prepare warnings and forecasts, and disseminate products to users. In addition, AWIPS will be the platform on which the complex interactive data analysis, information assimilation, and river forecasting systems will be executed at the RFCs.

AWIPS includes the communications network that interconnects all National Centers, RFCs, and WFOs for exchange of locallygenerated data. NOAAPORT will provide communications support for the operational distribution of the centrally-collected data and centrally-produced analysis and guidance products, as well as the satellite imagery and sounding data processed by the National Environmental Satellite, Data and Information service (NESDIS). In addition to supporting the requirements for AWIPS point-tomulti-point communications, NOAAPORT will also deliver a wide range of NOAA products, such as oceanographic and environmental data to external users including other government agencies, universities, private research organizations, and business interests.

\subsubsection{Advanced Satellite Observing systems}

Satellites will provide valuable support to the NwS' warning and forecast operations under the proposed modernization and restructuring of the NWS. Although their basic role will not be changed, greater emphasis will be placed on using satellite data and imagery to improve mesoscale forecasting techniques and longrange forecast services. 
4. costs

\subsection{CURRENT SYSTEM}

\subsubsection{Special Considerations}

The public benefits of weather information are so generally recognized around the world that every nation invests in some level of public weather and hydrologic services. Among the most advanced nations, these weather and hydrologic service programs are sophisticated and substantial.

Table 4.1 compares the weather service investments of seven industrialized nations on a per capita basis. Although these data are somewhat out-of-date, a search of published material did not produce more recent expenditure figures for foreign countries.

One conclusion to be drawn from this comparison is that although public demand for weather information in the United states is high, governmental investments in this country are modest in contrast to some industrialized countries. On a per capita basis, the United States invests at the same rate as industrialized countries having between $1 / 2$ and $2 / 3$ of its per capita GNP.

\subsubsection{Estimated costs}

The costs of providing meteorological services to the public are based on budget figures provided by the NWS. Fiscal year 1990 obligations, by line item of the NWs budget, for operating the current System are given in Table 4.2. These figures provide detailed information on such key budget categories as: (a) salaries and benefits; (b) contracts; (c) rent, communications, and utilities; (d) supplies; and (e) equipment. By far, the largest component of the NWS's operations budget is the cost of salaries and benefits, accounting for $\$ 213.7 \mathrm{million}$, almost twothirds of the overall total of $\$ 323.7$ million. One reason for the high level of staff costs is the current configuration of field offices; the NWS currently operates 249 field offices and 13 River Forecast centers. Of the 249 field offices, 52 have staffs of about 22 each and have forecast responsibility for entire states and warning responsibility for parts of states. A second tier of offices, generally with staffs of 8 to 12 each, have forecast and warning responsibility for parts of states. The costs of the four other key categories listed above are also influenced strongly by the current system of field offices. These costs, listed in the table, account for an additional $\$ 87.8$ million of the NWS's total operating budget. 
Table 4.1 Comparisons of National Investments for Meteorological Services ${ }^{6}$ and Gross National Product ${ }^{7}$

\begin{tabular}{|c|c|c|}
\hline Country & $\begin{array}{l}\text { Per Capita (\$US) } \\
\text { Meteorological } \\
\text { Services }\end{array}$ & $\begin{array}{c}\text { Per Capita (\$US) } \\
\text { GNP }\end{array}$ \\
\hline Australia & 4.20 & 11,178 \\
\hline Canada & 4.76 & 13,285 \\
\hline France & 1.91 & 8,907 \\
\hline West Germany & 1.91 & 10,025 \\
\hline Japan & 2.26 & 10,457 \\
\hline United Kingdom & 1.96 & 7,495 \\
\hline USA & 1.96 & 15,356 \\
\hline
\end{tabular}

Geteorological figures are based on averages between 19791981 presented in "comparison of the Costs of Providing Meteorological Services," Atmospheric Environmental Service, Management Committee Supporting Paper 47/131, undated.

${ }^{7} \mathrm{All}$ GNP figures are for calendar year 1984, and are based on figures published by the organization for Economic Cooperation and Development (OECD). 
Table 4.2 Fiscal Year 1990 NWS Operating Plan

\begin{tabular}{|l|r|}
\hline \multicolumn{1}{|c|}{ Category } & Cost (\$K) \\
\hline Salaries and Benefits & $213,687.5$ \\
\hline Travel of Persons & $5,915.2$ \\
\hline $\begin{array}{l}\text { Transportation of } \\
\text { Things }\end{array}$ & $4,509.9$ \\
\hline $\begin{array}{l}\text { Rent, Communications \& } \\
\text { Utilities }\end{array}$ & $31,920.0$ \\
\hline Printing & 628.5 \\
\hline Contracts & $43,466.1$ \\
\hline Supplies & $16,204.1$ \\
\hline Equipment & $6,468.6$ \\
\hline Land \& Structures & 153.2 \\
\hline Grants & $1,003.5$ \\
\hline $\begin{array}{l}\text { Insurance, Claims, } \\
\text { etc. }\end{array}$ & 46.7 \\
\hline Quarters & $(298.3)$ \\
\hline \hline ToTAL & $323,705.0$ \\
\hline
\end{tabular}


Comparisons with actual expenditures for previous fiscal years support that an annual real increase of $4 \%$ (i.e., in terms of 1990 dollars) for fiscal years 1991 through 2005 is reasonable. These projections are given in Table 4.3. The figures in Table 4.3 show that operating costs rise steadily from $\$ 323.7$ in 1990 to $\$ 583.0 \mathrm{milli}$ in in the year 2005 .

The costs of the GOES and POES satellite systems are included in the analysis of both alternatives. These costs include the procurement and launch of the satellites and procurement of the ground system components which command and control the satellites and acquire data from them.

The polar-orbiting program is a cooperative venture with the United states Air Force (USAF). The satellites are launched on USAF launch vehicles. The USAF launch vehicles also carry USAFfunded experimental instruments as a cost-saving approach to access to space.

Procurement of the GOES satellites is a cooperative venture in which NOAA and the National Aeronautics and Space Administration (NASA) each have key roles. NOAA, as the operating agency, represents the user and defines the basic requirements for the system. NASA, as the agency with multi-disciplinary engineering expertise, develops detailed specifications and procedures and launches the satellites. NASA is reimbursed for these services bY NOAA.

The costs for each of the satellite systems are given in Table 4.4. In order for these cost figures to be consistent with those presented elsewhere in this study, prior year costs back to 1987 are included for the GOES and POES satellite systems. These costs are based on actual NESDIS obligations. All other figures (i.e., the figures for fiscal years 1991 through 2005) are based on budgeting information provided by NESDIS. All costs are treated as real (i.e., in terms of 1990 dollars).

Table 4.5 summarizes the expected annual costs of the current system. All costs are classified as either non-recurring, recurring or satellite. Reference to the table reveals that aside from fiscal year 1990, which includes prior year expenditures, the annual costs are approximately $\$ 600$ million. 
Table 4.3 Estimated NWS Operating Costs: Fiscal Year 1990 through Fiscal Year 2005

\begin{tabular}{||l|l|}
\hline \hline Fiscal Year & Cost (SM) \\
\hline 1990 & 323.7 \\
\hline 1993 & 336.6 \\
\hline 1992 & 350.1 \\
\hline 1993 & 350.1 \\
\hline 1994 & 479.2 \\
\hline 1995 & 350.8 \\
\hline 1998 & 443.0 \\
\hline 1997 & 426.0 \\
\hline 1998 & 443.0 \\
\hline 1999 & 460.7 \\
\hline 2000 & 479.2 \\
\hline 2001 & 498.3 \\
\hline 2002 & 518.3 \\
\hline 2003 & 539.0 \\
\hline 2004 & 560.5 \\
\hline 2005 & 583.0 \\
\hline
\end{tabular}

${ }^{8}$ The entries in this table define the recurring costs for the current system (see also Table 4.5). Non-recurring costs for the current system are nil. 


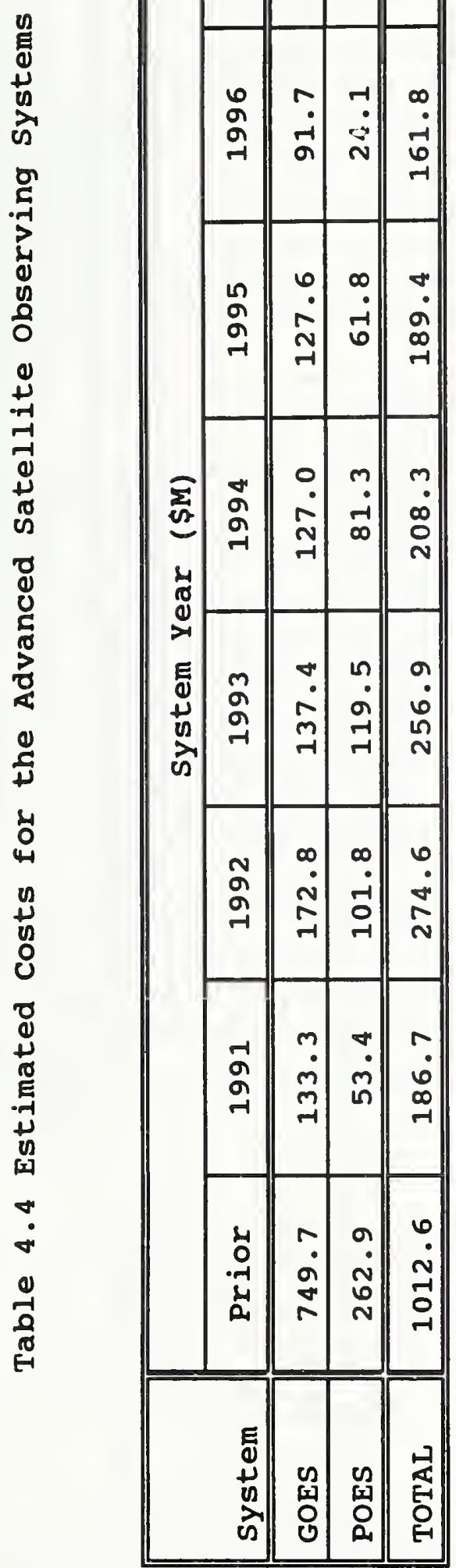

\begin{tabular}{|c|c|c|c|c|}
\hline & $\begin{array}{l}n \\
\stackrel{0}{0} \\
\stackrel{\circ}{N}\end{array}$ & $\begin{array}{l}-1 \\
\dot{v}\end{array}$ & $\begin{array}{r}\stackrel{-1}{*} \\
\dot{\sim}\end{array}$ & $\stackrel{\sim}{\infty}$ \\
\hline & $\begin{array}{l}\stackrel{+}{0} \\
\text { O } \\
\text { N }\end{array}$ & $\begin{array}{r}-1 \\
\dot{\sim}\end{array}$ & $\underset{\sim}{-1}$ & $\begin{array}{l}\sim \\
\dot{\infty}\end{array}$ \\
\hline & $\begin{array}{l}m \\
0 \\
0 \\
\text { N }\end{array}$ & $\begin{array}{l}r \\
\dot{\sim}\end{array}$ & $\begin{array}{l}r \\
\dot{\sim}\end{array}$ & $\stackrel{\sim}{\infty}$ \\
\hline 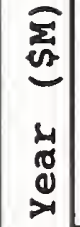 & $\begin{array}{l}\tilde{O} \\
0 \\
0 \\
\text { N }\end{array}$ & $\begin{array}{l}r \\
\dot{N}\end{array}$ & $\begin{array}{r}-1 \\
\dot{\sim}\end{array}$ & $\stackrel{\sim}{\infty}$ \\
\hline $\begin{array}{l}0 \\
0 \\
+ \\
0 n \\
\lambda_{0}\end{array}$ & $\begin{array}{l}-1 \\
0 \\
0 \\
\sim \\
N\end{array}$ & $\begin{array}{l}\dot{0} \\
\dot{m} \\
m\end{array}$ & $\begin{array}{r}r \\
\dot{N}\end{array}$ & $\stackrel{i}{i n}$ \\
\hline & $\begin{array}{l}0 \\
0 \\
0 \\
0 \\
\text { N }\end{array}$ & $\begin{array}{l}\text { n } \\
\dot{N} \\
\stackrel{n}{-1}\end{array}$ & $\begin{array}{r}-1 \\
\dot{\sim}\end{array}$ & $\begin{array}{l}0 \\
\dot{0} \\
+\end{array}$ \\
\hline & $\begin{array}{l}\sigma \\
\sigma \\
\sigma \\
\sigma\end{array}$ & $\begin{array}{r}-1 \\
\dot{d} \\
\sim\end{array}$ & $\begin{array}{l}r \\
\dot{N}\end{array}$ & $\underset{\sim}{\infty}$ \\
\hline & $\begin{array}{l}\infty \\
\sigma \\
\sigma \\
\sigma \\
-1\end{array}$ & $\begin{array}{r}r \\
\dot{H} \\
\sim\end{array}$ & $\begin{array}{l}\vec{\sim} \\
\stackrel{\sim}{N}\end{array}$ & $\begin{array}{l}N \\
-1 \\
\text { in } \\
-1\end{array}$ \\
\hline & 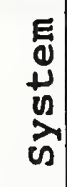 & 四 & $\begin{array}{l}\text { L } \\
\text { [1 } \\
0 \\
0 \\
0\end{array}$ & 䚾 \\
\hline
\end{tabular}



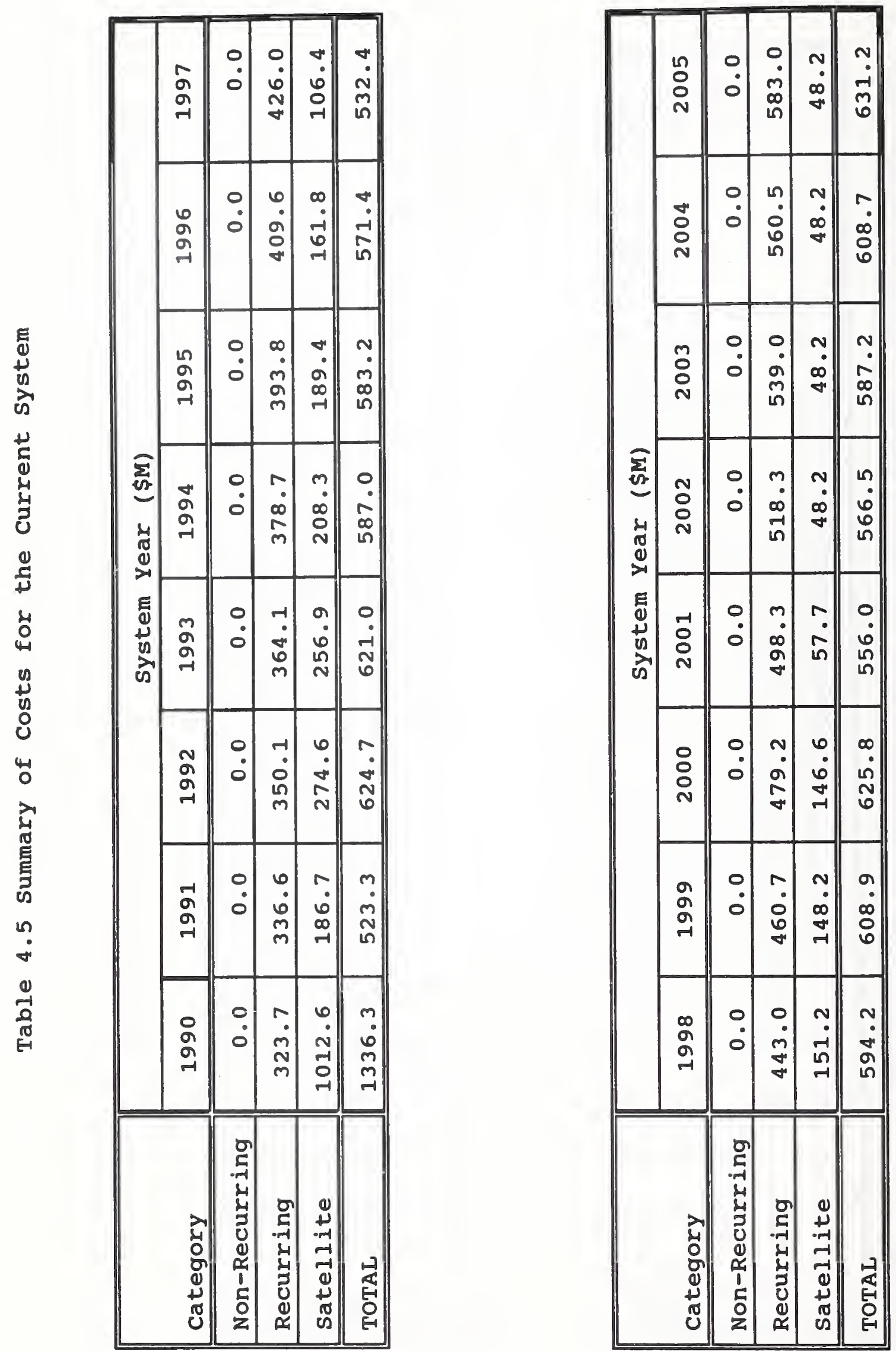


\subsection{PROPOSED SYSTEM}

$4.2 \cdot 1$

Special Considerations

This section defines the general transition strategy that will be used to implement the modernization and associated restructuring of the NWS. Transition strategies for a two-stage operation are presented; this section introduces the terms risk reduction, demonstration, and certification. The importance of risk reduction activities and demonstration programs as key ingredients in ensuring a successful transition are emphasized. The process that will be utilized to comply with the certification requirements of Public Law 100-685 is then described.

\subsubsection{Transition Strategy 9}

The fundamental transition strategy is an integrated, incremental step-by-step, office-by-office approach. Improvements in operations and services related to modernization and restructuring are the ultimate guiding force of the transition. Future services will define the system outputs, the staffing type and $\mathrm{mix}$ of an office, and the field structure needed to provide them efficiently. Future services, in turn, set requirements for training, education, and facility preparation, and guide a myriad of other dimensions of the modernization and restructuring. A realistic view of technology capabilities, resource availability and schedules, and the NWS environment will help shape the scope and pace of service changes.

The breadth of future operations and services is driven by the agency mission, scientific and technologic capability, and available resources. The transition strategy recognizes and incorporates these factors and must retain sufficient flexibility to respond to them. The approach acknowledges that plans for future operations and services may require adjustments as implementation proceeds. The NWS must be able to accommodate and capitalize upon the new knowledge and understanding that it will acquire throughout the transition period.

An important aspect to guiding the transition into the stages of modernization is the strategic use of resources. Transition strategies must make efficient use of the resources available today in order to advance current operations and services clearly on a path to meet the objectives of modernization and associated restructuring. Scarce resources, especially in the area of staffing levels, can be expected throughout the transition

'For more detailed information on the Nws' transition strategy, see: Fiscal Year 1992 Annual Update to the National Implementation Plan, TRANS-92-2, June 1992. 
period. This necessitates reliance on a transition strategy which concentrates programs and functions at offices that will become WFOs, permitting reallocation of staff and positions from one office to another. Close monitoring and careful management of scarce resources has to be done first and foremost at the regional level. At the national headquarters level, NWS management must also carefully monitor overall staffing throughout the transition period to address deficits and redistribute surpluses that may exist in individual regions.

The generalized Stage 1 and Stage 2 transition strategies described in the following paragraphs address primarily wSFOs, wSOs and meteorological observatories. While these represent the preponderance of the offices, the absence of transition strategies for other types of offices is not meant to imply that RFCs, National Centers, etc., will not also be undergoing substantial changes during the transition period. Indeed, related transition activities will take place concurrently at RFCs, National Centers, and other types of field offices. Transition activities for these offices are detailed in the appropriate National Center transition, Regional transition, and site implementation plans.

Stage 1 targets the efficient implementation and use of NEXRAD technology at RFCs, WSFOs, and WSOs. These offices will undergo a transformation in the first stage of modernized operations. Services and operations will be the impetus for this transformation. The transition of offices to Stage 1 will be paced, primarily, by delivery schedules of systems needed to support those services and operations. The timing of staffing changes and training also will be based on the NEXRAD delivery schedules with the goal of providing the necessary people on site, prepared to do the job when the systems are ready for operation.

NEXRAD offices will generally require additional staff to perform stage 1 operations. To the extent possible, these additional positions will be drawn from wSOs not scheduled to receive NEXRAD, but without degrading current services. The transformation of non-NEXRAD offices will be carried out in a step-wise fashion. First, programs in these WSOs will be automated and transferred. Freed resources will then be used in the development of NEXRAD offices. Any further wSo reduction will occur when a NEXRAD office assumes operational responsibility for the area formerly served by the wso. Any reduction or transfer of programs, as well as reallocation of staff, will depend upon NWS service responsibilities and user requirements.

It is expected that staffing at NEXRAD offices generally cannot be supplemented by positions coming from non-NEXRAD WSOs in the area the NEXRAD office will serve, because NEXRAD coverage may be 
a prerequisite for wSO draw-down. This suggests that Asos and NEXRAD deployment schedules can be used to optimize personnel assignments and moves. Regions will have to undertake feasibility studies for reducing non-NEXRAD WSOs. At the same time, for example, non-NEXRAD WSOs with surface observation and/or local warning radar programs can not reduce their staffs below the minimum levels required to carry out these programs until ASOS is commissioned at the site and/or NEXRAD coverage has proved satisfactory for the wso's area of responsibility. In any reduction of a wSO's responsibilities, the region must make every effort possible to ensure that community leaders and affected organizations are kept informed of significant changes, as well as show that warning services and required observations will not be degraded.

Stage 2 operations and services are based on full attainment of the modernization and restructuring goals. This includes complete restructuring to WFO and modernized RFC operations, deployment of the full suite of new technologies, and complete integration of systems and operations. The transition strategy does continue to treat this as a fully defined goal, but it may need to be adjusted to reflect changes in resources, schedules, technology capabilities, and/or the supporting sciences.

Transition to stage 2 will generally follow the same strategy outlined above for stage 1. The final resolution of stage 1 and work accomplished in that stage will be directed toward the attainment of stage 2 goals. WFO operations and WSO draw-downs will be synchronized with system acquisition, deployment, and commissioning. The important elements of staff allocation and training will be timed and adjusted to the goal of having Nws personnel in place and prepared to use the new technologies when they are available. Future operations and services will again be the impetus for stage 2 transition planning.

At the outset of stage 2, WFOs and RFCs will operate with systems that will have been deployed with an initial operating capability (IOC). This portion of stage 2 will be referred to as Initial Stage 2. Deferred capabilities (i.e., system capabilities not included in the IOC but required to achieve the full benefits of the modernization) will be part of an integrated systems upgrade required for full stage 2 operations. This phased introduction of system capabilities will provide the opportunity to assess system maturity and allow sufficient time for development and validation of the deferred capabilities while the forecasters are becoming familiar with operational use of the new systems.

\subsubsection{Risk Reduction Activities}

User acceptance of NWS modernization and restructuring requires the accomplishment of stage 1 and 2 objectives without degrading services to users. To a great extent, the future service 
programs rely on new systems developed near the leading edge of science and technology. The capabilities and applications of these systems are being refined and updated, even as the transition begins. Some of the new operational concepts for the 1990 s have had only limited operational testing. This is recognized in the system acquisition plan for AWIPS which allows for staged development. At each stage of development, there are opportunities to incorporate new scientific understanding and the latest NWS requirements. On the other hand, systems such as NEXRAD are based on known, existing technology that is well supported by theory and, in some cases, has undergone extensive field testing.

The risks involved with bringing the major new systems on line are obvious. The sequential implementation of several major technological systems dramatically increases risk. Extensive testing, development, and demonstration will be pursued to mitigate these risks and uncertainties. For example, some areas of risk are currently being addressed by the joint NWS and Environmental Research Laboratory (ERL) Denver AWIPS Risk Reduction and Requirements Evaluation ( $D A R^{3} E$ ) project in Colorado; the development of a prototype WFO at Norman; and the Prototype Real-time operational Test, Evaluation and User simulation (PROTEUS) project. It is expected that additional risk reduction projects will be needed throughout the entire transition period, and even beyond. To date, risk reduction efforts have been primarily directed to questions concerning technology. other questions in equally critical areas remain unanswered. These range from appropriate staffing levels at stage 1 and stage 2 offices, to the feasibility of totally integrating all warning and forecast functions in future wFos.

The early stage of modernized operations and the transition process itself will certainly reveal other areas where risk can be mitigated. Well-defined risk reduction projects are critical to a successful transition. The NW' transition strategy calls for agency support and response to significant risk reduction activities and their results.

\subsubsection{Modernization and Associated Restructuring Demonstration (MARD) Activities}

The modernization and restructuring of the NWs targets improved services through the effective and efficient use of new technologies operated by trained and professional staff. Active participation by NWS employees and external users is imperative for a successful transition. Support will follow if all parties understand what changes are planned and why these changes are needed. Clear demonstrations of the service improvements that will result from these changes are a critical element in obtaining support from NWS employees and external users. 
Demonstrations of improved capabilities and services will take place through a wide range of activities. The MARD will be the centerpiece for demonstrating the fully modernized NWS of the 1990 s.

An operational demonstration of service delivery from weather service offices equipped with the technological systems of the 1990 s will serve as a model for transition to national operations of the modernized and restructured NWS.

The operational MARD is designed to involve the application of new technologies and techniques, and the conversion of existing offices into WFOs. Some WFOs will be collocated with an RFC. The RFCs will be an integral component of the MARD as they capitalize on the technologies of the modernized NWS to provide a new generation of water resources forecast products in support of the operations of the WFOs and water resources cooperators.

The proposed demonstration area and the overall design of MARD are responsive to Public Law 100-685. The MARD is an approach towards verifying the service improvements expected without restructuring the entire country. The field offices to participate in the MARD were chosen for the high probability of severe weather in their areas and also in light of the advanced scientific and technological capabilities at facilities in Denver/Boulder, Kansas City, and Oklahoma City/Norman. Valuable experience with the current demonstration of the new Asos technology in the state of Kansas was also an important factor in the selection of this region.

Several basic criteria have been developed to test the new operating configuration. These criteria include the integration of NEXRAD coverage from several contiguous sites, not just the data from a single NEXRAD collocated with a WFO; inclusion of a sufficient number of WFO and RFC offices to test the coordination and interactive support functions in realistic situations; involvement of a sufficient number of WFOs and RFCs to test the implementation of new hydrometeorological support and forecasting operations; involvement of a sufficient number of offices to test a true communications network; and provision of warning and forecast services over a major area that encompasses important geographical entities (i.e., at least two complete states).

In order to ensure a successful MARD, a number of preparatory activities are being accomplished prior to the actual

demonstration. MARD office staffs are being supplemented with additional meteorologists, and scientific education in the interpretation of new data sources, such as Doppler radar, and in mesoscale forecasting techniques are being provided for meteorologists and hydrologists at these MARD offices. In addition, the new technology systems are being deployed; integrated not only with each other, but also with existing 
systems at the MARD offices; and commissioned to ensure that each performs its unique, but complementary role in supporting modernized operations. After a stabilization period, including initial testing and evaluation of the new operations, adjustments necessary to begin the MARD will be accomplished. Based on the currently scheduled deliveries of NEXRAD and the availability of AWIPS, the selected offices will be configured for the operational demonstration during the early to mid-1990s, and MARD will begin during the mid-1990s.

\subsubsection{Certification Process}

Public Law 100-685 requires that the secretary of commerce certify to the congress that closure, consolidation, automation, or relocation of any WSFO or WSO pursuant to implementation of the modernization and restructuring of the NWs will not result in any degradation of services to the affected area. Such

certification shall include:

- a detailed comparison of the services provided to the affected area and the services to be provided after such action;

-

any recent or expected modernization of NwS operations which will enhance services in the affected area; and

-

evidence, based upon operational demonstration of modernized NWS operations, which supports the conclusion that no degradation in services will result from such action.

When all necessary actions have been completed, but prior to the actual closure, consolidation, automation, or relocation of a WSFO or WSO, the Regional Director will prepare a Certification statement and send it to NWS Headquarters. The Assistant Administrator for Weather services will endorse the Certification statement and deliver it to the secretary of commerce. The secretary of Commerce will approve the certification statement and deliver it to the congress.

\subsubsection{Estimated Costs}

The costs of providing meteorological services to the public under the proposed modernization and restructuring are based on budget figures provided by the NwS. The figures for fiscal year 1990 are based on actual Nws obligations. The figures for fiscal year 1991 are based on NWS appropriations. The figures for fiscal year 1992 are based on the fiscal year 1992 President's budget. The figures for fiscal years 1993 through 2005 are based on budgetary estimates, with fiscal years 1999 through 2005 representing a projected "steady state" of operations. Costs of steady-state operations after the transition to the modernized and restructured NWS has been completed are lower than the costs 
of current operations due to savings resulting from: a reduction in overall NWS staffing levels; elimination of maintenance and support costs for existing systems replaced by ASOS, NEXRAD and AWIPS; and elimination of rents, utilities and facilities maintenance costs for offices that will be closed under modernization and restructuring. Tables 4.6 and 4.7 summarize these figures. All costs are treated as real (i.e., in terms of 1990 dollars).

Table 4.6 summarizes the non-recurring costs associated with the Proposed system, including the acquisition and deployment of the NW' new suite of technologies. Costs of preparing new and modified facilities to house the WFOs and RFCs are included in the NEXRAD budget. The Modernization and Associated Restructuring Demonstration and Implementation (MARDI) budget covers costs to implement and conduct the MARDI, as well as other transition costs not included in the technology program budgets (e.g., interim staffing augmentation, training on mesoscale science, office and personnel relocations, and removal and disposition of existing systems replaced by ASOS, NEXRAD, and AWIPS). Each cost category is summarized by year; total estimated costs by year are also given. Reference to Table 4.6 shows that costs for different systems peak in different years. For example, NEXRAD peaks in fiscal year 1993, the MARDI peaks in fiscal year 1994 and AWIPS/NOAAPORT peaks in fiscal year 1997. overall funding for the modernization and restructuring of the NWS peaks in fiscal year 1993. Since the proposed modernization and restructuring is expected to be completed by the end of fiscal year 1998, non-recurring costs drop to zero for fiscal years 1999 through 2005.

Table 4.7 summarizes the expected annual costs of the Proposed system. All costs are classified as either non-recurring, recurring, or satellite. Because the role of satellites is the same for both alternatives, the costs of satellite systems under the Proposed system are the same as under the Current system. Fiscal year 1990 receives special treatment because it includes prior year expenditures for all major systems.10 These prior year expenditures are treated as initial costs in all of the calculations performed in Chapters 6 and 7 . Reference to the table shows that overall NWS costs peak at $\$ 598.1$ million in fiscal year 1993, then decline, and finally reach a "steady state" of $\$ 294.8$ million in fiscal year 1999. It is important to note that annual recurring costs include the same budget categories shown in Table 4.2 .

${ }^{10}$ Prior year costs back to 1987 for all major systems totalling $\$ 259.0 \mathrm{M}$ are included in the Non-Recurring Cost Category for 1990. The actual total for the NWS in 1990 is $\$ 425.1 \mathrm{M}$. 


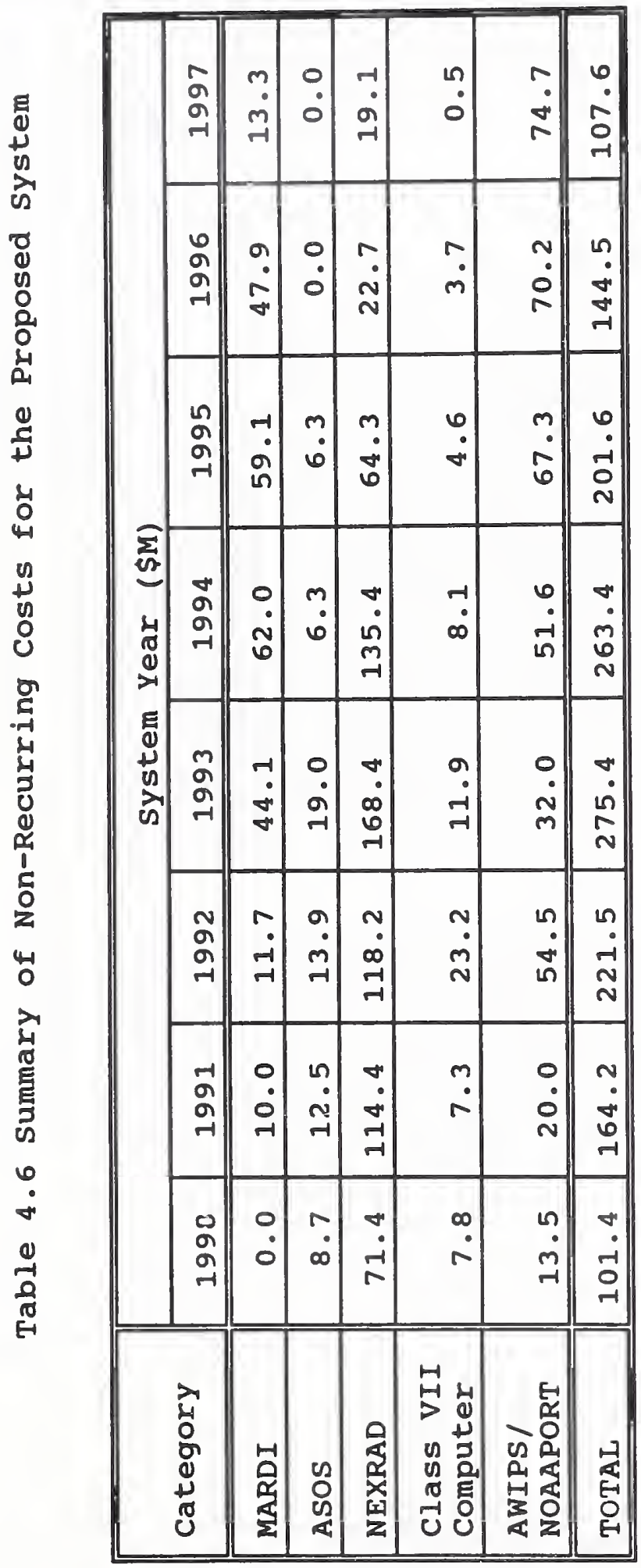

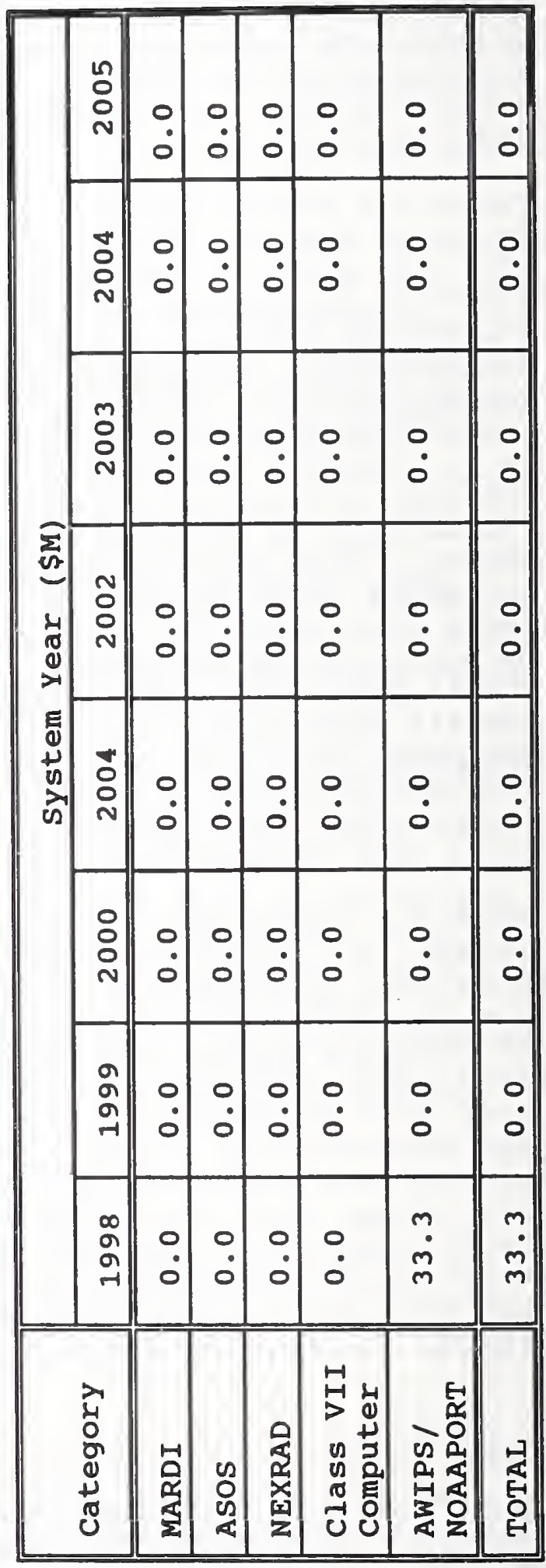




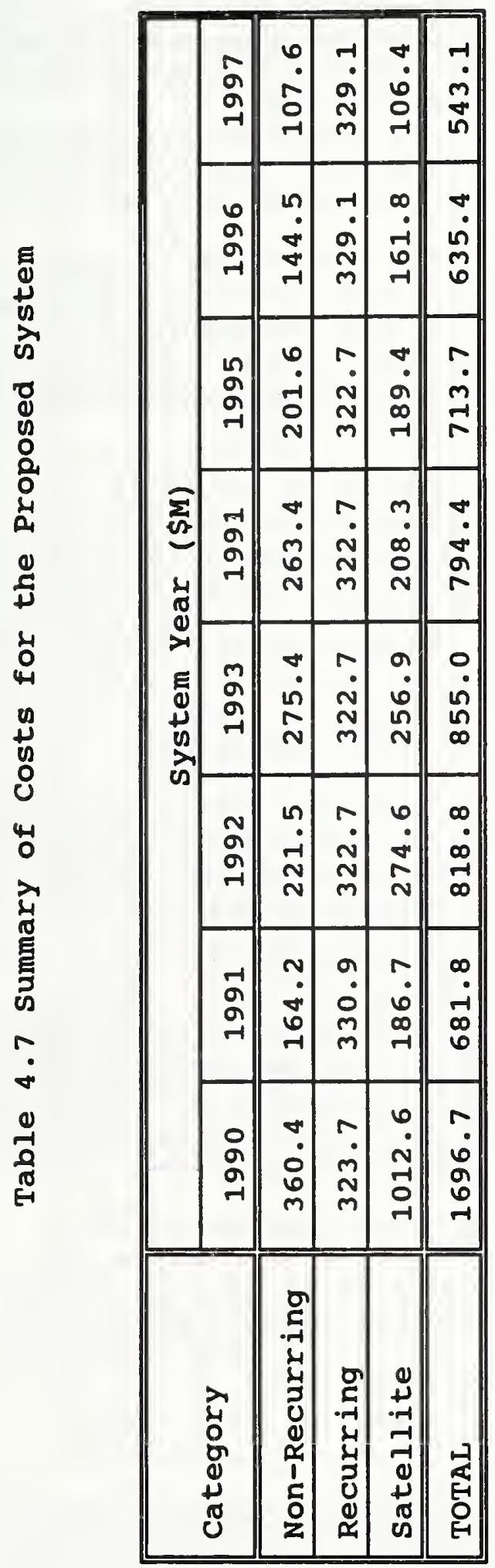

\begin{tabular}{|c|c|c|c|c|c|}
\hline \multirow{8}{*}{ 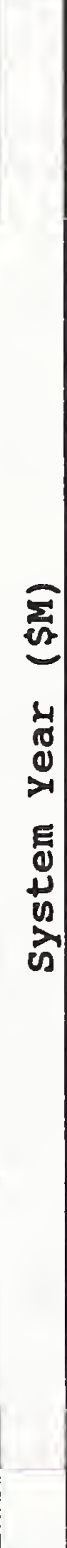 } & $\begin{array}{l}n \\
\text { O } \\
0 \\
\text { N }\end{array}$ & $\begin{array}{l}0 \\
0\end{array}$ & $\begin{array}{c}\infty \\
\dot{\vdots} \\
\stackrel{N}{N}\end{array}$ & $\begin{array}{l}\sim \\
\dot{\infty} \\
+\end{array}$ & $\begin{array}{l}0 \\
\dot{m} \\
\dot{m}\end{array}$ \\
\hline & $\begin{array}{l}\text { O } \\
\text { O } \\
\text { N }\end{array}$ & : & $\begin{array}{l}\infty \\
\dot{\sigma} \\
\sigma \\
\sim\end{array}$ & $\underset{\infty}{\sim}$ & $\begin{array}{l}0 \\
\dot{m} \\
\dot{m}\end{array}$ \\
\hline & $\begin{array}{l}m \\
\text { O } \\
\circ \\
\stackrel{N}{N}\end{array}$ & $\begin{array}{l}0 \\
0\end{array}$ & $\begin{array}{c}\infty \\
\dot{\sigma} \\
\sigma \\
\sim\end{array}$ & $\begin{array}{l}\sim \\
\dot{\infty}\end{array}$ & $\stackrel{0}{\circ}$ \\
\hline & $\begin{array}{l}\text { N } \\
\text { O } \\
\text { O } \\
\text { N }\end{array}$ & $\begin{array}{l}0 \\
0\end{array}$ & $\begin{array}{c}\infty \\
\dot{b} \\
\stackrel{\leftrightarrow}{ } \\
\sim\end{array}$ & $\begin{array}{l}\sim \\
\infty \\
\infty\end{array}$ & $\begin{array}{l}\dot{0} \\
\dot{m} \\
\dot{m}\end{array}$ \\
\hline & $\begin{array}{l}-1 \\
0 \\
0 \\
\text { N }\end{array}$ & 0 & $\begin{array}{c}\infty \\
\dot{b} \\
\stackrel{\sigma}{\sim}\end{array}$ & $\begin{array}{l}n \\
\text { in }\end{array}$ & $\begin{array}{l}n \\
\dot{N} \\
\text { in }\end{array}$ \\
\hline & $\begin{array}{l}\text { 응 } \\
\text { O } \\
\text { N }\end{array}$ & $\begin{array}{l}0 \\
0\end{array}$ & $\begin{array}{l}\infty \\
\dot{b} \\
\stackrel{\sigma}{N}\end{array}$ & $\begin{array}{l}0 \\
\dot{b} \\
\dot{\sigma}\end{array}$ & $\underset{\dot{\sigma}}{\stackrel{+}{\sigma}}$ \\
\hline & $\begin{array}{l}a \\
\sigma \\
\sigma \\
\sigma\end{array}$ & $\begin{array}{l}0 \\
0\end{array}$ & $\begin{array}{l}\infty \\
\dot{\bullet} \\
\stackrel{\sim}{\sim}\end{array}$ & $\begin{array}{l}\sim \\
\dot{\infty} \\
\dot{H}\end{array}$ & $\stackrel{0}{\stackrel{9}{*}}$ \\
\hline & $\begin{array}{l}\infty \\
\sigma \\
\sigma \\
\sim\end{array}$ & $\stackrel{m}{m}$ & $\begin{array}{l}\infty \\
\dot{\sim} \\
\stackrel{\sim}{m}\end{array}$ & $\begin{array}{l}N \\
-1 \\
n \\
-1\end{array}$ & $\begin{array}{l}\text { ? } \\
\dot{H} \\
\text { in }\end{array}$ \\
\hline & 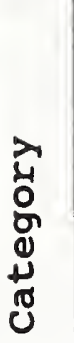 & 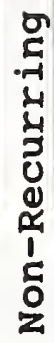 & 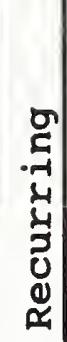 & 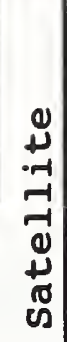 & 是 \\
\hline
\end{tabular}




\section{BENEFITS}

The purpose of this chapter is to document how all benefits used in the analysis were estimated and to provide a qualitative description of certain key intangible benefits. Due to the combined service/research orientation of the NWS, it was necessary to develop a specialized set of benefit categories that differ from those recommended in PIP8 POB-64. The organization of the chapter is, however, consistent with FIP8 POB-64.

At this juncture, it is worth noting that most benefit-cost studies divide benefits into two basic types, private benefits and social benefits. In the context of this study, private benefits are those which accrue to the NwS. Social benefits, almost by definition, produce positive cash flows which cannot be captured by the organization which generates them.

For purposes of this study, three categories of benefits are evaluated. These categories are: (1) benefits of weather information to the public; (2) potential savings due to improved forecasts; and (3) potential efficiency gains due to improved forecasts. Brief descriptions of each benefit category are given in the text which follows. All three categories result in social, rather than private, benefits.

\section{Benefits of Weather Information to the Public}

It is a truism to say that every citizen of the United states is affected by the weather, both directly and indirectly. However, quantification of the benefits of weather information to the public is difficult, at best, with any degree of precision. Fortunately, available statistics demonstrate the extent to which the public seeks and relies upon weather information. One study 11 estimated that $89 \%$ of the American public consult weather forecasts one or more times daily. Approximately half of the public (based upon an interview sample of 1300 persons) felt that weather information had a frequent impact on their activities. A very large majority (83\%) considered weather information to be important to daily activities and making travel plans.

\section{Potential Savings Due to Improved Forecasts}

Weather information also affects virtually every sector of the nation's economy. Trends in the most weather sensitive sectors underscore this importance.

${ }^{11}$ Public Requirements for Weather Information and Attitudes Concerning Weather Service, M.S.I. Services Incorporated, June 1981. 
Though weather conditions are generally uncontrollable, prudent action based upon knowledge of developing weather can often minimize resulting business losses. Eight key industrial sectors, representing $20 \%$ of the Gross National Product, are particularly sensitive. They are:

- $\quad$ Agriculture

- Aviation (Commercial)

- Construction

- Communications

- Electric Power

- Manufacturing

- Transportation

- Other (General Public, Government, etc.)

In the short run (one to ten days), these and many other industrial sectors can make cost-saving adjustments based upon reliable weather forecasts. In the longer run (weeks to seasons), industries can develop major weather-related cost savings and income-protection adjustments, with considerable economic return. Studies show that when weather differs from baseline climatological averages, annual business-cost increases can exceed $\$ 30$ billion. Although difficult to estimate, some portion of these costs are certainly avoidable.

Potential Efficiency Gains Due to Improved Forecasts

More accurate weather information provides not only the ability to reduce losses but also an opportunity for improving the efficiency of certain weather-sensitive operations. Five weather-sensitive operations are analyzed to determine where more accurate weather information would improve efficiency. They are:

Reduced expenditures for dams and other water control structures

Increased water yields for hydroelectric power and irrigation

Effects of increases in agricultural output on related industries

Improvements in navigation

Increased water availability 


\subsection{CURRENT SYSTEM}

5.1.1 Non-Recurring Benefits

There are no non-recurring benefits associated with the current system.

\subsubsection{Recurring Benefits}

\subsubsection{Benefits of Weather Information to the Public}

In 1980, the NWS commissioned a study aimed at answering several basic questions about the public's use of, understanding of, and need for weather information. The objective of acquiring such information was to improve services. The data were collected using a telephone interview survey of a statistically representative sample of some 1300 respondents, aged 18 years and older, throughout the country.

The sample was selected according to a two-stage random design. In the first stage, primary sampling areas (counties) were selected; in the second stage, working residential telephone numbers were selected. The telephone (as opposed to mail questionnaire, personal interview, or other technique) was selected as the best approach given the statistical confidence desired and the costs to conduct the study.

Primary sampling areas were further classified into four NwS regions, with 325 interviews to be completed in each region. each NwS region, the percentage of population living in urban and rural places was determined. Interviews were allocated to an urban or rural county according to the urban/rural population percentage within a region. For the purpose of this sample, a rural county was defined as one in which $40 \%$ or more of the population lived in rural places.

Within counties, listed numbers were selected from the latest telephone directories using a fixed-interval procedure with a random starting point. In counties known to have $10 \%$ or more unlisted telephone numbers, a random digit methodology was employed. In the random digit technique, computer-generated random digits were used with telephone number prefixes for the area of interest. All selected numbers were dialed a maximum of three times until either a contact was made or the number proved inoperable. For numbers where a contact was made, $24 \%$ of the contacts either refused or terminated the interview.

The major results of the study are summarized as follows:

- A majority of people (61\%) listen to a forecast 1-2 times a day; $27.9 \%$ listen more frequently. In other words, 89\% listen one or more times daily. The peak periods are 6-8 
a.m. (37.1\%) and 5-7.p.m. (33.8\%), followed by late evening listeners and viewers - 10-12 p.m. (24.9\%).

Three out of four (74.9\%) people feel they can get a forecast when they need it. of the balance who said they could not always get a forecast when needed, only $15 \%$ said they would be interested in getting a forecast as often as five or more times daily.

The average rating of weather forecasts was 2.14 on a 4point scale from EXCELLENT (1) to POOR (4). Most people (92.4\%) feel forecasts are accurate (5 or better on a $0-10$ scale, with an average rating of 7.02 ) and are MUCH MORE or MORE accurate than 10 years ago ( $82.5 \%)$.

A third suggested some improvements in current services. Ten percent felt improvements in "forecast accuracy" are called for. No other single suggestion was offered by more than $3 \%$ of the respondents, although several suggestions touched on some aspect of dissemination.

The NWS is seen as the author of the forecast by $61.1 \%$. Half the people (53\%) think the forecast is written locally. A majority feel it contains about the right amount of information (67\%). Most people (68.5\%) prefer numerical rather than verbal descriptions of probabilities as part of the forecast. Almost everyone (93\%) feels the forecasts are worded clearly.

About half (49\%) of those interviewed feel that weather information has a frequent impact on their activities. The vast majority (83\%) see it as important to daily activities and making travel plans.

About half (51.4\%) are aware of the capability to direct dial weather in other cities, and approximately two-thirds of those (68.1\%) say they are willing to pay for that service.

Improvement in weather services is seen as the primary responsibility of the NwS by slightly less than half (45.2\%). One-third identify the local media (31\%) and 1 of 10 local agencies (10.6\%).

The most frequent single response to the question of estimated annual dollar value of weather service to the respondent was $\$ 50$ OR MORE (29.8\%). Well over half (61.5\%) placed the estimated annual value at least $\$ 10$.

Data collected in the survey provide the basis for estimating the average value of the benefits of NWS-provided weather information to the public. The following components are central to the 
calculation: (1) the percentage of those surveyed who see the NWS as the author of weather forecasts; (2) the average amount an individual is "willing to pay" for weather forecasts: changes in the general price level since the survey was conducted; (4) the number of individuals aged 18 or older (i.e., the survey population); and (5) problems of system obsolescence which may result in an "erosion of confidence" for NWS forecasts.

From the survey data, it is clear that $61.1 \%$ of those surveyed viewed the NWS as the author of weather forecasts. Thus, in keeping with the conservative approach of this study, total benefits must be multiplied by 0.611 to obtain that portion which the public perceives as due to the NWS.

The willingness to pay approach is a recognized method for estimating benefits to the general public (i.e., social benefits).12 In developing an estimate for the average amount an individual is willing to pay, the following categories and weighing factors were used: (1) $\$ 50$ or more per year, $29.8 \%$; (2) $\$ 25-\$ 49$ per year, $15.1 \%$; (3) $\$ 10-\$ 24$ per year, $16.6 \% ;$ (4) $\$ 5-\$ 9$ per year, 7.8\%; (5) $\$ 1-\$ 4$ per year, $8.3 \% ;(6)$ less than $\$ 1$ per year, 15.7\%; and (7) don't know, no response, or refused, $6.7 \%$. In order to produce a conservative estimate of per capita benefits, if the respondent placed a value of $\$ 50$ or more per year, then the value used in the calculation was set at $\$ 50$. Similarly, if a respondent didn't know how to evaluate the services, provided no response, or refused to provide a value, then the value used in the calculation was $\$ 0.0$. For all other categories, the mid-point value was used in the calculation. The resultant per capita figure was $\$ 24.15$ per year.

It is important to note that the value just referenced is for persons aged 18 and older. Since both prices and population change over time, it is necessary to adjust the value of the benefits of weather information to the public for changes in purchasing power and population. To adjust for price changes, the GNP price deflator, ${ }^{13}$ has been used. Upon application to the estimated annual figure, the resultant value becomes $\$ 35.50$ per year. In order to obtain estimates for the value of benefits to the nation attributable to the NWS, it is necessary to multiply the average annual figure of $\$ 35.50$ by the population of persons aged 18 or older and by 0.611 , the proportion of the population which sees the NWS as the author of the forecast. Figures on the number of persons aged 18 or older are given in Table 5.1; they 1976 .

${ }^{12}$ E.J. Mishan, Cost-Benefit Analysis, New York: Praeger,

${ }^{13}$ Statistical Abstract of the United States: 1990, Table 775. 
are based on Census Bureau data. ${ }^{14}$ All data used in this study are based on the Census Bureau's "Middle Series" estimates.

Because the current system is rapidly becoming obsolete, the value of the weather information provided by the NWS may decline during the study period. A number of factors could cause this to happen. First, obsolescence may cause average forecast reliability (as perceived by the public) to decline. Second, forecasts may not be available when wanted because a site is inoperable and backup is impractical. Finally, a site may become inoperable during a local emergency. To adjust for such an "erosion of confidence," it is assumed that the per capita value of benefits from NWS-provided weather information declines by $5 \%$ per annum. The resultant per capita and national figures are given in Table 5.2.

\subsubsection{Potential Savings Due to Improved Forecasts}

Because the AFOs system is rapidly becoming obsolete, forecast accuracy is not expected to improve during the study period. Consequently, potential savings due to improved forecasts are expected to be $\$ 0.0$ for each year of the study period.

\subsubsection{Potential Efficiency Gains Due to Improved Forecasts}

Because the AFOS system is rapidly becoming obsolete, forecast accuracy is not expected to improve during the study period. Consequently, potential efficiency gains due to improved

forecasts are expected to be $\$ 0.0$ for each year of the study period.

\subsubsection{Summary of Recurring Benefits for the current system}

The recurring benefits associated with the current system are summarized in Table 5.3. The table lists the estimated annual benefits for each of the benefit categories. Note that only the first benefit category. Benefits of Weather Information to the Public, produces a non-zero value.

${ }^{14}$ Gregory spencer, Projections of the Population of the United States, by Age, Sex, and Race: 1988 to 2080, Washington, DC: Bureau of the Census, Series P-25, No. 1018, 1989. 
Table 5.1 Estimated Population of Persons Aged 18 and older ${ }^{15}$

\begin{tabular}{||c|c|}
\hline Year & $\begin{array}{c}\text { Population } \\
\text { (in thousands) }\end{array}$ \\
\hline 1992 & 186,372 \\
\hline 1994 & 187,929 \\
\hline 1992 & 189,432 \\
\hline 1994 & 190,879 \\
\hline 1994 & 192,273 \\
\hline 1995 & 193,965 \\
\hline 1998 & 195,752 \\
\hline 1994 & 197,499 \\
\hline 1998 & 199,210 \\
\hline 1999 & 204,361 \\
\hline 2000 & 202,553 \\
\hline 2000 & 204,364 \\
\hline 2000 & 206,161 \\
\hline 2003 & 207,951 \\
\hline 2004 & 209,739 \\
\hline 2005 & 211,522 \\
\hline
\end{tabular}

${ }^{15}$ Figures are based on Bureau of the Census projections (see Gregory Spencer, op cit, pp. 7 and 30 ). 
Table 5.2 Estimated Value of the Benefits of Weather Information to the Public: Current System

\begin{tabular}{||c||c|c|}
\hline Year & Per Capita & Nation (\$M) \\
\hline 1991 & 35.50 & $4,042.5$ \\
\hline 1991 & 33.81 & $3,882.2$ \\
\hline 1992 & 32.20 & $3,726.9$ \\
\hline 1993 & 30.67 & $3,576.5$ \\
\hline 1994 & 29.21 & $3,431.1$ \\
\hline 1995 & 27.82 & $3,296.5$ \\
\hline 1996 & 21.03 & $3,168.4$ \\
\hline 1997 & 25.23 & $3,044.5$ \\
\hline 1998 & 24.03 & $2,924.6$ \\
\hline 1999 & 27.82 & $2,890.0$ \\
\hline 2002 & 20.76 & $2,697.2$ \\
\hline 2004 & 20.76 & $2,591.7$ \\
\hline 2002 & 19.77 & $2,490.0$ \\
\hline 2003 & 19.93 & $2,392.1$ \\
\hline 2004 & 17.93 & $2,297.7$ \\
\hline 2005 & 17.08 & 206.9 \\
\hline
\end{tabular}




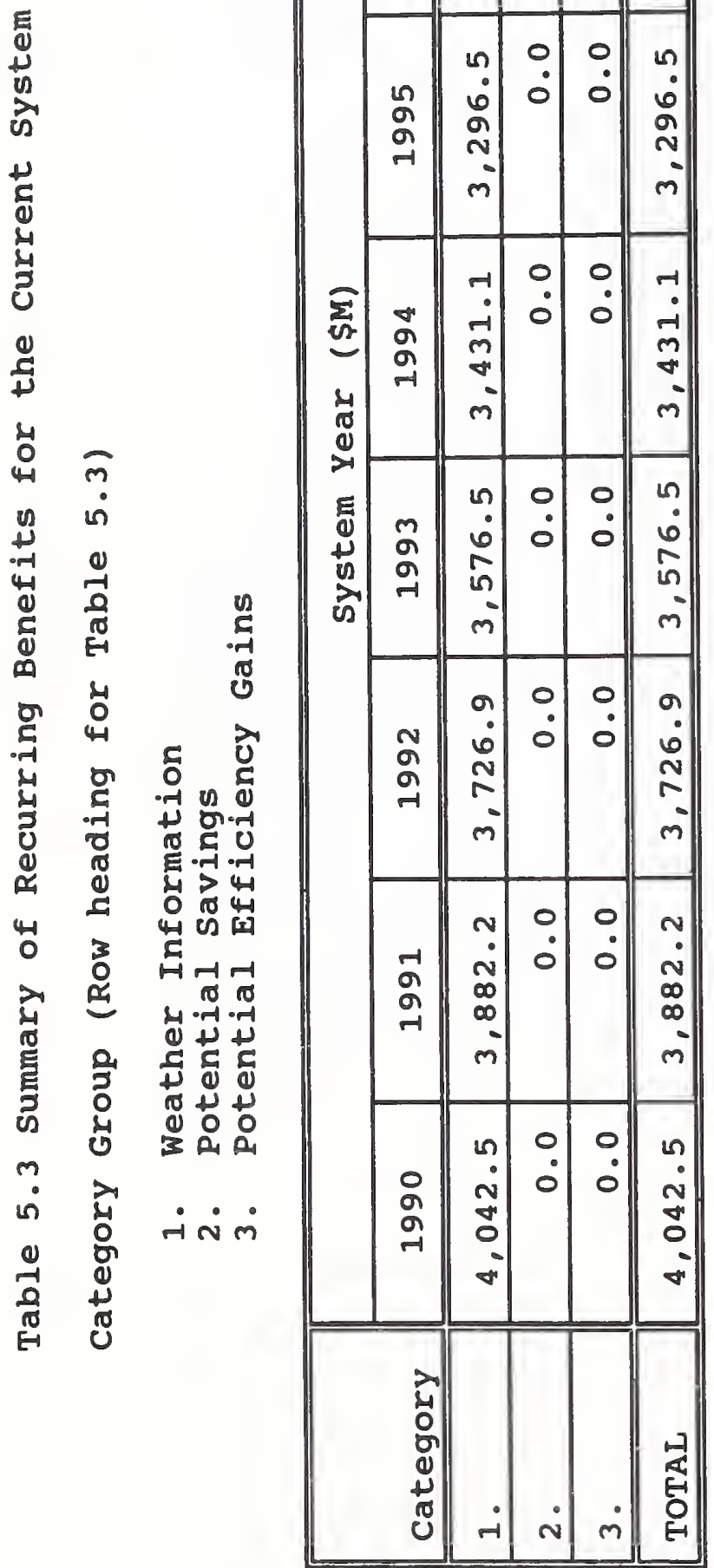

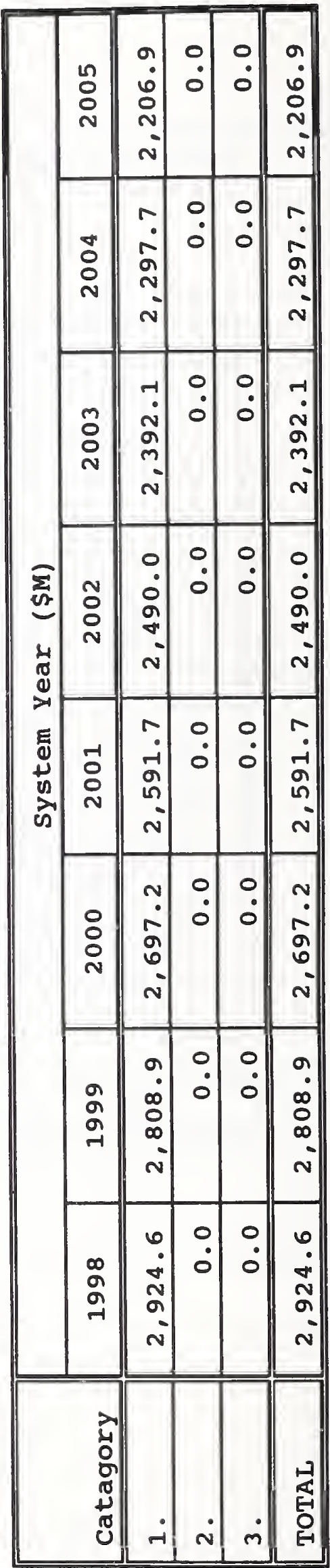


When AFOS was deployed, it provided a capability not previously available to the NWS. AFOs has resulted in better quality outputs and improved staff productivity. With the saturation of AFOS, many of these benefits have eroded. Continued constraints on workload growth will further reduce such benefits. It is an axiom of information systems that growth in data processing is to be expected and is necessary to continue to produce new and better products. A static environment, therefore, becomes one in which benefits inevitably decline.

\subsection{PROPOSED SYSTEM}

\subsubsection{Non-Recurring Benefits}

After the proposed system is fully operational, with all user files transferred and related work done, the current system could be released. Portions of the current system are leased and would be returned to the vendor; the purchased portions would be available for transfer or resale. In assessing the value of excess equipment, it must be remembered that much of it is obsolete. Since the information systems field is quite dynamic, resale values tend to drop sharply. Therefore, consistent with the conservative approach taken in this benefit-cost analysis, no residual value has been included in the calculations for excess equipment. We note, however, that the availability of spare parts may benefit sites which are converted late in the proposed modernization and restructuring of the NWS.

5.2.2 Recurring Benefits

\subsubsection{Benefits of Weather Information to the Public}

In order to obtain an estimate of the benefits to the public of weather information which are attributable to the NWS, the approach described previously in section 5.1.2.1 was used. The only difference between the two sets of estimates is due to the fact that system obsolescence is not a factor here. Therefore, the average amount an individual is willing to pay can be held constant at $\$ 35.50$ per year. The resultant per capita and national figures are given in Table 5.4.

It is important to note that the proposed modernization and restructuring of the NWS is expected to produce significantly better forecasts than prevailed at the time of the survey. These additional benefits are the subject of the sections which follow. 
Table 5.4 Estimated Value of the Benefits of Weather Information to the Public: Proposed system

\begin{tabular}{|c||c||c|}
\hline Year & Per Capita & Nation (\$M) \\
\hline 1993 & 35.50 & $4,042.5$ \\
\hline 1994 & 35.50 & $4,076.3$ \\
\hline 1992 & 35.50 & $4,108.9$ \\
\hline 1993 & 35.50 & $4,140.3$ \\
\hline 1994 & 35.50 & $4,170.5$ \\
\hline 1998 & 35.50 & $4,207.2$ \\
\hline 1998 & 35.50 & $4,246.0$ \\
\hline 1997 & 35.50 & $4,283.9$ \\
\hline 1998 & 35.50 & $4,321.0$ \\
\hline 1993 & 35.50 & $4,357.5$ \\
\hline 2004 & 35.50 & $4,393.5$ \\
\hline 2004 & 35.50 & 4.432 .8 \\
\hline 2002 & 35.50 & $4,471.7$ \\
\hline 2003 & 35.50 & $4,510.6$ \\
\hline 2004 & 35.50 & $4,549.3$ \\
\hline 2005 & 35.50 & 488.0 \\
\hline
\end{tabular}


In 1972, a study of the potential economic benefits of improvements in weather forecasting was conducted by the california state University for NASA. ${ }^{16}$ The study is noteworthy because it made use of: (1) factual records compiled by the weather forecasting profession for the purpose of verifying its own technical competence; and (2) quantitative accounting information concerning the monetary value of weather-caused losses obtained from representative samples of agricultural, commercial and industrial organizations. ${ }^{17}$

Data from these two sources were combined into a "meteorologiceconomic model" relating potential improvements in meteorological information to the associated economic gains, including the limits which are placed upon such gains by the nature of weather information itself.

Considering the general case of deciding whether or not to take protective measures against predicted adverse weather, it is postulated that economic gains resulting from improved weather forecasts may be achieved as a consequence of:

(1) operational improvements; (2) scientific advances; and (3) total potential gains.

Operational Improvements. These may be accomplished by providing information concerning the uncertainty of the weather prediction so that the user, within a given state of the science, may make decisions which are of optimum utility for their purpose.

Scientific Advances. These may be attained by increasing scientific understanding of weather processes to such a degree that operationally errorless decisions (not necessarily scientifically without error) can be made by the forecast user.

Total Potential Gains. These represent the limit of economic gains due to both operational improvements and scientific advances.

${ }^{16} \mathrm{~J}$. C. Thompson, The Potential Economic Benefits of Improvements in Weather Forecasting, San Jose, CA: California State University, 1972 .

${ }^{17} \mathrm{No}$ calculations in this section include reductions in weather-related fatatilies. For example, potential savings due to improved forecasts for commercial aviation are limited to reductions in cancellations, delays and diversions of airline flights. 
Using the meteorologic-economic model, these statements can be translated into numerical form, and the future economic gains due to improved weather forecasts can then be estimated. A two-stage procedure was used. In the first stage, data are developed in a non-dimensional (percentage) form -- specifically as the potential economic gain, per unit forecast, per unit of economic loss due to adverse weather. This approach results in an assessment which is independent of inflation or other secular economic factors which may seriously influence monetary evaluation. Next, to produce dollar estimates, the potential economic gain can be obtained simply taking the product of the appropriate percentage gain and the currently experienced, but protectable, weather-caused losses.

In order to obtain dollar estimates of protectable weather-caused losses, it was first necessary to secure information concerning such losses in the required form. A survey of major agricultural, industrial and commercial organizations in the United states was conducted for this purpose. The survey took the form of a questionnaire. About 250 replies were received, representing a $22 \%$ response rate on the part of those contracted.

Since it was realized that no survey could, inherently, secure data on the total weather-caused losses in the United States, information was requested of each respondent on the percentage of the gross revenue represented by such losses. Assuming, then, that the mean percentage thus obtained from the survey sample was representative of the major activity of which it was a part, estimates of total losses for the United states were computed from total gross revenues for each activity compiled. These estimates are given in Table 5.5. The figures in Table 5.5 have been adjusted to reflect changes in purchasing power since the original study was performed.

A monetary evaluation of the potential economic benefits from improvements in weather forecasting may be simply determined, in principle, as the product of the meteorological (non-dimensional) appraisal of potential gains and the economic (dimensional) estimates of currently observed, but protectable, weather-caused losses. However, an improvement in this simple computation of the potential gains may be achieved by weighting the results by the length of the forecast period designated by survey respondents as the minimum necessary to provide adequate warning of adverse weather. These estimates are given in Tables 5.5 and 5.6. The potential gains due to "operational improvements" 
Table 5.5 Summary of Annual Dollar Losses Due to Adverse Weather In the United States: Estimated ${ }^{18}$ and Preventable 19

\begin{tabular}{|c|c|c|}
\hline \multirow[b]{2}{*}{ Activity } & \multicolumn{2}{|c|}{ Value (\$M) } \\
\hline & Estimated & Preventable \\
\hline Agriculture & $22,413.8$ & $9,667.4$ \\
\hline Aviation (Commercial) & 251.3 & 154.8 \\
\hline Construction & $2,714.6$ & 893.8 \\
\hline Communications & 210.5 & 17.4 \\
\hline Electric Power & 124.3 & 37.8 \\
\hline Manufacturing & $1,625.7$ & 647.4 \\
\hline Transportation & 251.3 & 124.6 \\
\hline Other & $6,886.5$ & $2,877.2$ \\
\hline TOTAL & $34,488.6$ & $14,420.4$ \\
\hline
\end{tabular}

${ }^{18}$ Total losses, irrespective of whether or not protective measures could be taken against adverse weather.

${ }^{19}$ Losses due to adverse weather which could be protected against if adequate warnings for appropriate period in advance could be provided. 
Table 5.6 Percents of Protectable Losses Due to Operational Improvements ${ }^{20}$ and Scientific Advances ${ }^{21}$ by Forecast Period

\begin{tabular}{|c||c||c|}
\hline $\begin{array}{c}\text { Forecast } \\
\text { Period }\end{array}$ & $\begin{array}{c}\text { Operational } \\
\text { Improvements }\end{array}$ & $\begin{array}{c}\text { Scientific } \\
\text { Advances }\end{array}$ \\
\hline $1-5$ hours & 0.011 & 0.022 \\
\hline $6-11$ hours & 0.016 & 0.028 \\
\hline $12-36$ hours & 0.032 & 0.052 \\
\hline $2-5$ days & 0.063 & 0.075 \\
\hline 30 days & 0.083 & 0.088 \\
\hline 90 days & 0.123 & 0.167 \\
\hline
\end{tabular}

${ }^{20}$ These entries correspond to $g_{\text {of }}$.

${ }^{21}$ These entries correspond to $g_{\mathrm{af}}$. 
and/or "scientific advances" thus may be computed from the following expressions:

$$
\begin{aligned}
& P G_{0}=\sum_{f=1}^{6} g_{o f} \sum_{a=1}^{8} L_{a} W_{a f} \\
& P G_{s}=\sum_{f=1}^{6} g_{s f} \sum_{a=1}^{8} L_{a} W_{a f}
\end{aligned}
$$

where $g_{\text {of }}=$

percent of protectable loss due to operational improvements for forecast period $f(f=1, \ldots, 6$; where 1 corresponds to 1-5 hours; $2,6-11$ hours; $3,12-36$ hours; 4, 2-5 days; 5,30 days; 6, 90 days) given in Table 5.6.

$g_{\text {sf }}=$ percent of protectable loss due to scientific advances for forecast period $f$ given in Table 5.6;

$\mathbf{I}_{\mathbf{a}}=$

protectable loss, in dollars, associated with adverse weather events which affect activity group a (1, Agriculture; ...; 8, Other) given in Table 5.5 ; and

$\mathrm{w}_{\mathrm{af}}=$

weighting factor (percent of respondents in activity group a who designated forecast period $f$ as the minimum required for an adequate warning of adverse weather) given in Table 5.7.

Based on the relationships given above and the values of the key variables given in Tables 5.5 through 5.7 , it is possible to estimate annual savings as a function of economic activity. These values are presented in Table 5.8. As one might expect, the largest potential savings are associated with agriculture. ${ }^{22}$

It is important to point out that these potential savings would only result after the modernization and restructuring of the NwS is essentially complete. In order to best determine how much of

${ }^{22}$ A similar study (W. J. Hussey, "The Economic Benefits of Operational Environmental Satellites," in Monitoring Earth's ocean, Land, and Atmosphere from Space - sensor, Systems, and Applications, A. Schnopf (editor), 1985, pp. 216-260) estimated potential agricultural savings in excess of $\$ 1.0$ billion for selected crops and geographical regions (e.g., grape harvest in Monterey county California, California raisin crop drying, and cherry harvest). 


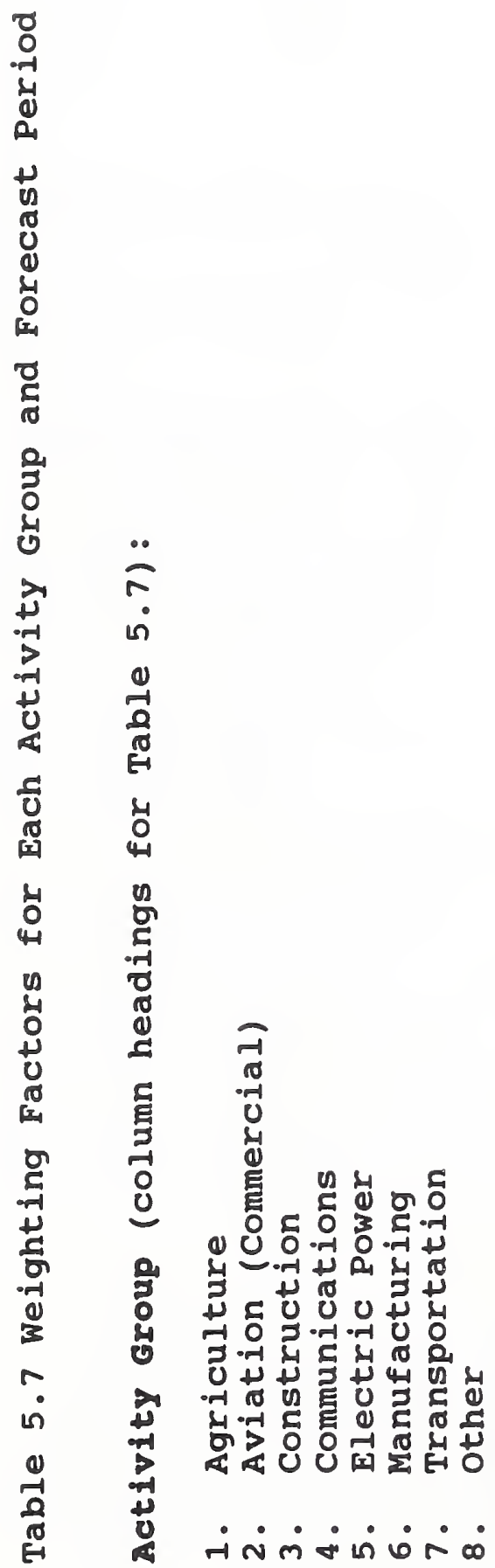

\begin{tabular}{|c|c|c|c|c|c|c|c|}
\hline \multirow{8}{*}{$\begin{array}{c}0 \\
3 \\
0 \\
0 \\
0 \\
-1 \\
-1 \\
-1 \\
7 \\
-7 \\
\pm \\
0 \\
0\end{array}$} & $\infty$ & $\begin{array}{l}\pi \\
+ \\
-1 \\
0\end{array}$ & $\begin{array}{l}\infty \\
r \\
-1 \\
0\end{array}$ & $\begin{array}{l}\dot{0} \\
\text { m } \\
\dot{0}\end{array}$ & $\begin{array}{l}n \\
\infty \\
-1 \\
\dot{0}\end{array}$ & $\begin{array}{l}\infty \\
\sigma \\
0 \\
0\end{array}$ & $\begin{array}{l}0 \\
\infty \\
0 \\
0 \\
0\end{array}$ \\
\hline & $r$ & $\begin{array}{l}0 \\
\infty \\
N \\
\dot{0}\end{array}$ & $\begin{array}{l}r \\
\sigma \\
-1 \\
\dot{0}\end{array}$ & 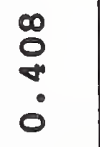 & $\begin{array}{l}m \\
\sigma \\
0 \\
\dot{0}\end{array}$ & $\begin{array}{c}+ \\
-1 \\
0 \\
0\end{array}$ & $\begin{array}{l}\infty \\
0 \\
0 \\
0\end{array}$ \\
\hline & 6 & $\begin{array}{l}0 \\
1 \\
N \\
0\end{array}$ & $\begin{array}{l}0 \\
\infty \\
-1 \\
0\end{array}$ & $\begin{array}{l}N \\
m \\
0\end{array}$ & $\begin{array}{l}\infty \\
0 \\
-1 \\
0\end{array}$ & $\begin{array}{c}N \\
\tilde{o} \\
\dot{0}\end{array}$ & $\begin{array}{l}\infty \\
1 \\
0 \\
0 \\
0\end{array}$ \\
\hline & n) & $\begin{array}{c}n \\
\infty \\
N \\
\dot{0}\end{array}$ & $\begin{array}{l}0 \\
0 \\
\sim \\
\dot{0}\end{array}$ & $\stackrel{N}{i}$ & $\begin{array}{c}-1 \\
0 \\
-1 \\
0\end{array}$ & $\begin{array}{l}0 \\
1 \\
0 \\
0\end{array}$ & $\begin{array}{l}\tilde{0} \\
\stackrel{-1}{0} \\
\dot{0}\end{array}$ \\
\hline & + & $\begin{array}{c}N \\
\text { in } \\
0 \\
0\end{array}$ & $\begin{array}{c}m \\
0 \\
-1 \\
0\end{array}$ & $\begin{array}{l}\dot{0} \\
\text { 우 } \\
\dot{0}\end{array}$ & $\begin{array}{l}n \\
\infty \\
\sim \\
\dot{0}\end{array}$ & $\begin{array}{l}0 \\
1 \\
0 \\
0\end{array}$ & $\begin{array}{l}0 \\
0 \\
0 \\
0\end{array}$ \\
\hline & $m$ & $\begin{array}{c}-1 \\
0 \\
0 \\
0\end{array}$ & $\begin{array}{c}m \\
\infty \\
-1 \\
\dot{0}\end{array}$ & $\begin{array}{l}0 \\
0 \\
0 \\
0\end{array}$ & $\begin{array}{l}0 \\
a \\
-1 \\
0\end{array}$ & $\begin{array}{l}-1 \\
0 \\
0 \\
0\end{array}$ & $\begin{array}{c}n \\
n \\
0 \\
0\end{array}$ \\
\hline & N & $\begin{array}{l}0 \\
17 \\
N \\
0\end{array}$ & 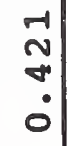 & $\begin{array}{l}N \\
\infty \\
-1 \\
0\end{array}$ & $\begin{array}{l}+ \\
\overrightarrow{1} \\
\dot{0}\end{array}$ & $\begin{array}{c}m \\
m \\
0 \\
\dot{0}\end{array}$ & $\begin{array}{l}\circ \\
\circ \\
\circ \\
0\end{array}$ \\
\hline & r- & $\begin{array}{l}N \\
N \\
0 \\
0\end{array}$ & $\begin{array}{l}0 \\
1 \\
0 \\
0\end{array}$ & $\begin{array}{l}o \\
0 \\
\stackrel{0}{0} \\
\dot{0}\end{array}$ & $\begin{array}{l}a \\
6 \\
\sim \\
0\end{array}$ & 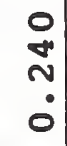 & \begin{tabular}{l}
0 \\
$\stackrel{-}{1}$ \\
\multirow{0}{0}{} \\
0
\end{tabular} \\
\hline & 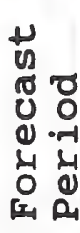 & $\begin{array}{c}n \\
\mu \\
\mathcal{L} \\
n \\
1 \\
-1\end{array}$ & 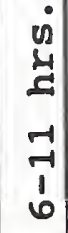 & $\begin{array}{ll}0 & \\
\sim & n \\
1 & 2 \\
\sim & \sigma \\
-1 & \sigma\end{array}$ & $\begin{array}{l}n \\
2 \\
0 \\
\sigma \\
0 \\
1 \\
1 \\
N\end{array}$ & $\begin{array}{l}n \\
2 \\
0 \\
0 \\
0 \\
0\end{array}$ & $\begin{array}{l}n \\
\text { ते } \\
\text { व } \\
0 \\
0\end{array}$ \\
\hline
\end{tabular}


Table 5.8 Summary of Potential Annual Savings Due to Operational Improvements, Scientific Advances and Total Gains Due to Improvements in Weather Forecasting

\begin{tabular}{|c|c|c|c|}
\hline Activity & $\begin{array}{l}\text { Operational } \\
\text { Improvements }\end{array}$ & $\begin{array}{l}\text { Scientific } \\
\text { Advances }\end{array}$ & $\begin{array}{l}\text { Total } \\
\text { Gains }\end{array}$ \\
\hline Agriculture & 680.8 & 861.4 & $1,542.2$ \\
\hline $\begin{array}{l}\text { Aviation } \\
\text { (Commercial) }\end{array}$ & 3.8 & 6.0 & 9.8 \\
\hline Construction & 35.6 & 50.0 & 85.6 \\
\hline Communications & 0.8 & 1.1 & 1.9 \\
\hline Electric Power & 0.8 & 2.2 & 3.6 \\
\hline Manufacturing & 22.0 & 32.4 & 54.4 \\
\hline Transportation & 0.8 & 5.2 & 8.7 \\
\hline Other & 128.7 & 175.4 & 304.1 \\
\hline TOTAL & 876.7 & $1,133.7$ & $2,010.3$ \\
\hline
\end{tabular}


the potential annual savings due to improvements in weather forecasting can be attributed to the NWS, reference was made to the NWS's National Implementation Plan. The National Implementation Plan shows that expenditures ramp up rapidly in fiscal years 1992 and 1993 and then begin to decline. By fiscal year 1998, the modernization and restructuring of the NWS should be essentially complete. To obtain the estimates given in Table 5.9, it was assumed that the degree of completion of the modernization and restructuring of the NWS will be: approximately $2 \%$ in 1991; 7\% in 1992; $24 \%$ in 1993; $51 \%$ in 1994; $77 \%$ in 1995; $90 \%$ in 1996; $97 \%$ in $1997 ;$ and $100 \%$ in 1998 and beyond.

\subsubsection{Potential Efficiency Gains Due to Improved Forecasts}

The information contained in this section is drawn from several studies which analyzed effects of accurate and detailed weather and hydrologic information on five weather/streamflow sensitive operations.

\section{Reduced Expenditures for Dams and other water Control structures}

Improved water management, due to advances in hydrologic technology and improved data collection and analysis techniques, is estimated to have the potential to increase the efficiency of all structural systems (e.g., dams and levees) in the range of 5 to 15 percent. In keeping with the conservative approach of this study, the lower limit of 5 percent will be used as the basis for calculations. Since a portion of the improvements in efficiency may be attributable to other sources, it is estimated that only $3 / 4$ of the 5 percent improvement is attributable to the modernization and restructuring of the NWS. The resultant gain in efficiency attributable to the NWS is therefore 3.75 percent. This figure will be used to estimate the reductions in expenditures for new construction and remodeling of currently in place control structures.

A 1984 study by the Hudlow, et al, NWS ${ }^{23}$ estimated a current value of $\$ 170$ billion for all existing control structures. Annual expenditures, based on 5 percent of the current value, were estimated to be $\$ 8.5$ billion. Although most control structures are expected to last 50 years or more, there are six factors which form the basis of the 5 percent of current value figure as an estimate of annual expenditures. These factors are: (1) the increased water demand resulting from increases in population; (2) the saturation of most favorable sites to build dams; (3) the increasing costs to acquire land and materials;

\footnotetext{
${ }^{23}$ M.D. Hudlow, R.F. Farnsworth and P.A. Ahnert, NEXRAD Technical Requirements for Precipitation Estimation and Accompanying Economic Benefits, Silver Spring, MD: National Weather Service, Hydro Technical Note-4, December 1984 .
} 
Table 5.9 Estimated Annual Savings Due to Improvements in Weather Forecasting Attributable to the Modernization and Restructuring of the NWS

\begin{tabular}{||c||c||}
\hline Year & $\begin{array}{c}\text { Estimated } \\
\text { Savings (\$M) }\end{array}$ \\
\hline 1992 & 0.0 \\
\hline 1991 & 31.9 \\
\hline 1992 & 147.6 \\
\hline 1993 & 486.6 \\
\hline 1994 & $1,029.1$ \\
\hline 1995 & $1,551.6$ \\
\hline 1996 & $1,950.5$ \\
\hline 1998 & $1,950.5$ \\
\hline 1998 & $2,010.3$ \\
\hline 1999 & $2,010.3$ \\
\hline 2001 & $2,010.3$ \\
\hline 2001 & $2,010.3$ \\
\hline 2002 & $2,010.3$ \\
\hline 2003 & $2,010.3$ \\
\hline 2004 & $2,010.3$ \\
\hline 2005 & $2,010.3$ \\
\hline
\end{tabular}


the increasing relocation costs associated with moving residents, businesses, railroads, etc., from the areas to be flooded; (5) increased demand for hydroelectric power; and (6) increased interest in water-related recreation.

Adjusting for changes in purchasing power since the publication of the study by Hudlow, et al, produces an estimated annual expenditure for all control structures of $\$ 11.2$ billion. Estimation of the reduction in expenditures for dams and other control structures is obtained by multiplying the estimated annual expenditures for control structures, $\$ 11.2$ billion, by the increased efficiency of the structures attributable to the NWS, 3.75 percent. The resultant figure is $\$ 403.2$ million.

Improved Water Yields for Hydroelectric Power and Irrigation

A 1981 study by castruccio, et al, ${ }^{24}$ provides the basis for estimating the benefits (resulting from improved forecasts) in the management of water for hydroelectric power generation and for agricultural irrigation. That study produced an estimate of annual benefits totaliing $\$ 36.5$ million for the 11 Western states. Three adjustments are required to extrapolate these benefits to the entire United states. First, it is necessary to adjust for changes in purchasing power since the study by Castruccio, et al, was published. This adjustment produces a figure of $\$ 51.1 \mathrm{million}$. Second, Castruccio, et al, based their estimate on a 6 percent improvement in forecasts for irrigation and hydropower. A more recent study by the office of Technology Assessment (OTA) of improvements in forecasts for irrigation and hydropower, produced an estimate of 10 percent. ${ }^{25}$ The calculations presented here use the OTA figures, assuming as before that $3 / 4$ of the 10 percent improvement are attributable to the NWS and that the adjustment is linear (i.e., 7.5/6). This adjustment produces a figure of $\$ 63.9 \mathrm{million}$. Third, the Castruccio, et al, estimate was based on figures from the 11 Western states. Irrigation, once almost exclusively limited to the Western states, is now used in much of the Midwest and south. Hydroelectric power generation is also receiving greater emphasis

\footnotetext{
${ }^{24} \mathrm{P}$. Castruccio, H. Louts, D. Lloyd and P. Newman, Cost/Benefit Analysis for the ASVT on operational Applications of Satellite Snow-Cover Observations, Greenbelt, MD: Goddard Space Flight Center, NASA Tech Paper 1828, 1981.

${ }^{25}$ Water-Related Technologies for Sustainable Agriculture in U.S. Arid/Semiarid Lands, Washington, D.C.: Office of Technology Assessment, OTA-F-212, 1983.
} 
in all parts of the country. Consequently, the overall water management improvement in the remainder of the country should equal or exceed that of the 11 Western States. Assuming benefits for the remainder of the country equal those of the 11 Western States, produces an estimate of $\$ 127.8$ million for the entire country.

\section{Effects of Increases in Agricultural Output on} Related Industries

Because any increases in agricultural output have a ripple effect throughout the economy, there will be additional demands placed on other sectors. The associated multiplier analysis translates an increase in output in the agriculture sector across all other sectors of the national economy. ${ }^{26}$ A review of output multipliers for each state,27 weighted by the state's agricultural output, ${ }^{28}$ produced a value of 2.27 .

The previous section does not include these multiplier effects. Beginning with the figure of $\$ 26.5$ million for irrigation in the 11 Western States from Castruccio, et $a l,{ }^{29}$ and following the logic of the previous section, produces an increase in agricultural output for the entire country of $\$ 92.8$ million. This amount is already included in the $\$ 127.8$ million estimate. However, the effects of this increase in agricultural output, 1.27 times $\$ 92.8$ million, or $\$ 117.9$ million, is not.

\section{Improvements in Navigation}

Improvements in forecast accuracy will benefit both commercial shipping and aviation. For commercial shipping, knowledge of the river stage along navigable rivers is essential for planning the loading of commodities onto barges and other cargo vessels and for the scheduling of traffic. Other shipping areas include ice

${ }^{26}$ The output multiplier for the agriculture sector measures the sum of direct and indirect requirements from all sectors needed to deliver an additional dollar of output from the agriculture sector to final demand. Output multipliers for other sectors of the national economy are defined in a similar manner.

${ }^{27}$ Regional Multipliers: User Handbook for the Regional Input-Output Modeling System, Second Edition, Washington, DC: Bureau of Economic Analysis, May 1992. 1155 .

${ }^{28}$ Statistical Abstract of the United States: 1991, Table

${ }^{29} \mathrm{P}$. Castruccio, et al, 1981, op cit. 
monitoring by satellite and potential fuel savings to fishing and cargo vessels resulting from satellite images and information on currents. For commercial aviation, improved upper air wind and temperature forecasts have the potential of providing fuel savings of 2 to 3 percent on long-distance flights.

No estimates of the potential increase in revenues for commercial shippers using inland harbors are available on a national scale. However, a detailed analysis was performed on the port of Portland, oregon by the NWS. ${ }^{30}$ Estimates for the port of Portland indicate that, on the average, a ship may earn an additional $\$ 20,000$ in revenue for each additional foot of draft available.

Average monthly flows for the Columbia River at the Dalles, Oregon, are at least 100,000 cubic feet per second throughout the year, with a flow volume of 500,000 cubic feet per second for at least one month of the year. While it is difficult to convert the river runoff to an increase in depth at every critical point in the estuary, increases as high as 5 feet are expected. Improved forecasts would allow shippers to take advantage of increased depths when they occur. Based on such data, the Nws developed a distribution showing the percentage of time that discharges are above a given level and the incremental increase in revenue associated with that level. A detailed analysis for grain ships leaving portland each year resulted in a figure of $\$ 21.3$ million. When auto carriers, tankers and other cargo vessels were included, a figure of $\$ 60$ million resulted.

Adjusting for changes in purchasing power since the publication of the 1986 NWS study, produces an estimated annual benefit of $\$ 69.3$ million. It is important to note that this figure is for the port of Portland only. ${ }^{31}$ Benefits to the entire United states are expected to be significantly higher. However, until additional studies are performed, there is no basis for extrapolating the Portland experience to the rest of the country.

Shipping operations in the Arctic, Great Lakes and st. Lawrence Seaway are greatly affected by sea, lake and river ice. The NESDIS operational satellites provide support during the ice season to the U.S. Coast Guard International Ice Patrol. The satellite ice analyses are also extremely valuable to ice reconnaissance aircraft as an aid in preflight planning and in locating areas of improved visibility. This has resulted in

\footnotetext{
${ }^{30}$ Program Development Plan for Improving Water Resources Forecasting Services, Silver Spring, MD: National Weather Service, May 1986.

${ }^{31}$ Although increases in revenue for commercial shipping using the port of Portland have positive impacts on other sectors of the local, regional, and national economies, no analysis of these impacts is presented in this section.
} 
increased efficiency in the visual reconnaissance missions, producing a savings of about 1,500 aircraft flight hours and related cost reductions of about $\$ 5$ million annually. ${ }^{32}$ In the Great Lakes, satellite imagery can be used to find navigable waters for shipping as long as possible into the winter season. High-resolution satellite images can be used to show small icefree areas that can be used by ships to continue operations longer than previously possible. It is estimated that the extension of the shipping season by this method results in a savings of $\$ 1 \mathrm{million}$ for each day extended. Consequently, satelites could contribute $\$ 30 \mathrm{million}$ in annual benefits. Adjusting for changes in purchasing power since the publication of Hussey's 1985 study, produces an annual benefit of $\$ 41.3$ million from satellite-based ice monitoring.

Use of the swift Gulf stream currents to increase a ship's northbound speed is an old idea, but utilizing that idea has proved difficult. The swiftness and great variability of the Gulf stream position creates many uncertainties and hazards to navigation. Hussey's study concluded that the use of satellitederived Gulf stream position data would produce an annual savings of $\$ 945,000$ for 15 tankers navigating the Gulf stream effectively. The same study reported savings of 10 percent on the fuel bill for each of 1,000 fishing vessels in operation off the West Coast. The annual savings for the fleet was $\$ 440,000$. Adjusting for changes in purchasing power, produces a combined fuel savings of $\$ 1.6$ million.

The above referenced study by Hussey also analyzed airline fuel savings. The study concluded that an international carrier with a present fuel bill of $\$ 1$ billion could expect to save at least $\$ 20$ million annually on trip fuel alone. When one considers the potential for optimizing reserve fuel requirements, the savings could be considerably higher. Adjusting for changes in purchasing power, produces an annual airline fuel savings of $\$ 23.7$ million.

Combining all four components ((1) $\$ 69.3$ million in benefits to the port of Portland; (2) $\$ 41.3$ million in benefits from satellite-based ice monitoring; (3) $\$ 1.6 \mathrm{million}$ in fuel savings on fishing and cargo vessels; and (4) $\$ 23.7$ million in fuel savings of for commercial aircraft), produces a total annual benefit for improved navigation of $\$ 135.9$ million.

\section{Increased Water Availability}

Improvements in forecast accuracy coupled with new modeling techniques will improve not only the efficiency with which the nation's water resources are used but should also increase the

\footnotetext{
${ }^{32}$ W.J. Hussey, 1985, op cit.
} 
volume of water resources available for use. For purposes of the current analysis, a 1 percent increase for consumptive uses and a 2 percent increase for nonconsumptive uses is assumed. A study by the office of Technology Assessment (OTA) estimated a range of water costs by use. ${ }^{33}$ Using the mid-range estimate from the OTA study and estimates of national water use, produces a value of \$43.2 million for consumptive domestic uses. The estimate for industrial uses is based on 10 percent of the maximum value, since the minimum value is $\$ 0.00$ per acre foot. This conservative estimate produces a value for consumptive industrial uses of $\$ 34.5$ million. The total annual benefit for these two consumptive uses comes to $\$ 77.7$ million. Finally, using the midrange estimates for all nonconsumptive uses (e.g., recreation, fish habitat, hydropower generation), results in a value of $\$ 6.9$ million. This yields an estimated annual benefit due to increased water availability of $\$ 84.6$ million. ${ }^{34}$

Total annual benefits across all five weather-sensitive operations come to $\$ 869.4$. It is important to point out that these potential gains in efficiency would only result once the modernization and restructuring of the Nws is complete. In order to best determine how much of the total annual benefits due to potential gains in efficiency could be attributed to the Nws, the same rationale used in the previous section was adopted. ${ }^{35}$ The estimates are given in Table 5.10 .

\subsubsection{Summary of Recurring Benefits for the Proposed system}

The recurring benefits associated with the Proposed system are summarized in Table 5.11, which lists the estimated annual benefits for each of the benefit categories. Note that total benefits increase steadily throughout the study period. The principal source of the increase is anticipated improvements in the reliability of the NW' forecasts.

${ }^{33}$ Office of Technology Assessment, 1983, op cit.

${ }^{34}$ Although a portion of these benefits will result in increased outputs which will have positive impacts on other sectors of the economy, no analysis of these impacts is presented in this section.

${ }^{35}$ The calculations assume that the degree of completion of the modernization and restructuring of the NWs will be: approximately 2\% in 1991; 7\% in 1992; 24\% in 1993; 51\% in 1994; $77 \%$ in 1995; $90 \%$ in 1996; $97 \%$ in 1997; and $100 \%$ in 1998 and beyond. 
Table 5.10 Estimated Annual Efficiency Gains Due to Improvements in Weather Forecasting Attributable to the Modernization and Restructuring of the NWS

\begin{tabular}{|c|c|}
\hline Year & $\begin{array}{c}\text { Estimated } \\
\text { Savings (\$M) }\end{array}$ \\
\hline 1990 & 0.0 \\
\hline 1991 & 17.4 \\
\hline 1992 & 60.9 \\
\hline 1993 & 208.7 \\
\hline 1994 & 443.4 \\
\hline 1995 & 869.4 \\
\hline 1996 & 782.5 \\
\hline 1997 & 843.3 \\
\hline 1998 & 869.4 \\
\hline 1999 & 869.4 \\
\hline 2000 & 869.4 \\
\hline 2001 & 869.4 \\
\hline 2002 & 869.4 \\
\hline 2003 & 869.4 \\
\hline 2004 & 869.4 \\
\hline 2005 & 869.4 \\
\hline
\end{tabular}




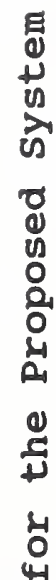

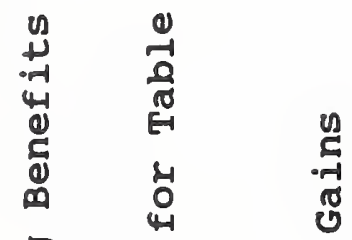

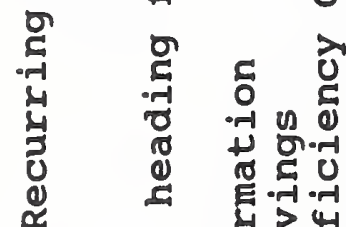

4

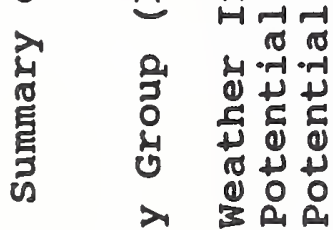

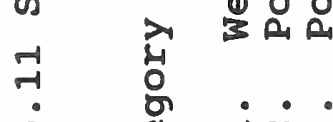

(1)

\begin{tabular}{|c|c|c|c|c|c|}
\hline & $\begin{array}{l}r \\
\sigma \\
\sigma \\
\sigma\end{array}$ & $\begin{array}{l}a \\
\dot{0} \\
\infty \\
\sim \\
+\end{array}$ & $\begin{array}{l}n \\
0 \\
10 \\
0 \\
-1\end{array}$ & $\begin{array}{l}m \\
\dot{\infty} \\
\dot{\infty}\end{array}$ & $\begin{array}{l}n \\
0 \\
0 \\
n\end{array}$ \\
\hline & $\begin{array}{l}0 \\
\sigma \\
\sigma \\
\text { ब }\end{array}$ & 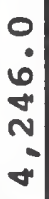 & $\begin{array}{l}a \\
\dot{N} \\
0 \\
\infty \\
-1\end{array}$ & $\begin{array}{l}\text { ? } \\
\stackrel{+}{N} \\
\infty \\
\sim\end{array}$ & $\begin{array}{l}+ \\
\dot{-1} \\
m \\
\infty \\
0\end{array}$ \\
\hline & $\begin{array}{l}n \\
\sigma \\
\sigma \\
\text { a }\end{array}$ & $\begin{array}{l}\sim \\
\therefore \\
0 \\
\sim \\
\sim\end{array}$ & $\begin{array}{l}0 \\
-1 \\
10 \\
0 \\
-1\end{array}$ & $\begin{array}{l}0 \\
0 \\
0 \\
0\end{array}$ & $\begin{array}{c}N \\
\infty \\
N \\
\sim \\
0\end{array}$ \\
\hline 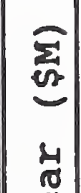 & $\begin{array}{l}\text { a } \\
\text { a }\end{array}$ & $\begin{array}{l}n \\
0 \\
0 \\
+1 \\
\infty\end{array}$ & $\begin{array}{l}-1 \\
0 \\
0 \\
0 \\
-1\end{array}$ & $\underset{+}{\infty}$ & $\begin{array}{l}0 \\
\dot{m} \\
\dot{0} \\
0 \\
i n\end{array}$ \\
\hline 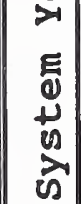 & 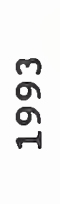 & $\begin{array}{l}m \\
\dot{0} \\
\dot{+} \\
\dot{+} \\
\dot{\sigma}\end{array}$ & $\begin{array}{l}0 \\
\dot{0} \\
\infty \\
+\end{array}$ & $\begin{array}{l}\sim \\
\infty \\
0 \\
N\end{array}$ & $\begin{array}{l}0 \\
\dot{1} \\
m \\
\infty \\
\dot{\infty}\end{array}$ \\
\hline & 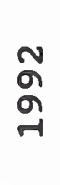 & $\begin{array}{l}0 \\
\infty \\
0 \\
\dot{-1} \\
\dot{\sigma}\end{array}$ & $\begin{array}{l}0 \\
\sim \\
+ \\
+\end{array}$ & $\begin{array}{l}\text { 0 } \\
0 \\
0\end{array}$ & $\begin{array}{c}+ \\
\dot{n} \\
\dot{m} \\
+\end{array}$ \\
\hline & $\begin{array}{l}{ }^{-1} \\
\sigma \\
\sigma \\
\sigma\end{array}$ & $\begin{array}{l}m \\
0 \\
0\end{array}$ & $\begin{array}{l}a \\
\dot{m}\end{array}$ & $\stackrel{+}{*}$ & $\begin{array}{l}0 \\
\dot{0} \\
N \\
-1 \\
+\end{array}$ \\
\hline & $\begin{array}{l}0 \\
\sigma \\
\sigma \\
\sigma\end{array}$ & $\begin{array}{l}n \\
\dot{0} \\
\dot{0}\end{array}$ & : & $\begin{array}{l}0 \\
0\end{array}$ & $\begin{array}{l}n \\
\dot{0} \\
\dot{0} \\
\dot{0}\end{array}$ \\
\hline & $\begin{array}{l}\text { y } \\
0 \\
0 \\
0 \\
+ \\
0 \\
0 \\
0\end{array}$ & - & $N$ & $m$ & $\begin{array}{l}1 \\
\mathbb{C} \\
\text { E-1 }\end{array}$ \\
\hline
\end{tabular}

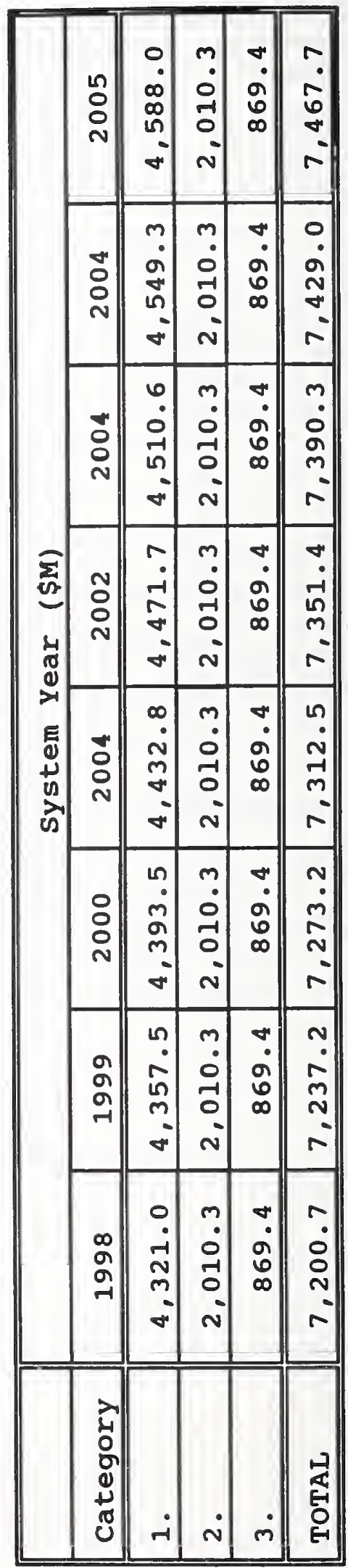




\subsubsection{Reductions in weather-Related Fatalities}

Americans encounter both a great variety and a high incidence of severe weather and flooding. In a typical year, the United States experiences some 10,000 severe thunderstorms, 4,000 floods, and 1,000 tornadoes, affecting virtually every state. An average of ten hurricanes can be expected along U.S. shores or nearby waters per year. In 1985, 6 hurricanes and 2 tropical storms made landfall along the Gulf and East Coast. In 1986, a severe drought throughout the Southeastern United states was the worst on record. These dangerous weather events translate into considerable human suffering and property loss. In terms of responsibilities of the Federal Government, more than $85 \%$ of presidentially declared natural disasters are weather or flood related.

On the average, approximately 1,000 persons die as a direct result of weather hazards (i.e., blizzards, cold waves, heat waves, lightning, floods, tornadoes, and hurricanes) each year. In addition, more than 8,000 persons lose their lives each year due to traffic accidents in bad weather. Although any definitive estimate is elusive, more reliable forecasts of severe weather conditions will undoubtedly reduce weather-related fatalities.

The vulnerability of the United states to weather and flood dangers continues to grow steadily due to demographic, economic, social, and technological trends. In the past 20 years, the U.S. population in the Atlantic and Gulf coastal areas increased dramatically. In Florida alone, the coastal population has doubled. Nearly 60 million people now live in hurricane-prone coastal areas and are exposed to the devastating wind and storm surge of hurricanes.

The current average annual flood-related death toll is nearly 200, and the continuing industrialization and population growth of river valleys are increasing the economic cost and death toll of flood-related disasters. Another important trend involves the explosive growth of outdoor recreation in this country and the increasing risk of death or injury in such activities as a result of weather and flood hazards.

Aviation safety will remain a major public concern as reliance on air travel continues to rise. It is estimated that domestic aviation alone will transport the equivalent of every man, woman and child in North America each year in the 1990s. Weather services have always been vital to aviation safety. In 1985, 40\% of aviation accidents were weather-related. 


\subsubsection{Basic and Applied Research}

A wide range of research programs are in place, within the NOAA organization and in cooperation with academic communities and other agencies of the federal government, that provide for the transfer of scientific and technological knowledge to the Nws modernization program. These research programs cover a spectrum of activities that include, on one end of the scale, fundamental research in the atmospheric and hydrologic sciences, and on the other end of the scale, the development of specific products and techniques for direct use at NWS field offices in support of the warnings and forecast programs. Research programs are also playing important roles in developing techniques for assimilating data from the diverse observational systems that are coming into operational use, both on a national scale as input to numerical weather prediction and on the local level for short-term mesoscale forecasting at NWS field offices. The bulk of the NOAA research program that supports the NWS modernization is concentrated within three components of the organization -- the Environmental Research Laboratory (ERL), the National Weather Service (NWS) and the National Environmental Satellite, Data and Information Service (NESDIS). Focusing first on the NWS, we shall review the potential benefit from research programs at the Hydrologic Research Laboratory, the Techniques Development Laboratory, and the National Centers.

The Hydrologic Research Laboratory serves as the nucleus for applied hydrologic research and development activities. A significant amount of these activities are underway to capitalize on the new data collection and analysis technologies of the modernized era. Significantly more emphasis will be placed on hydrometeorology, a hybrid science interrelating hydrology and meteorology. NEXRAD, ASOS, and other automated sensors will greatly increase the volume of available hydrometeorological data, and AWIPS will provide enhanced computational power for hydrologic modeling and data management. Through the PROTEUS project, which is in direct support of the NWS modernization, considerable efforts are underway to reduce the risk associated with implementation of these new technologies under the PROTEUS project. The critical components of PROTEUS include data handling and quality control procedures, NEXRAD precipitation processing algorithms, and an on-site interactive version of the NWS River Forecast System (NWSRFS) . Other NWSRFS enhancements include improved snow melt and rainfall-runoff models and river mechanics procedures.

While considerable efforts are underway to develop an initial operating capability for hydrometeorological operations, efforts will continue in the 1990s to capitalize on the new technologies. The critical importance of water highlights the need for water resources forecasting services to improve management of this resource. The next generation of extended streamflow prediction 
models will be developed and implemented. New emphasis will be placed on simulating the transfer of soil moisture to the atmosphere for use in both short-range numerical weather prediction models and long-range global climate models, and on predicting the impacts of global climate change on water resources. At the other end of the time scale, the new Nws emphasis on improved forecasts and warnings for mesoscale events highlights the need to develop and implement hydrologic forecasting tools for smaller watersheds such as flash flood prone basins and urban areas. Significant efforts will be undertaken to implement technologies such as geographical information systems and distributed hydrologic models.

The Techniques Development Laboratory (TDL) of the NWS office of Systems Development conducts applied research aimed at developing techniques that have promise in application to weather forecasting and analysis. TDL develops techniques for objectively forecasting basic weather elements used in public and aviation forecasts, such as clouds, temperature, and visibility. Also emphasis is given to marine-related forecasts, to those forecasts associated with mesoscale processes, and to techniques targeted for implementation at AWIPS-equipped NWS field offices. The supporting research at TDL covers areas of national/regional scale weather prediction, mesoscale weather prediction, marine environmental prediction, and local field office forecast applications. The synoptic analyses are directed towards procedures to be run on centralized computer systems in contrast to mesoscale weather techniques and local applications designed for use at the modernized NWS field offices. Local applications include interactive techniques to support a digital database, product formatters to prepare specific products from the digital database, and verification techniques. Mesoscale weather prediction efforts include techniques for the prediction of short-lived thunderstorms, severe local storms, and heavy precipitation forecasting. Short-term forecasting techniques involve the application of sensor-produced data, such as from NEXRAD, the GOES sateliites, and the experimental profiler system, to develop thunderstorm forecasting procedures and specialized radar algorithms.

The marine prediction activities support NWS field offices, the NHC, and local emergency management officials during the hurricane season. A numerical model was developed by TDL that produces forecasts for oceanic flooding over coastal areas during hurricane landfall situations. This storm surge model has been implemented operationally at NHC and provides critical guidance on expected flooding in advance of the hurricane. The program has also been used extensively as a tool for hurricane evacuation planning through the use of a series of computer simulations of hypothetical hurricanes that delineate areas of potential flooding. 
We turn now to a consideration of the benefits to meteorological research associated with the enhanced computing capabilities of the National Centers. Those benefits that can be quantified readily have been enumerated in the previous sections; the more fundamental ones are intimately bound up with the nature of meteorological research. Contributions to scientific and engineering knowledge influence, and are influenced by, work at many institutions in the United states and abroad. In the aggregate, this work constitutes the intellectual capital on which the meteorological community draws for new technologies, innovations that improve the quality of meteorological services, and developments to meet major problems in the future. The total value of such research, the share that can be allocated fairly to any institution, and the fraction that can be attributed to information systems are all difficult to assess. Here, we will suggest through a few examples that the total benefits to society of meteorological research are very high, and indicate areas in which NOAA staff make contributions. Information systems are central to much of the work in these areas, but there is no realistic way to assign monetary values.

The ability to gather data on atmospheric and oceanographic conditions, and the ability to model phenomena in these areas have both improved dramatically in the last 20 years. To the average person, an obvious application is improved weather prediction. Certainly predicting weather is important, and it is apparent that economic implications are great. But society has an interest in oceanography and atmospheric research that is broader than such predictions. Air quality, toxic substances in bodies of water, rare but severe storms, oceans and lakes as an economic resource - these and other topics are important to the typical citizen. Solutions to existing or future problems in these areas depend on improved understanding.

The NOAA Environmental Research Laboratory (ERL) conducts research in all of these areas, and while the importance of increased knowledge is apparent, the monetary value of specific new knowledge is not. One phenomenon that has a huge economic impact is the El Nino effect. Both the Climate Research Program of the Air Resources Laboratory in Boulder and the Pacific Marine Environmental Laboratory in Seattle are engaged in investigations of this. At the latter, a major modeling effort uses a supercomputer to address, for example, "hindcast" modeling of the El Nino effect. Such a "hindcast" generates -- despite extensive efforts to compress -- massive amounts of data. This type of problem would benefit greatly from enhanced supercomputing capability, but the monetary value to be assigned to improved modeling is elusive.

The ozone layer is another subject that has received a lot of attention recently. A research project in the Aeronomy Laboratory in Boulder is concerned with modeling the 
stratospheric and tropospheric ozone. The Aeronomy Laboratory is also engaged in studies of acid deposition. Both of these projects involve large 3-D models running on a supercomputer.

The quality of water in lakes (and other bodies of water) is a matter of widespread concern with major cost implications. A project at the Great Lakes Environmental Research Laboratory in Ann Arbor attempts to mathematically model toxic organic contaminants in a real lake. This is a complex model that requires a supercomputer; it results in information about the movement of contaminants and concentrations of dissolved solids throughout the lake as a function of time.

The Space Environment Lab in Boulder has an effort underway that links a $3-D$, time-dependent model of the thermosphere with initial conditions on solar heat input (from the sun) given by the TIROS/NOAA satellite. This model describes the response of the neutral atmosphere at $100 \mathrm{~km}$ to variations in solar heat input and will enhance understanding of the impact of this response on global weather.

NESDIS research programs are carried out by its office of Research and Application. Programs are directed toward the improvement of meteorological prediction capabilities to support the modernization of the NWS. The focus of this activity is directed towards providing information derived from satellite sensors to support all levels of NWS analysis and prediction models. These satellite applications span the spectrum of NWS observational and forecast needs ranging from the lower levels of the atmospheric boundary layer to the tracking and monitoring of synoptic and mesoscale systems for estimating precipitation rates. Numerical weather prediction efforts at NESDIS have concentrated on developing enhanced moisture products, wind fields, and three dimensional vertical soundings of temperature and moisture. Work is underway to develop surface vegetation, temperature, and snow cover products from satellite sensors for use in the initialization of boundary conditions for the models. Data from various satellites are being processed and evaluated as potential new "blended" products for the future. Warming and cooling effects resulting from volcanic eruptions and airborne sand can be tracked and adjustments/corrections can be made to the sea surface temperature products which are key to numerical model initialization. A satellite cloud observation algorithm to supplement ASOS is also being developed.

NESDIS support to the NWS warning and forecast program includes research and development work on rapidly deepening storms, tropical storms, clear air turbulence, wind downbursts and microbursts, and quantitative precipitation estimates in support of flash flood warnings. Scientists recently completed an extensive publication on the use of water vapor imagery. This publication and others are part of an intensive training program 
that ranges from visits to NWS forecast offices to workshops and the development of training modules in the cooperative Program for Operational Meteorology and Education and Training.

New multichannel products are under development in preparation for the data stream from the GOES I-M satellites. Increased emphasis is being placed on quantitative products that can be used to assist forecast operations both at National Centers and the local forecast office.

These few examples from a wide range of research activities suggest the importance and relevance of this work to outstanding problems, and give some indication of the crucial role of information resources management in this research. 
This chapter presents the results of the "baseline" benefit-cost analysis for each of two alternative NWS configurations. ${ }^{36}$ The first configuration represents a continuation of the status quo; it is referred to as the current system. The second represents a full deployment of the proposed modernization and restructuring of the NWS; it is referred to as the Proposed System. All information is presented in a format which is consistent with FIPS POB-64. The presentation is in tabular form and includes both annual and life-cycle figures. Among the life-cycle figures included are:

(1) Net Present Value: the difference between the present value of total benefits and the present value of total costs;

(2) Benefit-cost Ratio: the ratio of the present value of total benefits and the present value of total costs; and
Payback Period: the time in years it takes the sum of the present value of benefits to exceed the present value of total costs.

The results of the baseline benefit-cost analysis are presented in a three-part tabular form. Each part - A through $C$-- is presented on a separate page. This method of presentation serves to focus attention on selected "key" measures resulting from the baseline analysis.

Part A of each table summarizes the costs of each alternative. Both non-recurring, recurring, and satellite costs are presented for each year of the study period. Total cost is also given. It is important to note that these costs are undiscounted (i.e., they do not adjust for the time-value of money). Consequently, it is necessary to calculate several summary measures in order to compare undiscounted and discounted costs. The first measure calculated is system Life costs. This measure is the sum total of all undiscounted costs over the study period. The second measure is Present Value costs. This measure incorporates the time value of money (i.e., all future costs are discounted at $10 \%$ per annum). The third measure is the Residual value of the "system" (i.e., its value at the end of the study period). In keeping with the conservative approach of this study, Residual

\footnotetext{
${ }^{36}$ The word baseline is placed within quotes to highlight the fact that all data entering into the calculations for both benefits and costs are at their most-likely values. These basecase data represent a fixed state (or deterministic level) of analysis. For this reason, the results are referred to as the baseline analysis. Cases where data can vary about their mostlikely values are the subject of Chapter 7.
} 
Value is assumed to be zero. The final measure is Adjusted cost, the difference between the Present Value costs and the present discounted value of the Residual Value.

Part B of each table summarizes the benefits of each alternative. Both non-recurring and recurring benefits are presented for each year of the study period. Total benefits are also given. As in Part $A$, all benefits are undiscounted. Consequently, it is necessary to calculate two summary measures: (1) system Life Benefits; and (2) Present Value Benefits. The first measure summarizes undiscounted benefits over the study period. The second measure incorporates the time-value of money (i.e., all future benefits are discounted at $10 \%$ per annum).

Part $C$ presents the baseline values for the key life-cycle figures defined at the beginning of the chapter. These lifecycle figures are: (1) Net Present Value; (2) Benefit-cost Ratio; and (3) Payback Period. These baseline values are the direct result of figures presented in Parts $A$ and $B$, respectively. It is important to note that the payback measure used in this study is more stringent than the traditional measure, which would result in an almost immediate payback because system benefits greatly exceed system costs in the first year. Such an approach ignores the "lumpiness" of costs, a serious weakness of the traditional method of calculating payback. The measure used in this study is the length of time it takes system benefits to exceed the present value of all system costs (i.e., Adjusted cost).

\subsection{CURRENT SYSTEM}

Table 6.1, Parts A through C, present the results of the baseline analysis of the current system. Part $A$ shows that only recurring and satelite costs are incurred. However, these costs rise steadily over the study period. The sum total of these costs, system Iife costs, is $\$ 10,157.8 \mathrm{million}$. The present discounted value of these annual totals, Present Value costs, is $\$ 5,787.3$ million. No Residual value is assigned. Consequently, the Adjusted Cost is also $\$ 5,787.3$ million. Part $B$ shows that recurring benefits decline steadily over the study period; there are no non-recurring benefits. The sum total of these benefits, System Life Benefits, is $\$ 48,577.6 \mathrm{million}$. The present discounted value of these annual totals, Present Value Benefits, is $\$ 28,203.5$ million. Part $C$ reveals the values of the three key life-cycle figures. Although the current system is largely obsolete, it still produces favorable values for the three key life-cycle figures. For example, the Net Present Value of the Current system is $\$ 24,416.2 \mathrm{million}$. The Benefit-cost Ratio is 4.873 and the system achieves payback in 1.5 years. 


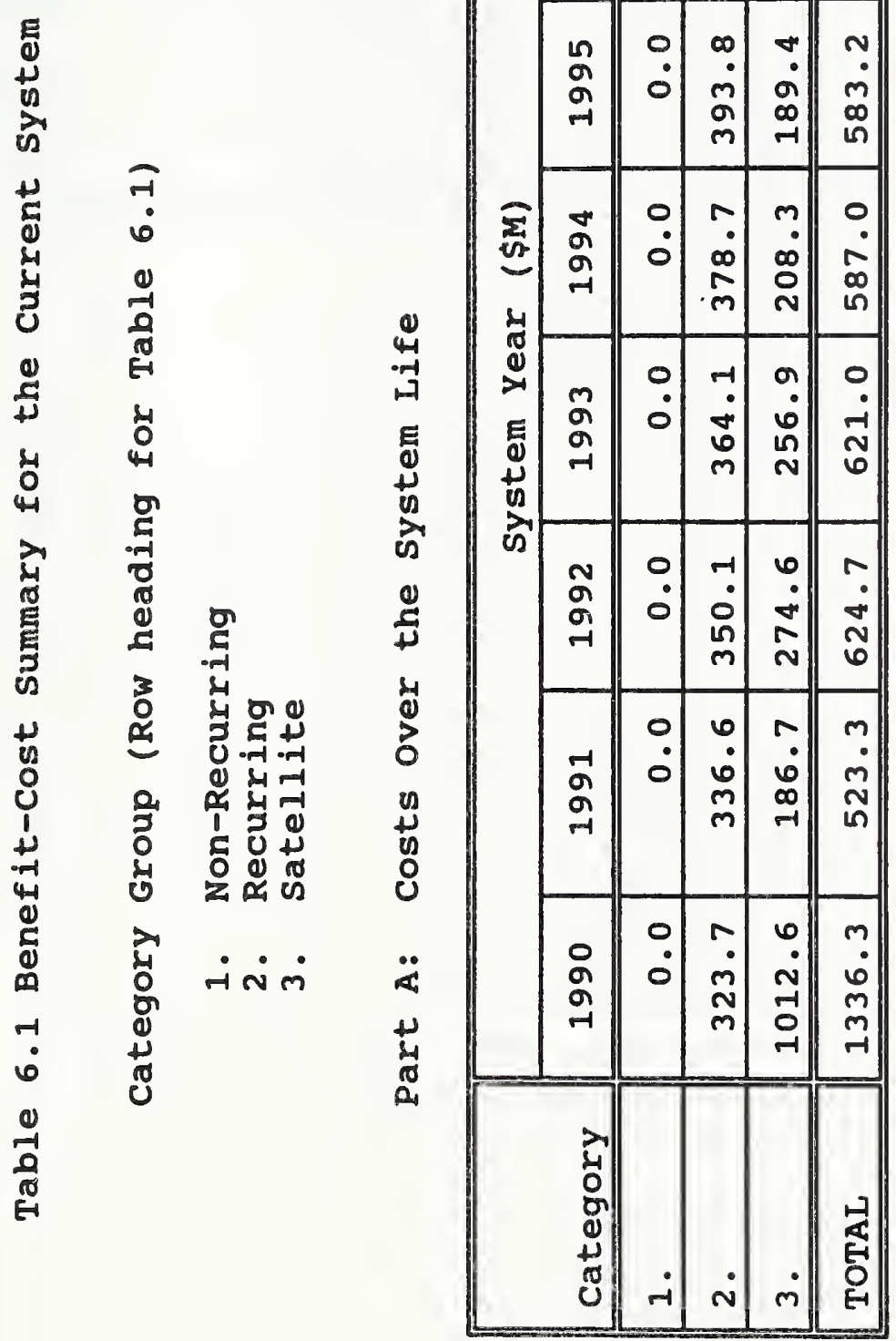

\begin{tabular}{|c|c|c|c|c|c|}
\hline \multirow{8}{*}{ 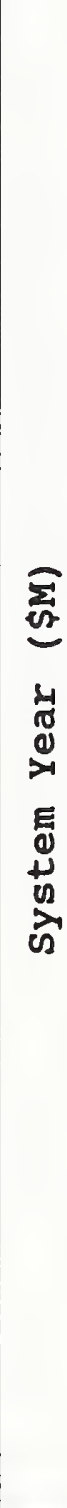 } & $\begin{array}{l}\text { Ln } \\
\text { } \\
\stackrel{\circ}{N}\end{array}$ & $\begin{array}{l}0 \\
\dot{0}\end{array}$ & $\begin{array}{l}0 \\
\dot{0} \\
\infty \\
0 \\
\end{array}$ & $\begin{array}{l}\sim \\
\dot{\infty} \\
\infty\end{array}$ & $\begin{array}{c}v \\
-1 \\
\tilde{b}\end{array}$ \\
\hline & $\begin{array}{l}\text { ガ } \\
\text { ㅇ } \\
\text { N }\end{array}$ & $\begin{array}{l}0 \\
\dot{0}\end{array}$ & $\begin{array}{l}\text { ம } \\
\dot{0} \\
\bullet \\
\llcorner\end{array}$ & $\begin{array}{l}\sim \\
\dot{\infty} \\
\ddot{\sigma}\end{array}$ & $\begin{array}{l}r \\
\dot{0} \\
0 \\
0\end{array}$ \\
\hline & $\begin{array}{l}\text { m } \\
\text { ○ } \\
\text { N }\end{array}$ & $\begin{array}{l}0 \\
\dot{0}\end{array}$ & $\begin{array}{l}0 \\
\dot{0} \\
\tilde{n} \\
\text { மn }\end{array}$ & $\begin{array}{l}\sim \\
\dot{\infty} \\
\infty\end{array}$ & $\begin{array}{l}\sim \\
\sim \\
\infty \\
1\end{array}$ \\
\hline & $\begin{array}{l}\text { Ñ } \\
\text { ○ } \\
\text { N }\end{array}$ & $\begin{array}{l}0 \\
0\end{array}$ & $\begin{array}{c}m \\
0 \\
\infty \\
-1 \\
n\end{array}$ & $\begin{array}{l}N \\
\dot{\infty} \\
\dot{\sigma}\end{array}$ & $\begin{array}{l}n \\
\dot{b} \\
0 \\
n\end{array}$ \\
\hline & $\begin{array}{l}\text {-1 } \\
\text { O } \\
\text { N }\end{array}$ & $\begin{array}{l}0 \\
\dot{0}\end{array}$ & $\begin{array}{l}m \\
\dot{\infty} \\
\sigma \\
\sigma\end{array}$ & $\begin{array}{r}\hat{n} \\
\hat{n}\end{array}$ & $\begin{array}{l}0 \\
\dot{0} \\
\text { டி } \\
\text { ก) }\end{array}$ \\
\hline & $\begin{array}{l}\stackrel{ }{\circ} \\
\text { ○ } \\
\text { N }\end{array}$ & $\begin{array}{l}0 \\
0\end{array}$ & $\begin{array}{l}N \\
\dot{\sigma} \\
\sim\end{array}$ & $\begin{array}{l}0 \\
\dot{0} \\
\stackrel{-}{-1}\end{array}$ & 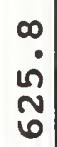 \\
\hline & $\begin{array}{l}9 \\
\sigma \\
\text { o } \\
-1\end{array}$ & $\begin{array}{l}0 \\
0\end{array}$ & $\begin{array}{l}r \\
\dot{0} \\
0 \\
\forall\end{array}$ & $\begin{array}{l}\sim \\
\dot{\infty} \\
\dot{\Gamma}\end{array}$ & $\begin{array}{l}9 \\
0 \\
0 \\
0 \\
0\end{array}$ \\
\hline & $\begin{array}{l}\infty \\
\sigma \\
\sigma \\
-1\end{array}$ & $\begin{array}{l}0 \\
0\end{array}$ & $\begin{array}{l}0 \\
\dot{m} \\
\dot{\sigma}\end{array}$ & $\begin{array}{l}\sim \\
-1 \\
\text { in } \\
\text { - }\end{array}$ & $\begin{array}{l}N \\
\dot{\sigma} \\
\sigma \\
\text { గn }\end{array}$ \\
\hline & 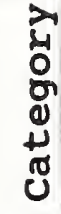 & -1 & $\boldsymbol{N}$ & $m$ & $\begin{array}{l}\text { 是 } \\
\text { E } \\
\text { O }\end{array}$ \\
\hline
\end{tabular}


Table 6.1 Benefit-Cost summary for the current system (continued)

Part A: Costs over the System Life (continued)

\begin{tabular}{|l|c|}
\hline \multicolumn{1}{|c|}{ Summary Measures } & Cost (\$M) \\
\hline System Life Costs & $10,157.8$ \\
\hline Present Value Costs & $5,787.3$ \\
\hline Residual Value & 0.0 \\
\hline Adjusted Cost & $5,787.3$ \\
\hline
\end{tabular}




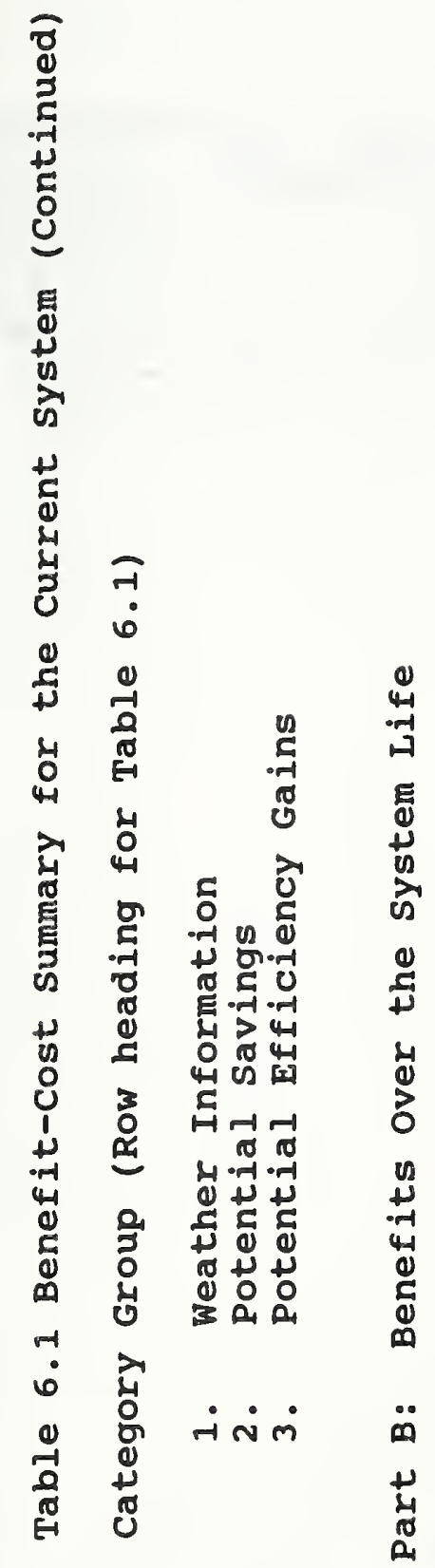
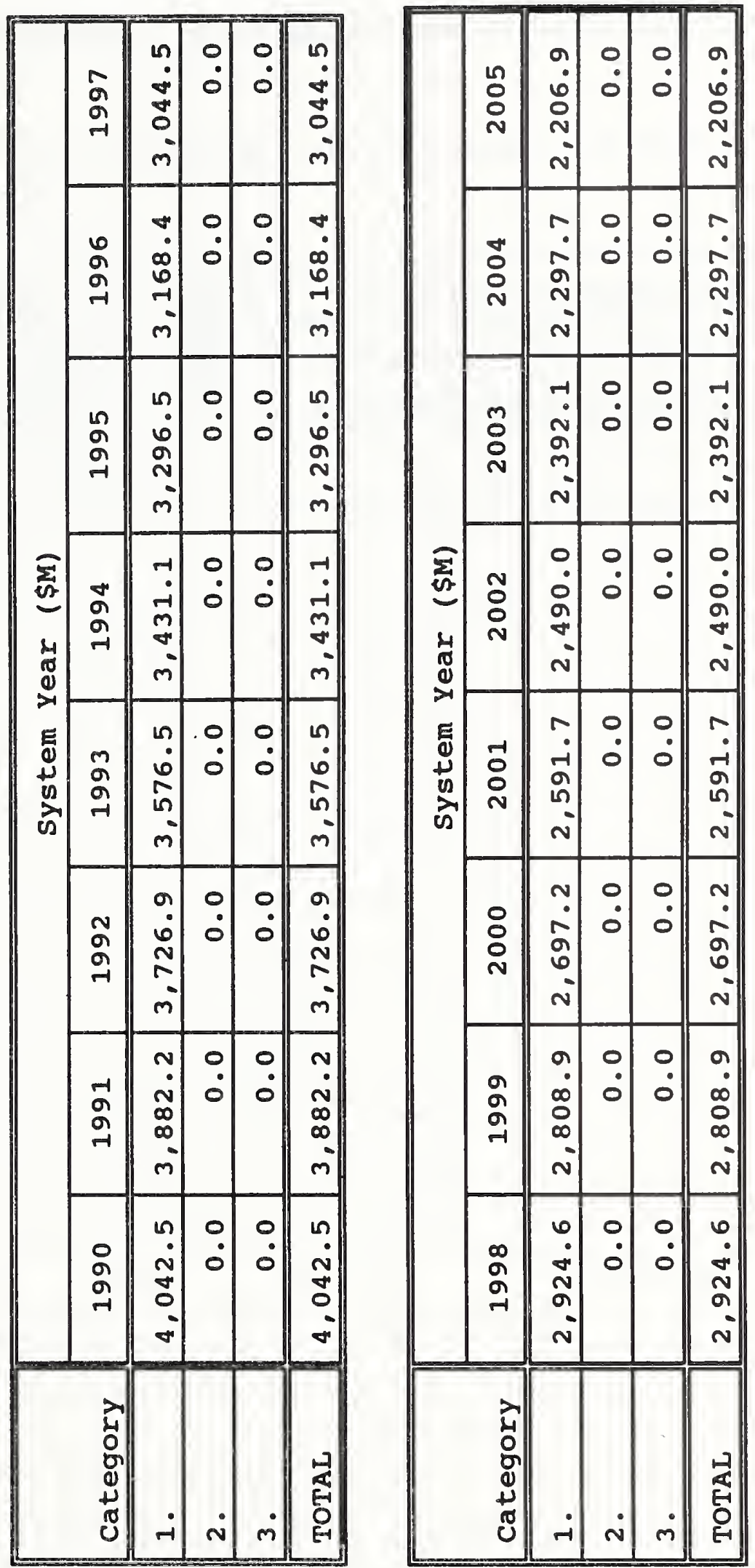
Table 6.1 Benefit-Cost Summary for the Current System (Continued)

Part B: Benefits over the system Life (continued)

\begin{tabular}{||c||c|}
\hline Summary Measures & Benefits (\$M) \\
\hline System Life Benefits & $48,577.6$ \\
\hline Present Value Benefits & $28,203.5$ \\
\hline
\end{tabular}


Table 6.1 Benefit-Cost Summary for the Current system (Continued)

\section{Part c: Summary}

\begin{tabular}{||c|c|}
\hline Measure & Value \\
\hline Net Present Value (\$M) & $22,416.2$ \\
\hline Benefit-Cost Ratio & 4.873 \\
\hline Payback Period (Years) & 1.5 \\
\hline
\end{tabular}




\subsection{PROPOSED SYSTEM}

Table 6.2 , Parts $A$ through $C$, present the results of the baseline analysis for the Proposed System. Part A shows that nonrecurring costs vary as the NW' new technologies are installed and the MARD is implemented. Non-recurring costs fall to zero once the new technologies have been installed and the MARD has been completed. Recurring costs remain fairly constant throughout the study period. The sum total of non-recurring, recurring, and satellite costs, system Life costs, is $\$ 9,862.1$ million. The present discounted value of these annual totals, Present Value Costs, is $\$ 6,361.3$ million. No Residual Value is assigned. Consequently, the Adjusted Cost is also $\$ 6,361.3$ million. Part $B$ shows that recurring benefits increase steadily over the study period; there are no non-recurring benefits. The sum total of these benefits, system Life Benefits, is $\$ 101,963.2$ million. The present discounted value of these annual totals, Present Value Benefits, is $\$ 50,350.5$ million. Part $C$ reveals the values of the three key life-cycle figures. The Proposed system greatly exceeds the performance characteristics of the current System. Net Present Value is $\$ 43,989.2$ million, a gain of more than $\$ 20$ billion. The Benefit-cost Ratio has risen from 4.873 to 7.915; payback is achieved in 1.6 years. 


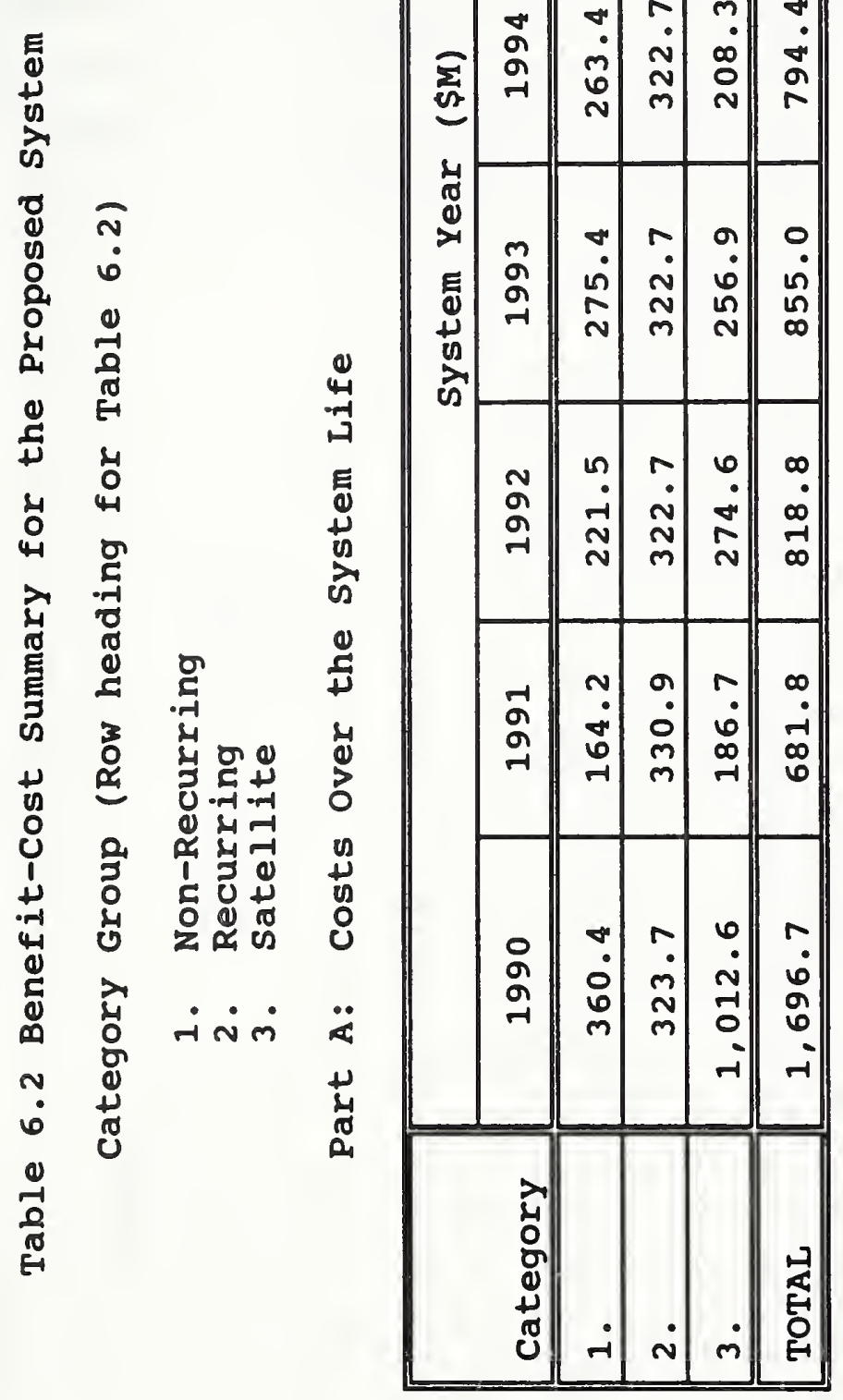

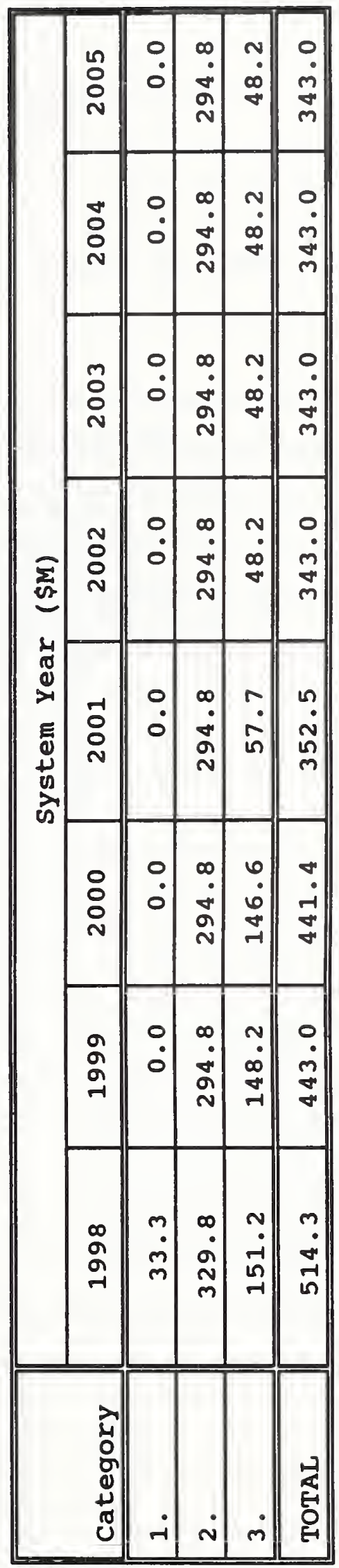


Table 6.2 Benefit-Cost summary for the Proposed System (continued)

Part A: Costs over the system Life (continued)

\begin{tabular}{||c|c|}
\hline Summary Measures & Cost (\$M) \\
\hline \hline System Life Costs & $9,862.1$ \\
\hline Present Value Costs & $6,361.3$ \\
\hline Residual Value & 0.0 \\
\hline Adjusted Cost & $6,361.3$ \\
\hline
\end{tabular}




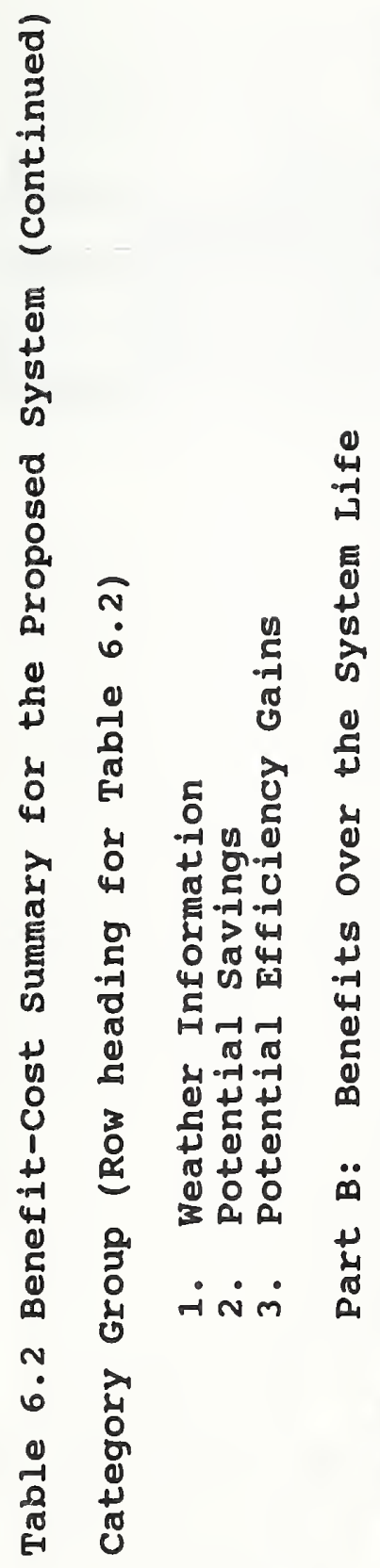

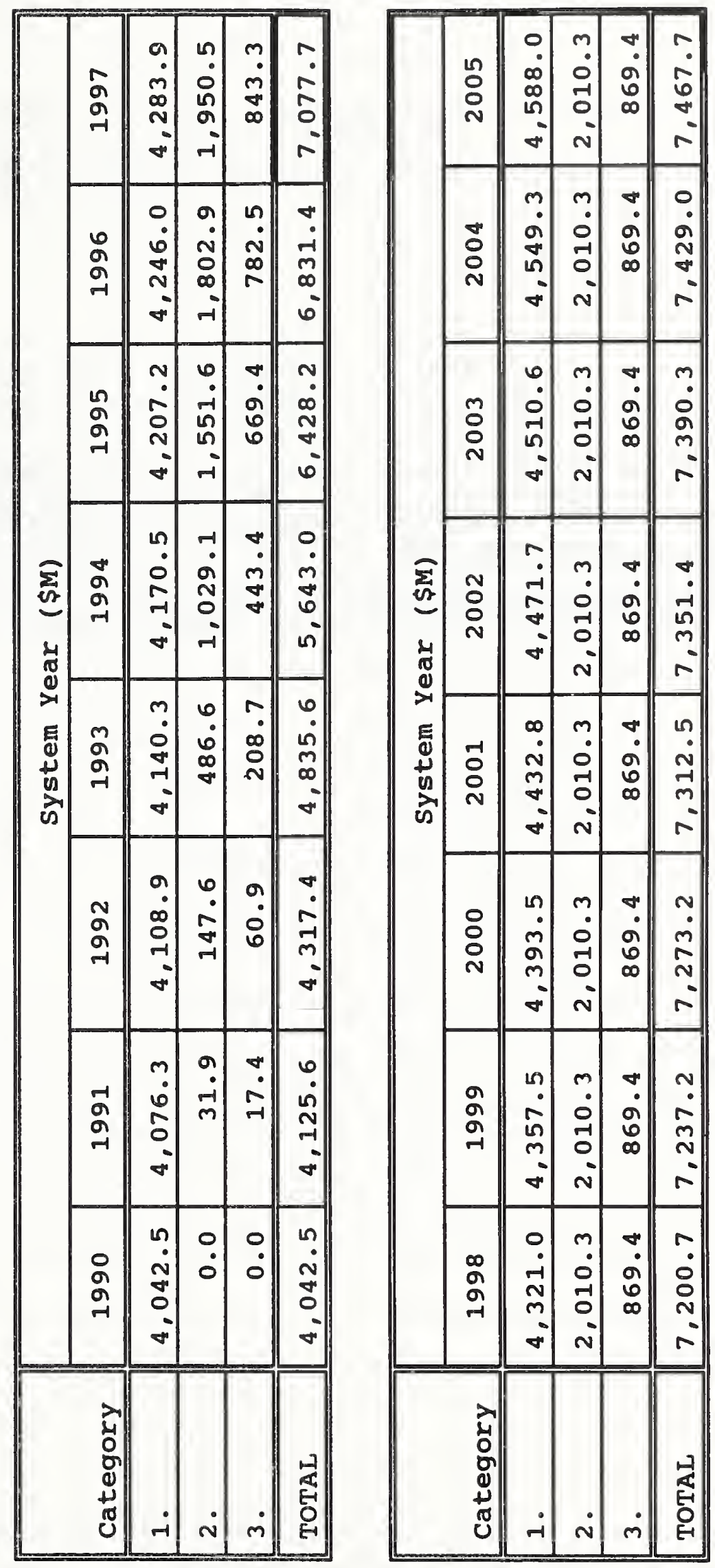


Table 6.2 Benefit-Cost Summary for the Proposed System (Continued)

Part B: Benefits over the System Life (Continued)

\begin{tabular}{||c||c|}
\hline Summary Measures & Benefits ( \$M) \\
\hline \hline System Life Benefits & $101,963.2$ \\
\hline Present Value Benefits & $50,350.5$ \\
\hline
\end{tabular}


Table 6.2 Benefit-cost summary for the Proposed system (Continued)

\section{Part c: Summary}

\begin{tabular}{|c|c|}
\hline Measure & Value \\
\hline \hline Net Present Value (\$M) & $43,989.2$ \\
\hline Benefit-Cost Ratio & 7.915 \\
\hline Payback Period (Years) & 1.6 \\
\hline
\end{tabular}


The benefit-cost analysis described in this study was carried out in two stages. In the first stage, a baseline analysis was performed. The assumptions behind the baseline analysis were documented in chapters 4 and 5; and the results of the baseline analysis were presented in chapter 6.

In the second stage, four variables were varied in combination according to an experimental design. The structured sensitivity analysis described in this chapter was based on Monte Carlo techniques. The objective of the analysis was to evaluate how uncertainty in the values of the four "input" variables translated into changes in the benefit-cost ratio, the present value of benefits, the present value of net benefits, and the present value of costs for each alternative. Recall that the present value of net benefits is equal to the present value of benefits minus the present value of costs.

\subsection{METHODOLOGY: AN INTRODUCTION TO STRUCTURED SENSITIVITY ANALYSIS}

Because the values of many variables which enter into the benefit and cost calculations are not known with certainty, it is advisable to select a small set of variables, whose impact is likely to be substantial and subject them to a structured sensitivity analysis. Variations in the values of these input variables translate into variations in the value of the output (e.g., the benefit-cost ratio) in such a manner that the impacts of uncertainty can be measured quantitatively.

The approach selected for this study makes use of works by Mckay, Conover and Beckman ${ }^{37}$ and by Harris ${ }^{38}$ based on the method of model sampling. That method is a procedure for sampling from a stochastic process to determine, through multiple trials, the nature and effects of a probability distribution. The method of model sampling, also called distribution sampling, has a long history of use by statisticians to derive distributions empirically if they are difficult or impossible to derive by other means. It permits the effects of uncertainty to be rigorously analyzed.

${ }^{37}$ M. C. MCKay, W. H. Conover and R. J. Beckman, "A Comparison of Three Methods for Selecting Values of Input Variables in the Analysis of Output from a Computer Code, "Technometrics, Vol. 21, No. 2, 1979, pp. 239-45.

${ }^{38} \mathrm{C}$. M. Harris, Issues in sensitivity and statistical Analysis of Large-scale, Computer-Based Models, Gaithersburg, MD: National Bureau of Standards, NBS GCR 84-466, 1984. 
The procedure employed in this study is known as the Latin hypercube sampling scheme. The procedure, as its name implies, is patterned after the classical Latin square. Latin squares consist of a set of permutations such that a given character or value appears only once in each row and each column. A Latin hypercube is similar to a Latin square with the important exception that it contains more rows than columns. For example, if each column is thought of as a variable and each row as a simulation number, then entries in the cells may either contain the values of a set of equally-spaced percentiles from the parent cumulative distribution function (CDF) of the variable of interest ${ }^{39}$ or pointers to these values. For the case at hand, with selected variables of interest and 50 simulations, the entries in the cells are pointers to the values of the $1^{\text {at }}, 3^{\text {rd }}$, $5^{\text {th }}, \ldots .99^{\text {th }}$ percentiles of the parent CDF.

In reality, the exact nature of the parent CDF (e.g., measures of central tendency and dispersion) is unknown. Estimates of the parameters (e.g., mean and variance) of the CDF can be made and uncertainty can be reduced by investigation and research. However, uncertainty can never be eliminated completely because new sources of uncertainty arise continually. The true specification of the CDF can only be known after the system has been operating for some time. In order to implement the procedure without undue attention to the characterization of the CDF, it was decided to focus on the uniform distribution, which may be specified by two values, a minimum and a maximum. In addition, all values between the minimum and maximum are equally likely.

\subsection{KEY VARIABLES USED IN THE SENSITIVITY ANALYSIS}

The four variables which were the subject of the structured sensitivity analysis were varied in combination according to an experimental design. These variables and their names as they appear in Tables 7.1 through 7.3, which follow, are:

(1) COSINC, the average annual rate of cost increase for operating the current system;

(2) DECPAY, the average annual rate of decrease for the amount an individual is willing to pay for weather information provided by the current system;

(3) CoMcos, the average commissioning cost per site for the Proposed system; and

${ }^{39}$ The CDF records the probability that the variable of interest is less than or equal to a specified value. 
(4) WILPAY, the average amount an individual is willing to pay for weather information provided by the Proposed system.

The data which were the focus of the structured sensitivity analysis are summarized in Table 7.1. Table 7.1 records the baseline minimum and maximum values for each of the four variables. The minimum and maximum values served to define the CDF for each variable. The odd percentiles (i.e., 1st, 3rd, $5 \mathrm{th}, . . .99 \mathrm{th})$ for each of the four variables are recorded in Table 7.2. The experimental design is shown in Table 7.3; it makes use of a randomly generated Latin hypercube sampling scheme. ${ }^{40}$ Table 7.3 provides the mechanism for implementing the experiment. The entries in Table 7.3 relate the row number of Table 7.2 for each of the four variables to the simulation number. For example, the entry under cosINC which corresponds to simulation number 1 in Table 7.3 is 10 , which implies that the COSINC value to be used in simulation number 1 is found in the loth row of Table 7.2. This value is 0.0152 , or 1.52 percent per annum.

We note that the values recorded in Tables 7.1 and 7.2 are less conservative than the values presented in chapters 4 and 5 . This approach was taken because the values used in the baseline analysis were deliberately chosen to be very conservative. For example, the average commissioning cost per site, comcos, is estimated to be $\$ 8.0$ million. In the structured sensitivity analysis this value ranges from a low of $\$ 6.4$ million to a high of $\$ 9.6$ million (i.e., a variation of plus or minus 20 per cent from the baseline value). Similarly, the average annual rate of cost increase for the current system, cOSINC, is estimated to be 4 per cent per annum. In the structured sensitivity analysis, a range of values are analyzed, including no cost increase and rapidly escalating costs. The estimated average annual rate of decrease in willingness to pay for weather information provided by the current system is 5 per cent. Although this estimate serves to capture the public "erosion of confidence" due to deteriorating system performance, one might consider several scenarios, ranging from optimistic to pessimistic. In the optimistic scenario, one would expect little change in the public's willingness to pay; this scenario is associated with the minimum value of DECPAY in Table 7.1. In the pessimistic scenario, the public's willingness to pay declines sharply; this

${ }^{40} \mathrm{C}$. M. Harris, Computer Generation of Lat in Hypercube Sampling Plans, Gaithersburg, MD: National Bureau of Standards, NBS GCR84-476, 1985. 
Table 7.1 Baseline and Extreme Values Used in the Structured Sensitivity Analysis

\begin{tabular}{||l|r|r|c||}
\hline \multirow{2}{*}{$\begin{array}{c}\text { Variable } \\
\text { Name }\end{array}$} & \multicolumn{3}{|c|}{ Setting and Value } \\
\cline { 2 - 4 } & Baseline & Minimum & Maximum \\
\hline COSINC & 0.04 & 0.0 & 0.08 \\
\hline DECPAY & 0.05 & 0.02 & 0.08 \\
\hline COMCOS & 8.0 & 6.4 & 9.6 \\
\hline WILPAY & 35.50 & 30.00 & 50.00 \\
\hline
\end{tabular}

${ }^{41}$ Figures for COSINC and DECPAY are in per cent per annum, figures for comcos are in millions of dollars per site commissioned, and figures for WILPAY are in dollars per capita. 
Table 7.2 Values of Key Variables Used in the structured Sensitivity Analysis

\begin{tabular}{|c|c|c|c|c|}
\hline \multirow{2}{*}{$\begin{array}{c}\text { Row } \\
\text { Number }\end{array}$} & \multicolumn{4}{|c|}{ Variable Name and Value } \\
\hline & COSINC & DECPAY & COMCOS & WILPAY \\
\hline 1 & 0.0008 & 0.0206 & 6.432 & 32.200 \\
\hline 2 & 0.0088 & 0.0218 & 6.496 & 30.600 \\
\hline 3 & 0.0000 & 0.0230 & 6.560 & 33.000 \\
\hline 4 & 0.0056 & 0.0242 & 6.880 & 31.400 \\
\hline 5 & 0.0072 & 0.0206 & 6.688 & 31.800 \\
\hline 6 & 0.0088 & 0.0206 & 6.752 & 32.200 \\
\hline 7 & 0.0104 & 0.0278 & 6.816 & 32.600 \\
\hline$\Sigma$ & $0.010 \mathrm{~s}$ & 0.0230 & 6.880 & 33.000 \\
\hline 3 & 0.0136 & 0.0302 & 6.880 & 33.800 \\
\hline 10 & 0.0152 & 0.0314 & 7.008 & 33.800 \\
\hline 11 & 0.0182 & 0.0326 & 7.072 & 34.200 \\
\hline 11 & 0.0184 & 0.0338 & 7.136 & 30.600 \\
\hline 13 & 0.0200 & 0.0350 & 7.200 & 35.000 \\
\hline 11 & 0.0216 & 0.0362 & 7.264 & 35.400 \\
\hline 15 & 0.0232 & 0.0374 & 7.328 & 35.800 \\
\hline 16 & 0.0248 & 0.0386 & 7.392 & 36.200 \\
\hline 17 & 0.0264 & 0.0398 & 7.456 & 36.600 \\
\hline 18 & 0.0280 & 0.0410 & 7.520 & 37.000 \\
\hline 19 & 0.0296 & 0.0422 & 7.584 & 37.400 \\
\hline 20 & 0.0312 & 0.0434 & 7.648 & 37.800 \\
\hline 21 & 0.0328 & 0.0446 & 7.712 & 38.200 \\
\hline 22 & 0.0344 & 0.0458 & 7.776 & 38.600 \\
\hline 23 & 0.0360 & 0.0470 & 7.840 & 39.000 \\
\hline 24 & 0.0376 & 0.0482 & 7.904 & 39.400 \\
\hline 25 & 0.0392 & 0.0494 & 7.968 & 39.800 \\
\hline
\end{tabular}


Table 7.2 Values of Key Variables Used in the structured Sensitivity Analysis (continued)

\begin{tabular}{|c|c|c|c|c|}
\hline \multirow{2}{*}{$\begin{array}{c}\text { Row } \\
\text { Number }\end{array}$} & \multicolumn{4}{|c|}{ Variable Name and Value } \\
\hline & COSINC & DECPAY & COMCOS & WILPAY \\
\hline 26 & 0.0408 & 0.0506 & 8.032 & 40.200 \\
\hline 27 & 0.0424 & 0.0518 & 8.600 & 48.600 \\
\hline 29 & 0.0440 & 0.0590 & 8.160 & 41.000 \\
\hline 29 & 0.0456 & 0.0590 & 8.224 & 41.800 \\
\hline 30 & 0.0472 & 0.0554 & $8.22 \mathrm{~A}$ & 41.800 \\
\hline 34 & 0.0488 & 0.0506 & 8.352 & 42.200 \\
\hline 32 & 0.0504 & 0.0578 & 8.416 & 47.800 \\
\hline 34 & 0.0520 & 0.0590 & 8.880 & 44.600 \\
\hline 34 & 0.0536 & 0.0602 & 8.544 & 41.800 \\
\hline 35 & 0.0568 & 0.0614 & 8.800 & 44.600 \\
\hline 36 & 0.0568 & 0.0626 & 8.672 & 44.200 \\
\hline 32 & 0.0584 & 0.0638 & 8.736 & 44.600 \\
\hline 38 & 0.0400 & 0.0662 & 8.800 & 45.000 \\
\hline 39 & 0.0616 & 0.0662 & 8.800 & 45.400 \\
\hline 40 & 0.0632 & 0.0686 & 8.928 & 45.800 \\
\hline 41 & 0.0648 & 0.0686 & 8.032 & 48.200 \\
\hline 42 & 0.0664 & 0.0598 & 9.056 & 44.600 \\
\hline 43 & 0.0668 & 0.0710 & 9.120 & 44.600 \\
\hline 44 & 0.0661 & 0.0722 & 9.184 & 47.400 \\
\hline 45 & 0.0712 & 0.0734 & 9.248 & 47.800 \\
\hline 46 & 0.0728 & 0.0710 & 9.312 & 48.200 \\
\hline 47 & 0.0744 & 0.0758 & 9.376 & 48.600 \\
\hline 48 & 0.0760 & 0.0770 & 9.440 & 49.000 \\
\hline 49 & 0.0776 & 0.0782 & 9.504 & 49.400 \\
\hline 50 & 0.0792 & 0.0794 & 9.568 & 49.800 \\
\hline
\end{tabular}


Table 7.3 Experimental Design Used in the Structured Sensitivity Analysis

\begin{tabular}{|c|c|c|c|c|}
\hline \multirow{2}{*}{$\begin{array}{l}\text { Simulation } \\
\text { Number }\end{array}$} & \multicolumn{4}{|c|}{ Variable Name and Row Number } \\
\hline & COSINC & DECPAY & COMCOS & WILPAY \\
\hline 1 & 10 & 40 & 5 & 50 \\
\hline 2 & 21 & 37 & 10 & 29 \\
\hline 3 & 44 & 9 & 24 & 12 \\
\hline 4 & 20 & 43 & 37 & 30 \\
\hline 5 & 50 & 7 & 12 & 2 \\
\hline 6 & 34 & 5 & 33 & 21 \\
\hline 7 & 1 & 21 & 35 & 11 \\
\hline 9 & 23 & 3 & 47 & 31 \\
\hline 9 & 32 & 23 & 38 & 48 \\
\hline 10 & 13 & 50 & 19 & 15 \\
\hline 11 & 33 & 1 & 26 & 40 \\
\hline 10 & 38 & 15 & 50 & 7 \\
\hline 18 & 25 & 27 & 32 & 13 \\
\hline 14 & 36 & 44 & 17 & 16 \\
\hline 10 & 43 & 35 & 16 & 5 \\
\hline 16 & 39 & 12 & 42 & 33 \\
\hline 10 & 3 & 41 & 48 & 24 \\
\hline 18 & 46 & 8 & 44 & 22 \\
\hline 19 & 22 & 47 & 27 & 8 \\
\hline 20 & 6 & 11 & 8 & 47 \\
\hline 21 & 14 & 39 & 9 & 35 \\
\hline 22 & 40 & 33 & 20 & 39 \\
\hline 23 & 41 & 13 & 6 & 4 \\
\hline 23 & 27 & 14 & 31 & 1 \\
\hline 25 & 47 & 45 & 46 & 27 \\
\hline
\end{tabular}


Table 7.3 Experimental Design Used in the Structured Sensitivity Analysis (continued)

\begin{tabular}{|c|c|c|c|c|}
\hline \multirow{2}{*}{$\begin{array}{l}\text { Simulation } \\
\text { Number }\end{array}$} & \multicolumn{4}{|c|}{ Variable Name and Row Number } \\
\hline & $\operatorname{cosINC}$ & DECPAY & COMCOS & WILPAY \\
\hline 26 & 9 & 30 & 23 & 25 \\
\hline 27 & 12 & 20 & 14 & 41 \\
\hline 28 & 26 & 10 & 14 & 34 \\
\hline 29 & 11 & 6 & 21 & 23 \\
\hline $3 I$ & 5 & 30 & 2 & 34 \\
\hline 31 & 24 & 16 & 25 & 44 \\
\hline 32 & 30 & 42 & 39 & 10 \\
\hline 33 & 35 & 46 & 49 & 42 \\
\hline 34 & 31 & 48 & 22 & 14 \\
\hline 38 & 19 & 49 & 18 & 43 \\
\hline 45 & 15 & 31 & 4 & 32 \\
\hline 37 & 28 & 38 & 40 & 46 \\
\hline 38 & 37 & 36 & 29 & 9 \\
\hline 39 & 45 & 24 & 7 & 17 \\
\hline 45 & 18 & 19 & 13 & 3 \\
\hline 41 & 48 & 25 & 45 & 28 \\
\hline 42 & 17 & 28 & 11 & 49 \\
\hline 43 & 16 & 18 & 1 & 45 \\
\hline 44 & 7 & 17 & 36 & 37 \\
\hline 45 & 4 & 2 & 30 & 18 \\
\hline 38 & 42 & 26 & 3 & 19 \\
\hline 42 & 8 & 22 & 43 & 20 \\
\hline 38 & 2 & 29 & 34 & 6 \\
\hline 45 & 29 & 32 & 15 & 26 \\
\hline 50 & 49 & 4 & 28 & 38 \\
\hline
\end{tabular}


scenario is associated with the maximum value of DECPAY in Table 7.1.42 Finally, the values of WILPAY, the average amount an individual is willing to pay for weather information provided by the Proposed system, is allowed to range from $\$ 30.00$ to $\$ 50.00$. It is important to point out that unlike the other three variables discussed above, this range is not symmetric about the baseline value of WILPAY (i.e., \$35.50). This approach was taken because the public is expected to see both a quantitative and qualitative difference in the products/services provided by the NWS' Proposed system. Even with these projections, the estimated value of weather information to the public is likely to be conservative because the most frequent response to the question of estimated dollar value of weather information to respondents surveyed was "\$50.00 OR MORE" (see section 5.1.2.1).

\subsection{RESULTS OF THE SENSITIVITY ANALYSIS}

The results of the structured sensitivity analysis are summarized in a series of figures and tables below. The purpose of these figures and tables is to provide side-by-side comparisons of the two alternative NWS configurations.

The graphical results of the structured sensitivity analysis are shown in Figures 7.1 through 7.4, for the benefit-cost ratio, present value of benefits, present value of net benefits, and present value of costs, respectively. The figures were constructed by first sorting the values of each variable from smallest to largest. The resultant "cumulative distribution function" was then plotted. In each figure, the vertical axis records the probability that the variable of interest (e.g., the benefit-cost ratio) falls below a specified value. The values recorded on the horizontal axis cover the range of values encountered during the 50 simulations. Throughout all four figures, the traces are labeled to facilitate comparisons among the two alternative NWS configurations. In each figure, the trace of the current system is a dotted line and the trace of the proposed system is a solid line.

The tabular results of the structured sensitivity analysis are shown in Tables 7.4 through 7.7, for the benefit-cost ratio, present value of benefits, present value of net benefits, and present value of costs, respectively. The tables include the mean (i.e., arithmetic average), minimum and maximum values, and the standard deviation associated with each simulation. These measures were chosen to facilitate statistical comparisons.

${ }^{42} \mathrm{Alternatively,} \mathrm{as} \mathrm{system} \mathrm{performance} \mathrm{degrades,} \mathrm{the}$ proportion of the public which sees the NWS as the author of the forecast may decline. Reductions in this proportion (say from 0.611 to 0.5 ) would have an adverse impact on the value of weather information to the public at large. 
Referring to Figure 7.1, we see that the Proposed System produces substantially higher benefit-cost ratios than the current system. In particular, all of the benefit-cost ratios for the proposed system exceed the maximum value of the benefit-cost ratio associated with the current system. On the average, the benefitcost ratios associated with the Proposed system are 1.75 times those associated with the Current System. Reference to Table 7.4 serves to highlight these observations.

Referring to Figure 7.2, we see that the same characteristics prevail for the present value of benefits, where the Proposed system is clearly preferred. The traces of the two alternatives show an ever-widening gap between the current system and the Proposed System. Reference to Table 7.5 shows that the "gap" grows from approximately $\$ 20$ billion to more than $\$ 30$ billion. It is important to note that the traces in Figure 7.2 do not include an allowance for system costs.

The case where system costs are included is illustrated in Figure 7.3, where it becomes clear that the Proposed system dominates the current system. The same relationship between the two traces encountered in Figure 7.2 is repeated in Figure 7.3. The "gap" between the Current system and the Proposed System almost doubles; see Table 7.6 for a numerical comparison.

Referring to Figure 7.4, we see that the costs of the two alternatives overlap. For example, the range of values for the proposed system are a subset of the range of values for the current system. Reference to Table 7.7 shows that the minimum cost for the current System is $\$ 5,070.0$ million while the corresponding value for the Proposed system is $\$ 6,242.9 \mathrm{million}$. On the other hand, the maximum value of the current system is $\$ 6,777.5 \mathrm{milli}$ on while the corresponding value for the Proposed System is $\$ 6,479.7$ million. The relatively wider range of the costs of the current system is reflected in the value of the standard deviation. For example, the standard deviation of the costs of the current system is $\$ 501.2$ million while the corresponding figure for the Proposed system is $\$ 69.7$ million.

The fact that the two cost ranges overlap suggests that a comparison of the costs of the two alternatives is in order. since the mean of the costs of the Proposed system exceeds the mean of the costs of the current system, we test the hypothesis that the mean of the Proposed system, $x_{p s}$, exceeds the mean of the current system, $x_{c s}$, by using the $t$-distribution. Since each system was subjected to 50 simulations, the relevant $t$-statistic has 98 degrees of freedom. If a significance level of 0.05 (i.e., 5 percent) is chosen, the value of the t-statistic is equal to 1.66. The t-statistic is used to compute the critical value, $\mu$, used in testing the hypothesis. Specifically, if 


$$
\mathrm{X}_{\mathrm{ps}}-\mathrm{X}_{\mathrm{cs}}>\mu
$$

then the average cost of the Proposed System exceeds the average cost of the current system; otherwise, there is no reason to conclude that the average cost of the Proposed system exceeds the average cost of the current system.

The key values in performing the test are

(1) $\mathrm{X}_{p e}-\mathrm{x}_{\mathrm{cs}}=526.8$

(2) $\mu=t^{*} \cdot s^{*} \cdot\left((50+50) /(50)^{2}\right)^{1 / 2}$

where $t^{\circ}=1.66$

$$
s^{*}=\left(\left(49\left(s_{p s}\right)^{2}+49\left(s_{c s}\right)^{2}\right) / 98\right)^{1 / 2}
$$

$\left(s_{p s}\right)^{2}=$ the variance of the costs of the Proposed System $\left(s_{c s}\right)^{2}=$ the variance of the costs of the Current system

The value of $\mu$ may now be calculated as

$$
\begin{aligned}
& \mu=(1.66) \times(357.81) \times(0.2) . \\
& \mu=118.8
\end{aligned}
$$

This implies that

$$
\left(\mathrm{X}_{\mathrm{pu}}-\mathrm{X}_{\mathrm{cs}}\right)>\mu
$$

and we accept the hypothesis that the costs of the Proposed system exceed the costs of the current system.

\subsection{EVALUATION OF RESULTS}

The results presented in the previous section indicate that the Proposed System is clearly preferable to the current system if benefits to the public are taken into consideration, but the current system is less costly than the Proposed system. Although costs are a primary consideration, one must also pay attention to cost variability. This is of particular importance here, because the standard deviation of system costs is approximately seven times greater for the current System than for the Proposed system. 
Figure 7.1 Distributional Analysis of the Benefit-Cost Ratio

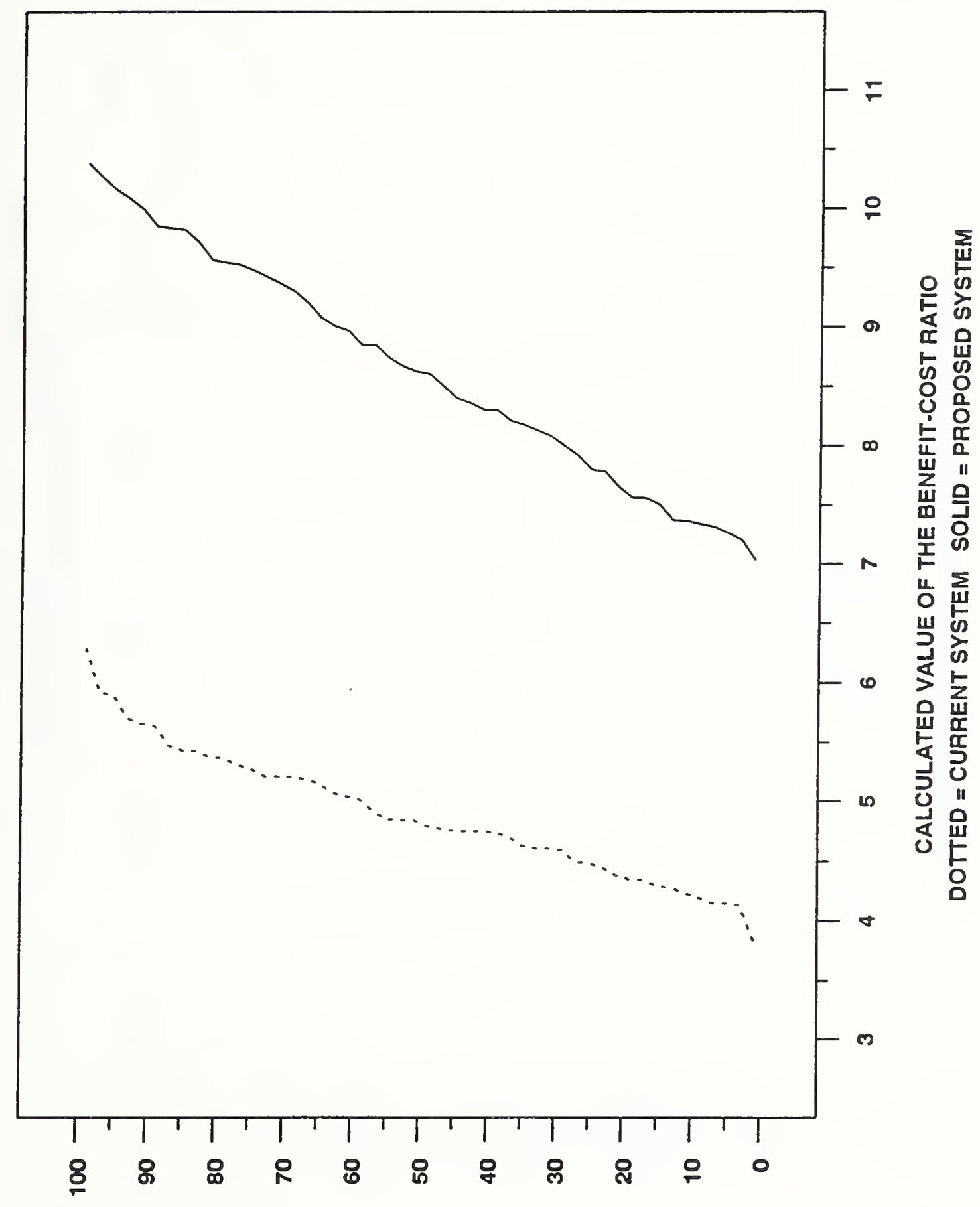

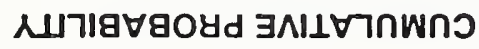


Figure 7.2 Distributional Analysis of Benefits

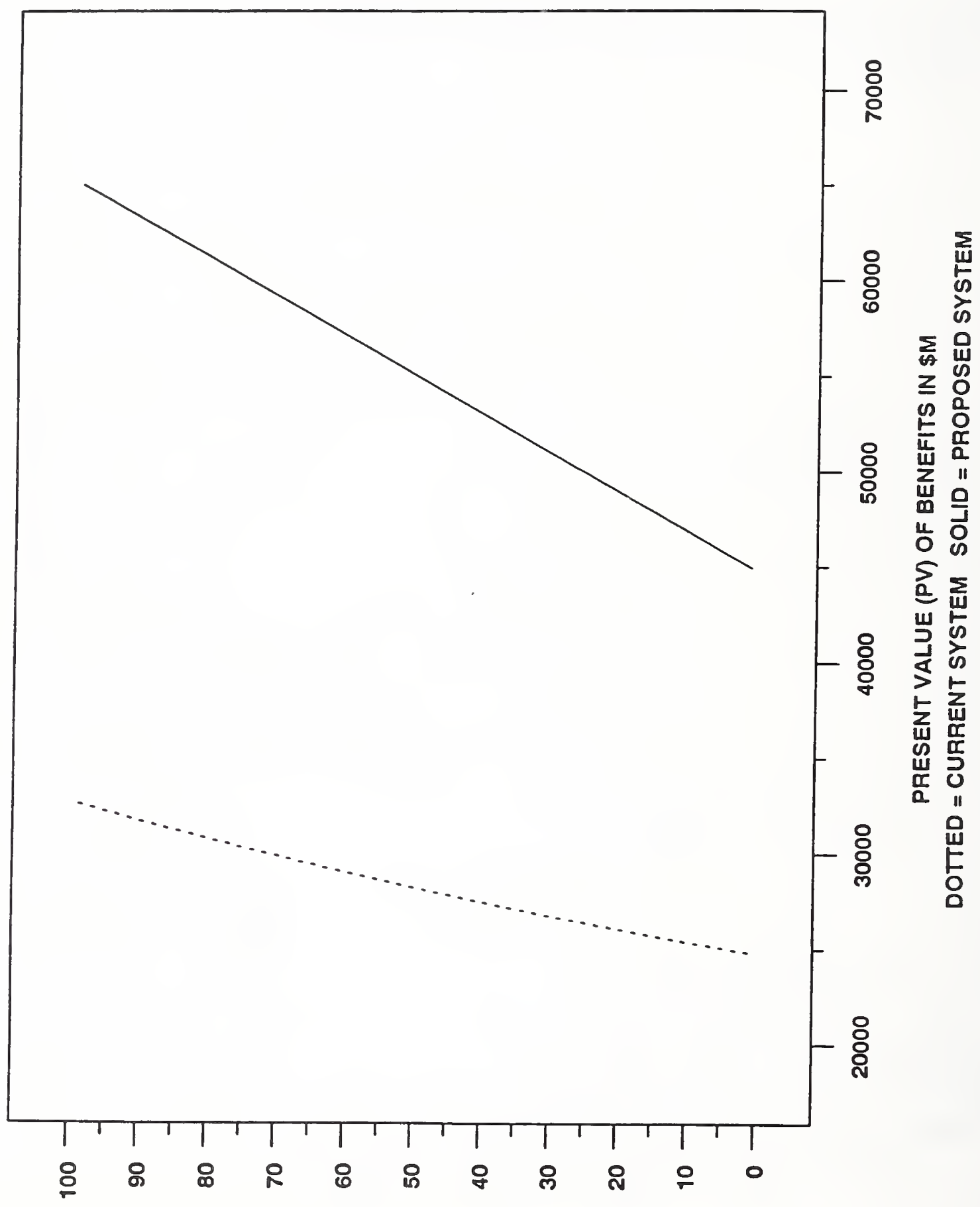

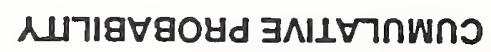


Figure 7.3 Distributional Analysis of Net Benefits

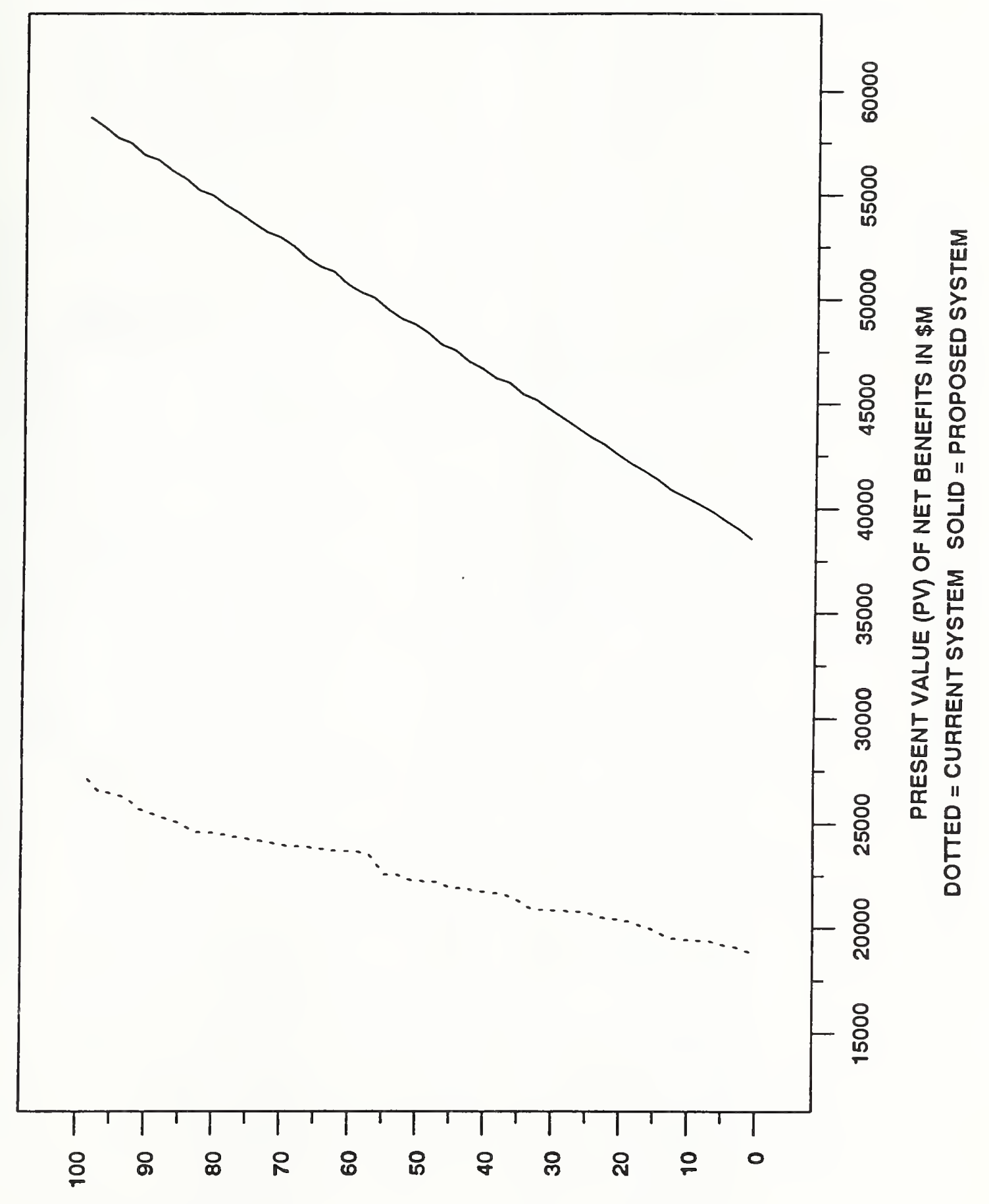

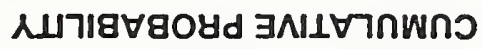


Figure 7.4 Distributional Analysis of Costs

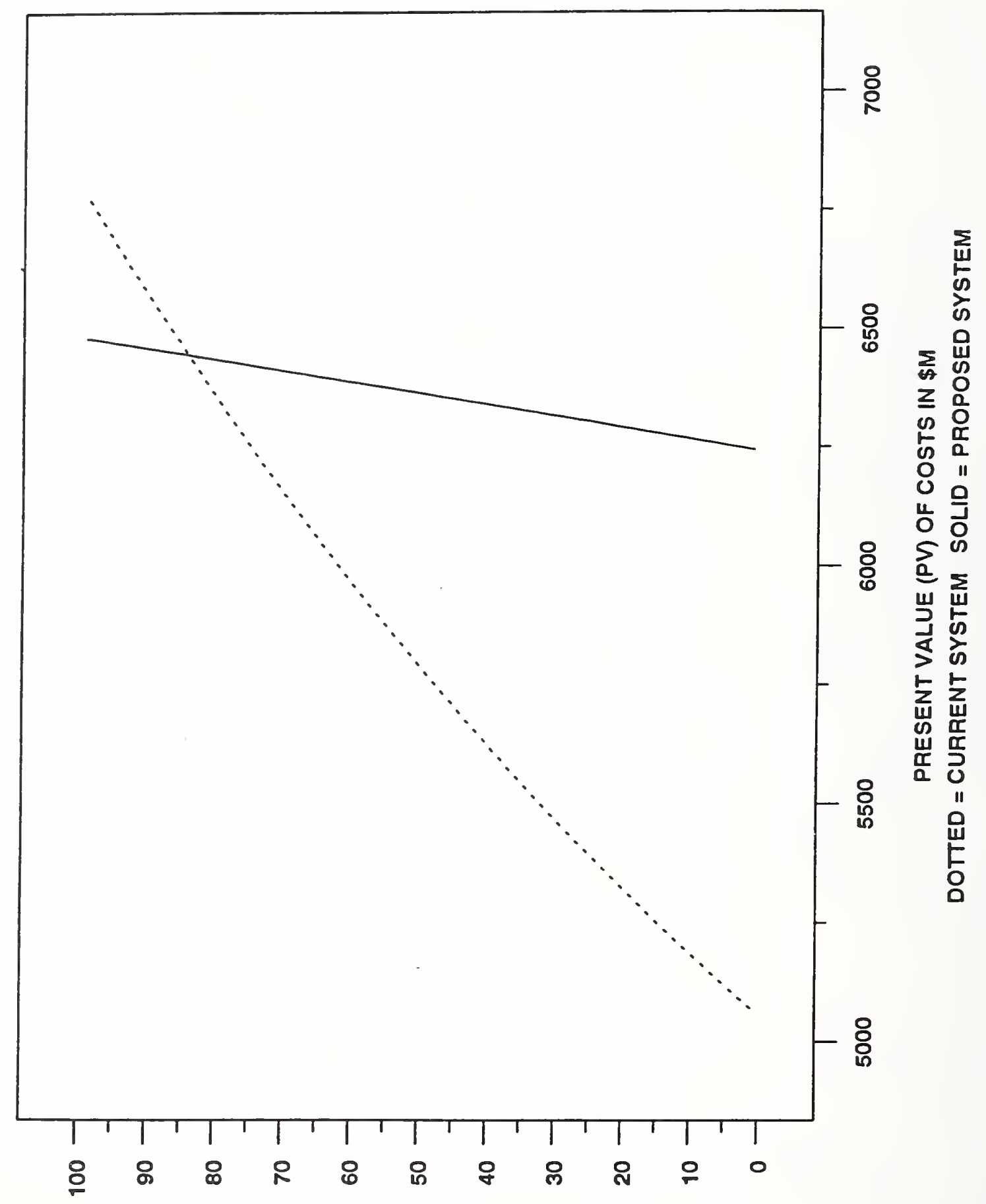

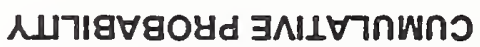



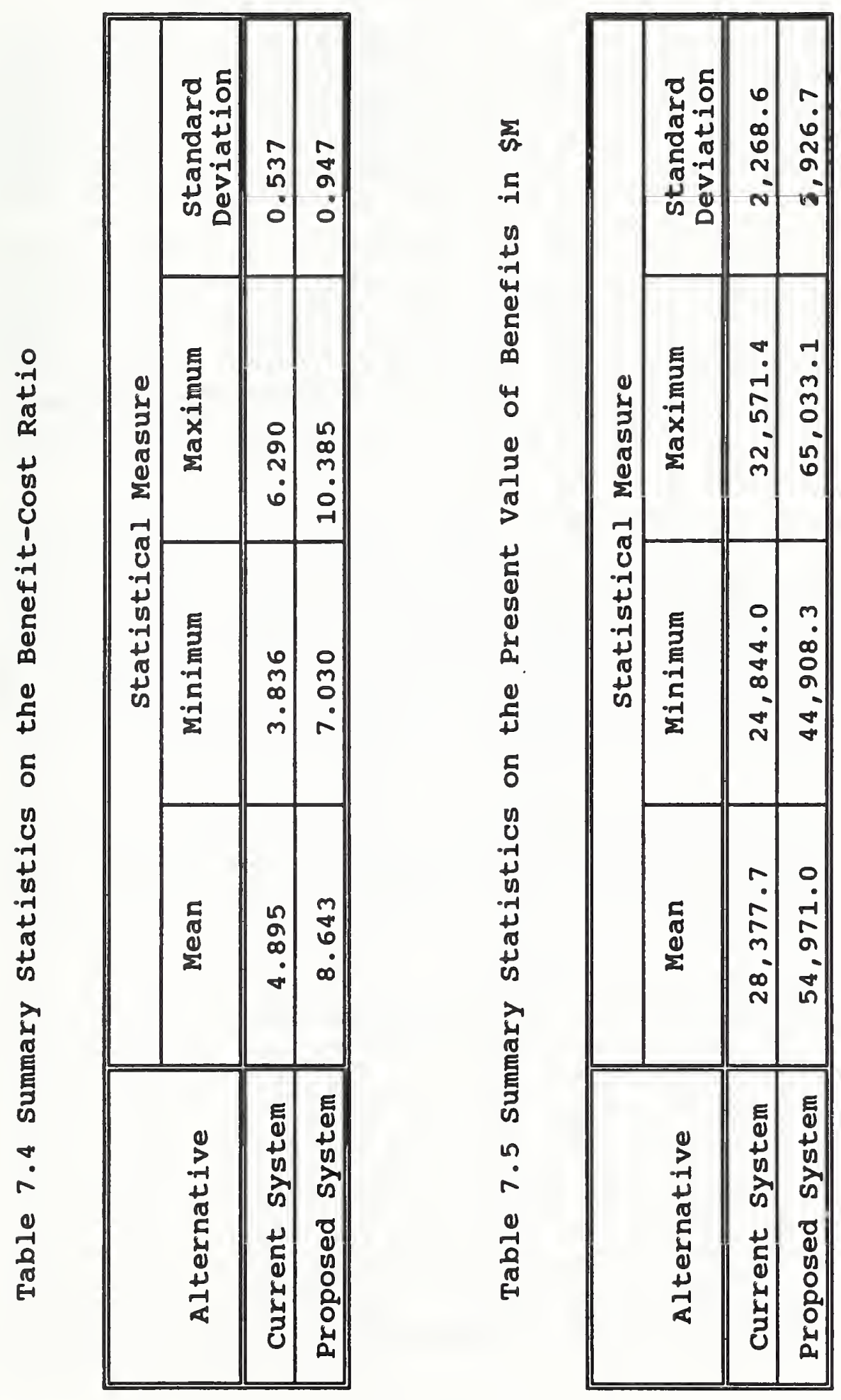


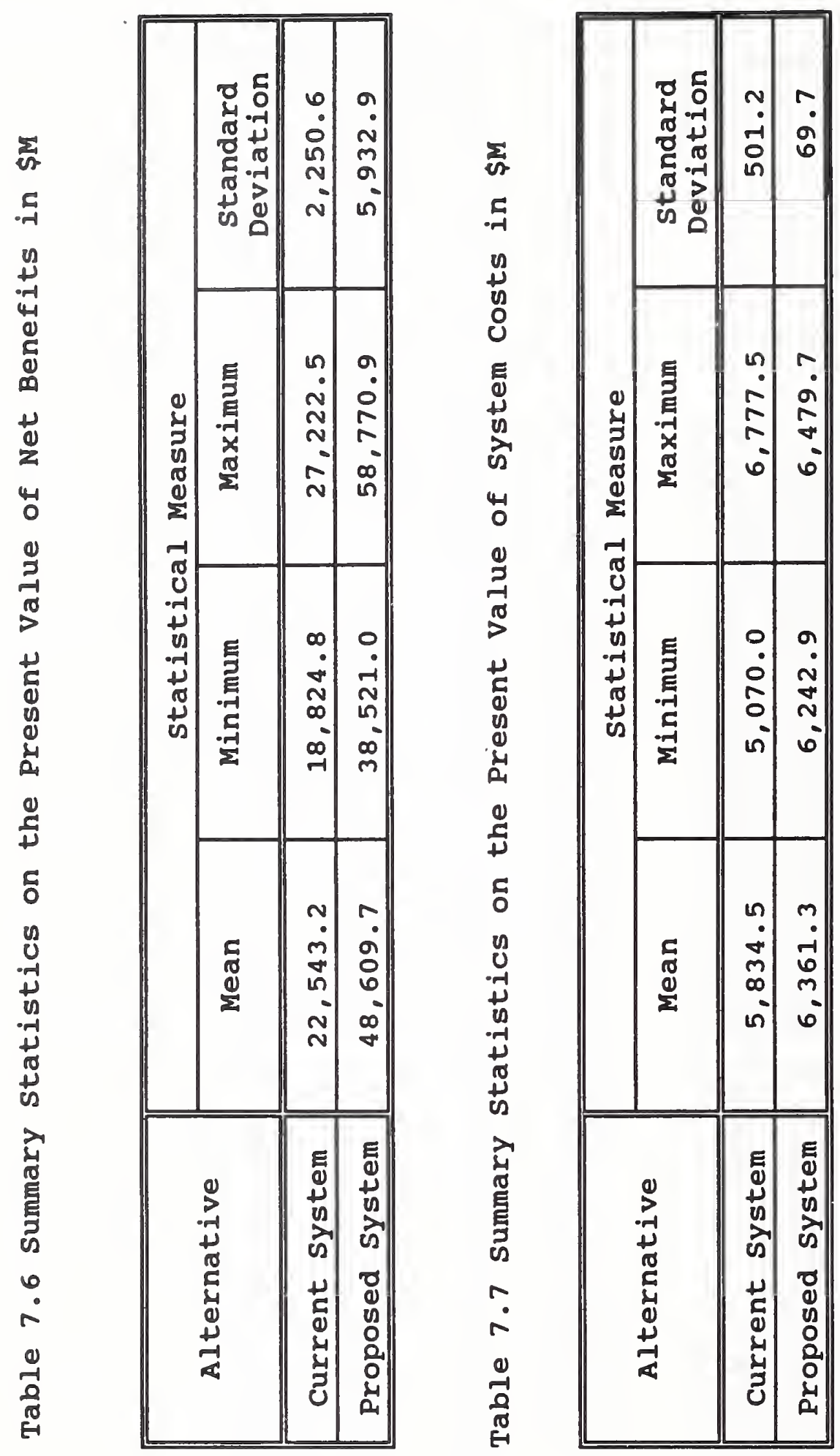


This report has focused on a critical evaluation of two alternative configurations for the NwS. The first configuration represents a continuation of the status quo; it is referred to as the current system. The second configuration represents a full deployment of the proposed modernization and restructuring of the NWS; it is referred to as the Proposed system.

The two systems differ greatly in their capabilities. The Current system is rapidly becoming obsolete and will require significant commitments if it is to continue service into the next century. Even with major commitments, in terms of staff and financial resources, the current system's forecast quality, as viewed by the public, is likely to deteriorate. This undesirable outcome has serious implications for the perceived value of the system to the public.

The Proposed system represents deployment of a suite of technologies focused on improving the accuracy, timeliness and capabilities of the NWS. These technologies are being tested in the field to simulate the environment under which the Proposed system would operate. The emphasis placed on risk reduction should ensure that only "appropriate" technologies are deployed. The Modernization and Associated Restructuring Demonstration will provide a benchmark on both system performance and profiles for staffing Weather Forecast Offices.

The economic evaluation of the two alternative configurations focused on system costs and system benefits. While system costs were internal to the NWS, system benefits accrue to the public. system benefits are therefore socioeconomic benefits, external to the NWS.

The economic evaluation was carried out in two stages. In the first stage, a baseline analysis was performed. In the baseline analysis, all data entering into the benefit and cost calculations were fixed at their most-likely values. In the second stage, four variables were varied in combination according to an experimental design. The objective of this "structured sensitivity analysis" was to evaluate how uncertainty in the values of the four "input" variables translated into changes in the values of four key economic indicators. These indicators are: (1) the benefit-cost ratio; (2) the present value of benefits: (3) the present value of net benefits; and (4) the present value of costs. Recall that the present value of net benefits is equal to the present value of benefits minus the present value of costs.

The baseline analysis produced results which strongly favor the Proposed system. Two key economic measures, the benefit-cost ratio and the present value of the net benefits, were 
dramatically higher for the Proposed system. For example, the benefit-cost ratio was 7.915 for the Proposed system, the corresponding value for the current system was 4.873. Another key measure, net present value, was $\$ 44.0$ billion for the Proposed system and $\$ 22.4$ billion for the current system. The difference between the two, $\$ 21.6$ billion, accrues to the public in terms of weather-related losses averted, gains in efficiency to selected weather-sensitive operations, and higher values imputed to weather information. These results indicate that the Proposed System is clearly the approach which has the greatest net benefits.

The structured sensitivity analysis produced results which were similar to the baseline analysis. Once again, the Proposed system was strongly favored - three of the four key economic indicators were markedly better for the Proposed system than for the current system. The fourth indicator, present value of system costs exhibited an interesting outcome. Although the mean value of costs for the Proposed system exceeded the mean value of costs for the current system, the range of costs for the Proposed system was a subset of the range of costs for the current system. In particular, the cost variability for the current system is seven times higher than for the Proposed system. A statistical test performed to determine if. the costs of the Proposed system exceeded those of the current system indicated that the costs of the Proposed System exceeded those of the current system.

Taking all of the information presented above and elsewhere in the study into consideration, the Proposed system, full

deployment of the proposed modernization and restructuring of the NWS, emerges as the most economical solution to the NWS' needs and responsibilities. There are two additional reasons why the Proposed system should be preferred.

First, the current system is nearing obsolescence. The Automation of Field Operations and Services (AFOS) system, the backbone of the current system, experiences frequent and sometimes major failures both at the site level and at the system level. As the equipment continues to age, these failures are expected to increase both in frequency and severity. Failures, especially system failures, will result in degraded service. If nothing is done to the current system, the NWs may be unable to carry out its mission. Because AFOS is already obsolete, it may be difficult to find replacement parts and equipment regardless of price. In addition, the skills required to repair AFos parts and equipment are vanishing and will probably no longer be available before the end of the period covered by this study (i.e., in 2005). Consequently, even with substantial outlays, it is likely that service quality will deteriorate to the point where the current system is no longer cost effective. 
Second, the study has made no attempt to estimate the number of lives saved due to better hydrometeorologic forecasts and warnings. The differences between the two systems are both qualitative and quantitative. As new products become available to forecasters, they will be able to review and manipulate data and information as never before. Combining new products with training and education for NWS employees should result in new insights, increased usability, productivity enhancements and improvements in forecast accuracy. Therefore, holding all else constant, it is likely that the Proposed system would reduce the number of weather-related fatalities. Those areas of the nation which should experience the greatest reductions are where severe weather conditions (e.g., tornadoes, downbursts, flash floods, etc.) are most likely. The increased lead time on the issuance of a warning should enable more persons to find shelter or avoid the hazardous condition altogether (e.g., rerouting of commercial aircraft). For example, the relationship between better weather information and flight safety is underscored by the joint use of the ASOS and NEXRAD systems by the FAA and the NWS.

In summary, the Proposed system is clearly preferred to the current system. When intangibles, such as reductions in weatherrelated fatalities and the potential for new products/services, are taken into consideration, the Proposed system emerges as an approach for positioning the NWS to meet the needs of the American public throughout the 1990s and into the beginning of the 21 st century. 



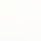



